\title{
Effects of Donor Size and Heavy Doping on Optical, Electrical and Thermoelectric Properties of Various Degenerate Donor-Silicon Systems at Low Temperatures
}

\author{
Huynh Van Cong \\ Department of Physics, Laboratory of Mathematics and Physics, University of Perpignan, Perpignan, France \\ Email address: \\ huynh@univ-perp.fr, huynhvc@outlook.fr \\ To cite this article: \\ Huynh Van Cong, Effects of Donor Size and Heavy Doping on Optical, Electrical and Thermoelectric Properties of Various Degenerate \\ Donor-Silicon Systems at Low Temperatures. American Journal of Modern Physics. Vol. 7, No. 4, 2018, pp. 136-165. \\ doi: $10.11648 /$ j.ajmp.20180704.13
}

Received: July 1, 2018; Accepted: July 13, 2018; Published: August 8, 2018

\begin{abstract}
In various degenerate donor-silicon systems, taking into account the effects of donor size and heavy doping and using an effective autocorrelation function for the potential fluctuations expressed in terms of the Heisenberg uncertainty relation and also an expression for the Gaussian average of $\mathbb{E}_{k}^{a-\frac{1}{2}}, a \geq 1 \mathbb{E}_{k}$ being the kinetic energy of the electron, calculated by the Kane integration method (KIM), we investigated the density of states, the optical absorption coefficient and the electrical conductivity, noting that this average expression calculated by the KIM was found to be equivalent to that obtained by the Feynman path-integral method. Then, those results were expressed in terms of $\mathbb{E}^{\mathrm{a}-(1 / 2)}$ for total electron energy $\mathbb{E} \geq 0$, vanished at the conduction-band edge: $\mathbb{E}=0$, and for $\mathbb{E} \leq 0$ exhibited their exponential tails, going to zero as $\mathbb{E} \rightarrow-0$ and $\infty$, and presenting the maxima, in good accordance with an asymptotic form for exponential conduction-band tail obtained by Halperin and Lax, using the minimum counting methods. Further, in degenerate d-Si systems at low temperatures, using an expression for the average of $\mathbb{E}^{p}, p \geq 3 / 2$, calculated using the Fermi-Dirac distribution function, we determined the mobility, electrical conductivity, resistivity, Hall factor, Hall coefficient, Hall mobility, thermal conductivity, diffusion coefficient, absolute thermoelectric power, Thomson coefficient, Peltier coefficient, Seebeck thermoelectric potential, and finally dimensionless figure of merit, which were also compared with experimental and theoretical results, suggesting a satisfactory description given for our obtained results.
\end{abstract}

Keywords: Donor Size, Heavy Doping, Electrical Conductivity, Hall Effect, Diffusion Coefficient

\section{Introduction}

Donor (acceptor)-silicon $\mathrm{d}$ (a)-Si system at a given temperature $\mathrm{T}$, doped with a given $\mathrm{d}$ (a)-density $\mathrm{N}$, assuming that all the impurities are ionized, is the base material of modern semiconductor devices [1-6]. Then, due to the FermiDirac statistics, there are three cases may be classified as: non-degenerate $\left(\mathrm{T}>\mathrm{T}_{\mathrm{D}}\right.$ and $\left.\mathrm{N}<<\mathrm{N}_{\mathrm{c}}\right)$, moderately degenerate $\left(\mathrm{T}>\mathrm{T}_{\mathrm{D}}\right.$ and $\left.\mathrm{N}>>\mathrm{N}_{\mathrm{C}}\right)$ and degenerate $\left(\mathrm{T}<<\mathrm{T}_{\mathrm{D}}\right.$ and $\mathrm{N}>>\mathrm{N}_{\mathrm{c}}$ )-cases, $\mathrm{T}_{\mathrm{D}}$ and $\mathrm{N}_{\mathrm{c}}$ being respectively the degenerate temperature defined in Eq. (15) and critical impurity density.

In the present paper, the degenerate $\mathrm{d}-\mathrm{Si}$ system is considered, noting that all the optical, electrical, and thermoelectric properties given in the degenerate a-Si system can also be investigated by a same treatment.
So, in the degenerate d-Si system, a good knowledge of: (i) energy-band structure parameters such as: the reduced band gap [7-12], $\mathrm{N}_{\mathrm{c}(\mathrm{d})}[11,12]$ and effective donor ionization energy [13], (ii) exponential conduction-band tails [14-25] and Fermi energy [26-28], and finally (iii) optical [29-48], electrical [49-69], and thermoelectric [58, 61, 68, 69] properties, due to the effects of donor size $[11,12,42,43$, 53], heavy doping [14, 17-30, 34, 35, 48-68], and low T [49, $58]$, is thus necessary for designing new devices and also understanding their performance.

In Section 2, we studied the effects of donor size [or compression (dilatation)], temperature, and heavy doping on the energy-band-structure parameters. At $\mathrm{T}=0 \mathrm{~K}$, with 
increasing values of donor radius $r_{d}$, since the effective dielectric constant $\varepsilon_{n}\left(r_{d}\right)$ decreases, due to the donor-size effect, the effective donor ionization $\mathbb{E}_{\mathrm{do}}\left(\mathrm{r}_{\mathrm{d}}\right)$, unperturbed intrinsic band gap $\mathbb{E}_{\text {go }}\left(\mathrm{r}_{\mathrm{d}}\right)$, and critical donor density $\mathrm{N}_{\mathrm{c}(\mathrm{d})}$ increase, as seen in Table 1 . Then, for a given $r_{\mathrm{d}}$, the effective intrinsic band gap $\mathbb{E}_{\mathrm{gi}}\left(r_{\mathrm{d}}, \mathrm{T}\right)$, due to the T-effect, decreases with increasing $\mathrm{T}$, as given in Eq. (3). Finally, due to the heavy doping effect (HDE), for a given $r_{d}$, the effective electron mass $\mathrm{m}_{\mathrm{n}}^{\mathrm{HDE}}\left(\mathrm{N}, \mathrm{r}_{\mathrm{d}}\right)$ increases with increasing $\mathrm{N}$, as given in Eq. (8), and for given $r_{d}$ and $\mathrm{T}$, the reduced band gap $\mathbb{E}_{\text {gn2 }}\left(\mathrm{N}, \mathrm{T}, \mathrm{r}_{\mathrm{d}}\right)$ decreases with increasing $\mathrm{N}$, as given in Eq. (10).

In Section 3, the effective autocorrelation function for potential fluctuations, $\mathrm{W}_{\mathrm{n}}$, was determined and in Eq. (B.6) the appendix $\mathrm{B}$, being a central result of the present paper, as noted in Eq. (20). It was suggested that $W_{n}(\mathbb{E} \rightarrow \pm \infty) \rightarrow \eta_{n}^{2}$, $\mathbb{E}$ and $\eta_{\mathrm{n}}$ being respectively the total electron energy and the energy parameter characteristic of the conduction-band tail states, and $\mathrm{W}_{\mathrm{n}}(\mathbb{E} \rightarrow \pm 0) \rightarrow 0$. Therefore, the density of states, the optical absorption coefficient and the electrical conductivity, being proportional to our result (20), vanished at the conduction-band edge $\mathbb{E}=0$, as given in Eqs. $(23,26)$. Those results were also compared with other theoretical results, obtained at $-\mathbb{E}=0$, in the small time approximation $[21,29,30]$ and in the full ground-state case and deep-tail approximation [21], which were found to be constant, being not correct, as discussed also in Eq. (26). Then, for $\mathbb{E} \leq 0$, their exponential tails were obtained in Figures 1, 4 and 7, in which they increased with increasing $r_{d}$ for a given value of $-\mathbb{E}$, due to the donor-size effect, and further they went to zero as $\mathbb{E} \rightarrow-0$ and $-\infty$ and presented the maxima, being found to be in good accordance with an asymptotic form for exponential conduction-band tail, obtained by Halperin and Lax [19], using the minimum counting methods.

In Section 4 , we determined the average of $\mathbb{E}^{\mathrm{p}}$ at low temperature $\mathrm{T}\left(\mathrm{T}<<\mathrm{T}_{\mathrm{D}}\right)$, using the Fermi-Dirac distribution function $(\mathrm{FDDF}),\left\langle\mathbb{E}^{\mathrm{p}}\right\rangle_{\mathrm{FDDF}} \equiv \mathrm{G}_{\mathrm{p}}\left(\mathbb{E}_{\mathrm{Fn}}\right) \times \mathbb{E}_{\mathrm{Fn}}^{\mathrm{p}}$, for $\mathrm{p} \geq 3 / 2$, as given in Eq. (34) and Table $3, \mathbb{E}_{\mathrm{Fn}}$ being the Fermi energy determined in Eq. (A10) of the Appendix C.

In Section $\mathrm{V}$, we determined the critical donor density, as given in Table 1, suggesting that its numerical results are in good agreement with the corresponding data given in Ref. 12 , and it increases with increasing $r_{d}$, due to the donor-size effect [12]. Then, for $\mathbb{E} \leq 0$, the exponential band-tail behaviors were investigated and reported in Table 4 , and also in Figures 1 and $2 \mathrm{a}(\mathrm{b})$.

In Section 6, various optical functions were determined in band-to-band transitions ( $\mathbb{E} \geq 0$ ) as found in Figs. 3a, 3b, 3c, being compared with other theoretical and experimental works [33-35, 38, 44-48], and also the exponential optical absorption-coefficient tail behaviors were investigated when $\mathbb{E} \leq 0$, as seen in Table 7, and Figures 4 and $5 \mathrm{a}(\mathrm{b})$.

In Section 7 , for $\mathbb{E} \geq 0$, using the functions $G_{p}$ obtained at low $\mathrm{T}$, given in Table 3, we determined various electric functions as those given in Tables 10-13, in good accordance with the corresponding experimental results $[50,53,54,56-$ $61]$, and for $\mathbb{E} \leq 0$, we also studied the exponential conductivity-tail behaviors, as those given in Tables 14 and Figures 7, 8a (b).

In Section 8 , for $\mathbb{E} \geq 0$, using also the function $G_{p}$, we studied various thermoelectric functions, and reported their numerical results in Table 15 and Figures 9a, 9b, 9c, 9d, 9e, and $9 \mathrm{f}$, noting that for $\mathbb{E} \leq 0$ we could also study the exponential thermoelectric function-tail behaviors by a same treatment, as those obtained in Sections 5-7.

Finally, some concluding remarks were given and discussed in Section 9.

\section{Energy-Band-Structure Parameters}

Here, we study the effects of donor size, temperature, and heavy doping on the energy-band-structure parameters.

\subsection{Donor-Size Effect}

In donor-Si systems at $\mathrm{T}=0 \mathrm{~K}$, since the d-radius, $\mathrm{r}_{\mathrm{d}}$, in tetrahedral covalent bonds is usually either larger (or smaller) than the $\mathrm{Si}$ atom-radius, $\mathrm{r}_{\mathrm{o}}$, assuming that in the P-Si system $\mathrm{r}_{\mathrm{P}}=\mathrm{r}_{\mathrm{o}}=0.117 \mathrm{~nm}$, with $\mathrm{nm}=10^{-9} \mathrm{~m}$, a local mechanical strain (or deformation potential-or-strained energy) is induced, according to a compression (dilation) for $r_{d}>r_{o}$ $\left(r_{d}<r_{o}\right)$, respectively, or to the donor size $\left(r_{d}\right)$-effect. In the Appendix A of our recent paper [12], basing on an effective Bohr model, such a compression (dilation) occurring in various donor (d)-Si systems was investigated, suggesting that the effective dielectric constant, $\varepsilon_{\mathrm{n}}\left(r_{\mathrm{d}}\right)$, decreases with increasing $r_{\mathrm{d}}$. This donor size $\left(r_{\mathrm{d}}\right)$-effect affects the changes in all the energy-band-structure parameters or the electronic properties of various donor-Si systems, expressed in terms of $\varepsilon_{\mathrm{n}}\left(r_{\mathrm{d}}\right)$, as those investigated in our recent paper [12], noting that $\varepsilon_{\mathrm{n}}\left(\mathrm{r}_{\mathrm{P}}\right)=11.4$. In particular, the changes in the unperturbed intrinsic band gap, $\mathbb{E}_{\mathrm{go}}\left(\mathrm{r}_{\mathrm{P}}\right)=1170 \mathrm{meV}$, effective donor ionization energy, $\mathbb{E}_{\mathrm{do}}\left(\mathrm{r}_{\mathrm{P}}\right)=33.58 \mathrm{meV}$, and critical donor $(\mathrm{P})$-density, $\mathrm{N}_{\mathrm{c}(\mathrm{P})}=3.5 \times 10^{18} \mathrm{~cm}^{-3}$, of the P-Si system at $0 \mathrm{~K}$, are obtained in an effective Bohr model, as [12]

$$
\mathbb{E}_{\mathrm{go}}\left(\mathrm{r}_{\mathrm{d}}\right)-\mathbb{E}_{\mathrm{go}}\left(\mathrm{r}_{\mathrm{P}}\right)=\mathbb{E}_{\mathrm{do}}\left(\mathrm{r}_{\mathrm{d}}\right)-\mathbb{E}_{\mathrm{do}}\left(\mathrm{r}_{\mathrm{P}}\right)=\mathbb{E}_{\mathrm{do}}\left(\mathrm{r}_{\mathrm{P}}\right) \times\left[\left(\frac{\varepsilon_{\mathrm{n}}\left(\mathrm{r}_{\mathrm{P}}\right)}{\varepsilon_{\mathrm{n}}\left(\mathrm{r}_{\mathrm{d}}\right)}\right)^{2}-1\right],
$$

and in a simple generalized Mott model, by [12]

$$
\mathrm{N}_{\mathrm{c}\left(\mathrm{r}_{\mathrm{d}}\right)}=\mathrm{N}_{\mathrm{c}(\mathrm{P})} \times\left(\frac{\varepsilon_{\mathrm{n}}\left(\mathrm{r}_{\mathrm{P}}\right)}{\varepsilon_{\mathrm{n}}\left(\mathrm{r}_{\mathrm{d}}\right)}\right)^{3}
$$

Therefore, with increasing $r_{\mathrm{d}}$, the effective dielectric constant $\varepsilon_{\mathrm{n}}\left(r_{\mathrm{d}}\right)$ decreases, implying thus that $\mathbb{E}_{\mathrm{go}}\left(\mathrm{r}_{\mathrm{d}}\right)$,
$\mathbb{E}_{\mathrm{do}}\left(\mathrm{r}_{\mathrm{d}}\right)$ and $\mathrm{N}_{\mathrm{c}\left(\mathrm{r}_{\mathrm{d}}\right)}$ increase. Those changes, given in our previous paper [12], are now reported in the following Table 1 , in which the numerical results of critical donor density, due to the exponential band tail (EBT)-effect, $\mathrm{N}_{\mathrm{c}(\mathrm{d}), b}^{\mathrm{EBT}}$, being obtained in the next Section $\mathrm{V}$, are also included for a comparison. Here, $b$ is normally equal to 1 , but it will be chosen as: $b=b_{0}=1.0028637416$, so that the obtained 
results of $\mathrm{N}_{c\left(\mathrm{r}_{\mathrm{d}}\right), \ell_{0}}^{\mathrm{EBT}}$ would be more accurate.

Table 1. The following values of $r_{d}, \varepsilon_{n}, a_{n o}, E_{g o}\left(r_{d}\right)$, and $N_{c(d)}$-data, given in our previous paper [12], are now reported in this TABLE, in which we also include the numerical results of $N_{c(d), b}^{E B T}$, where $b=1$ or $b_{o}=1.0028637416$, calculated using Eqs. $(41,42)$, and their absolute relative errors defined by: $|R E| \equiv\left|1-\frac{N_{c(d), v}^{E B T}}{N_{c(d)}}\right|$. Here, $n m \equiv 10^{-9} \mathrm{~m}$.

\begin{tabular}{lllllllll}
\hline Donor & Sb & $\mathbf{P}$ & $\mathbf{A s}$ & $\mathbf{B i}$ & $\mathbf{T i}$ & $\mathbf{T e}$ & $\mathbf{S e}$ & $\mathbf{S}$ \\
\hline$r_{\mathrm{d}}(\mathrm{nm})$ & 0.1131 & 0.1170 & 0.1277 & 0.1292 & 0.1424 & 0.1546 & 0.1621 & 0.1628 \\
$\varepsilon_{\mathrm{n}}\left(r_{\mathrm{d}}\right)$ & 12.02 & 11.40 & 8.47 & 7.95 & 4.71 & 3.26 & 2.71 & 2.67 \\
$\mathbb{E}_{\mathrm{d}}\left(r_{\mathrm{d}}\right)(\mathrm{meV})$ & 30.18 & 33.58 & 60.82 & 69 & 197 & 411 & 593 & 613 \\
$\mathbb{E}_{\mathrm{go}}\left(r_{\mathrm{d}}\right)(\mathrm{meV})$ & 1167 & 1170 & 1197 & 1205 & 1333 & 1547 & 1729 & 1749 \\
$\mathrm{~N}_{\mathrm{c}(\mathrm{d})}\left(10^{18} \mathrm{~cm}^{-3}\right)$ & 3 & 3.52 & 8.58 & 10.37 & 50 & 150.74 & 261.24 & 274.57 \\
$\mathrm{~N}_{\mathrm{c}(\mathrm{d}), b_{\mathrm{o}}}^{\mathrm{EBT}}\left(10^{18} \mathrm{~cm}^{-3}\right)$ & 3.000003 & 3.520005 & 8.579950 & 10.368890 & 49.999984 & 150.738620 & 261.241940 & 274.568990 \\
$|\mathrm{RE}|$ & $1.1 \times 10^{-6}$ & $1.3 \times 10^{-6}$ & $6.1 \times 10^{-6}$ & $1.1 \times 10^{-4}$ & $3.1 \times 10^{-7}$ & $4.1 \times 10^{-6}$ & $2.1 \times 10^{-7}$ & $2.2 \times 10^{-10}$ \\
$\mathrm{~N}_{\mathrm{c}(\mathrm{d}), 1}^{\mathrm{EBT}}\left(10^{18} \mathrm{~cm}^{-3}\right)$ & 2.991440 & 3.509950 & 8.555450 & 10.339280 & 49.857210 & 150.308180 & 260.495950 & 273.784950 \\
$|\mathrm{RE}|$ & $2.8 \times 10^{-3}$ & $2.8 \times 10^{-3}$ & $2.9 \times 10^{-3}$ & $3.0 \times 10^{-3}$ & $2.9 \times 10^{-3}$ & $2.8 \times 10^{-3}$ & $2.8 \times 10^{-3}$ & $2.8 \times 10^{-3}$ \\
\hline
\end{tabular}

The underlined $|R E|$-value is the maximal one, indicating that $N_{c(d), \mho_{o}}^{E B T} \cong N_{c(d)}$.

Moreover, it should be noted that in donor-Si systems such the $\mathbb{E}_{\mathrm{gi}}\left(\mathrm{r}_{\mathrm{d}}, 300 \mathrm{~K}\right)$-increase with increasing $\mathrm{r}_{\mathrm{d}}$ observed in Table I, $\mathbb{E}_{\text {gi }}$ being the effective intrinsic band gap given in next Eq. (3), well agrees with a result obtained recently by Ding et al. [42]. In fact, in their study of the optical properties of isolated silicon nano-crystals (nc-Si) with the size of $2 \mathrm{r}_{\mathrm{nc}-\mathrm{Si}}=4.2 \mathrm{~nm}\left(\gg 2 \mathrm{r}_{\mathrm{P}}=2 \times 0.117 \mathrm{~nm}\right)$ embedded in a $\mathrm{SiO}_{2}$ matrix, they showed that $\mathbb{E}_{\text {gi }}\left(r_{n c-S i}, 300 \mathrm{~K}\right)=1.79 \mathrm{eV} \gg \mathbb{E}_{\mathrm{gi}}\left(\mathrm{r}_{\mathrm{P}}, 300 \mathrm{~K}\right)=1.12 \mathrm{eV}$ given in the bulk crystalline $\mathrm{Si}$ at room temperature, being also due to the size effect $\left(r_{n c-S i} \gg r_{P}\right)$.

Now, the effective Bohr radius can be defined by

$$
a_{\mathrm{B}}\left(r_{\mathrm{d}}, \mathrm{m}^{*}\right) \equiv \frac{\mathrm{m}_{\mathrm{o}}}{\mathrm{m}^{*}} \times \varepsilon_{\mathrm{n}}\left(r_{\mathrm{d}}\right) \times 5.3 \mathrm{~nm}
$$

In Eq. (1), $\mathrm{m}^{*}$ is the effective electron mass given in the $\mathrm{Si}$, being equal to: (i) the effective mass $\mathrm{m}_{\mathrm{n}}=0.3216 \times \mathrm{m}_{\mathrm{o}}, \mathrm{m}_{\mathrm{o}}$ being the free electron mass, defined for the calculation of $\mathrm{m}_{\mathrm{n}}^{\mathrm{HDE}}(\mathrm{N})$, as determined in next Eq. (8), due to the heavy doping effect (HDE), (ii) the reduced effective mass: $\mathrm{m}_{\mathrm{r}}=\frac{\mathrm{m}_{\mathrm{n}} \times \mathrm{m}_{\mathrm{p}}}{\mathrm{m}_{\mathrm{n}}+\mathrm{m}_{\mathrm{p}}} \times \mathrm{m}_{\mathrm{o}}=0.171 \times \mathrm{m}_{\mathrm{o}}$, for the optical absorptioncoefficient calculation, where $\mathrm{m}_{\mathrm{p}}=0.3664 \times \mathrm{m}_{\mathrm{o}}$ is the effective hole mass in the silicon [12], (iii) $\mathrm{m}_{\mathrm{n}}^{\mathrm{HDE}}(\mathrm{N})$, given in next Eq. (8), for the determination of the density of states, as given in Section 5, and finally (iv) the conductivity effective mass: $m_{\text {cond }}=0.26 \times \mathrm{m}_{\mathrm{o}}$ for the electrical conductivity calculation [6], as used in Section 7.

Then, in the degenerate case $\left(\mathrm{N}>\mathrm{N}_{\mathrm{c}(\mathrm{d})}\right)$, denoting the Fermi wave number by: $\mathrm{k}_{\mathrm{Fn}}(\mathrm{N}) \equiv\left(3 \pi^{2} \mathrm{~N} / \mathrm{g}_{\mathrm{c}}\right)^{1 / 3}$, where $\mathrm{g}_{\mathrm{c}}=3$ is the effective average number of equivalent conduction-band edges $[11,12]$, the effective Wigner-Seitz radius $r_{s n}$ characteristic of the interactions is defined by

$$
\gamma \times \mathrm{r}_{\mathrm{sn}}\left(\mathrm{N}, r_{\mathrm{d}}, \mathrm{m}^{*}\right) \equiv \frac{\mathrm{k}_{\mathrm{Fn}}^{-1}}{a_{\mathrm{B}}}<1,
$$

being proportional to $\mathrm{N}^{-1 / 3}$. Here, $\gamma=(4 / 9 \pi)^{1 / 3}$, and $\mathrm{k}_{\mathrm{Fn}}^{-1}$ means the averaged distance between ionized donors.

\subsection{Temperature Effect}

Here, in d-Si systems, being inspired from recent works by Pässler [8,9], we can propose an accurate expression for the effective intrinsic band gap as a function of $r_{d}$ and $T$, as

$$
\mathbb{E}_{\mathrm{gi}}\left(\mathrm{T}, \mathrm{r}_{\mathrm{d}}\right) \simeq \mathbb{E}_{\mathrm{go}}\left(\mathrm{r}_{\mathrm{d}}\right)-0.071(\mathrm{eV}) \times\left\{\left[1+\left(\frac{2 \mathrm{~T}}{440.6913 \mathrm{~K}}\right)^{2.201}\right]^{\frac{1}{2.201}}-1\right\} .
$$

For example, in the (P, S)-Si systems, for $0 \leq \mathrm{T}(\mathrm{K}) \leq 3500$, the absolute maximal relative errors of $\mathbb{E}_{\text {gi }}$ are equal to: $0.22 \%, 0.15 \%$, respectively, calculated using the accurate complicated results given by Pässler [9].

\subsection{Heavy Doping Effect (HDE)}

HDE on $m_{n}$

Now, using Eq. (2) for $r_{s n}\left(N, r_{d}, m^{*}=m_{n}\right)$, the ratio of the inverse effective screening length $k_{s n}$ to Fermi wave number $\mathrm{k}_{\mathrm{Fn}}$ at $0 \mathrm{~K}$ is defined by [12]

$$
\mathrm{R}_{\mathrm{sn}}\left(\mathrm{N}, \mathrm{r}_{\mathrm{d}}\right) \equiv \frac{\mathrm{k}_{\mathrm{sn}}}{\mathrm{k}_{\mathrm{Fn}}}=\frac{\mathrm{k}_{\mathrm{Fn}}^{-1}}{\mathrm{k}_{\mathrm{sn}}^{-1}}=\mathrm{R}_{\mathrm{snWS}}+\left[\mathrm{R}_{\mathrm{snTF}}-\mathrm{R}_{\mathrm{snWS}}\right] e^{-\mathrm{r}_{\mathrm{sn}}}<1 .
$$

It is noted that, in the very high electron-density limit [or in the Thomas-Fermi (TF)-approximation], $\mathrm{R}_{\mathrm{sn}}$ is reduced to

$$
\mathrm{R}_{\mathrm{snTF}}\left(\mathrm{N}, \mathrm{r}_{\mathrm{d}}\right) \equiv \frac{\mathrm{k}_{\mathrm{snTF}}}{\mathrm{k}_{\mathrm{Fn}}}=\frac{\mathrm{k}_{\mathrm{n}}^{-1}}{\mathrm{k}_{\mathrm{snTF}}^{-1}}=\sqrt{\frac{4 \mathrm{r}_{\mathrm{sn}}}{\pi}} \ll 1
$$

being proportional to $\mathrm{N}^{-1 / 6}$. It should be noted that the effective screening length $\mathrm{k}_{\mathrm{snTF}}^{-1}$ is very larger than the averaged distance between ionized donors $\mathrm{k}_{\mathrm{Fn}}^{-1}$ (i.e., this is the TF-condition given in the very degenerate case, $\mathrm{N} \gg$ 
$\mathrm{N}_{\mathrm{c}(\mathrm{d})}$ ), and in the very low electron-density limit [or in the Wigner-Seitz (WS)-approximation], $\mathrm{R}_{\mathrm{sn}}$ is reduced to

$$
\mathrm{R}_{\mathrm{snWS}}\left(\mathrm{N}, \mathrm{r}_{\mathrm{d}}\right) \equiv \frac{\mathrm{k}_{\mathrm{snWS}}}{\mathrm{k}_{\mathrm{Fn}}}=\frac{3}{2 \pi}-\gamma \frac{\mathrm{d}\left[r_{\mathrm{sn}}^{2} \times \mathbb{E}_{\mathrm{CE}}\right]}{\mathrm{d} r_{\mathrm{sn}}}, \gamma=(4 / 9 \pi)^{1 / 3}
$$

Here, when the relative spin polarization $\zeta$ is equal to zero (paramagnetic state), $\mathbb{E}_{\mathrm{CE}}$ means the majority-electron correlation energy $(\mathrm{CE})$, determined by as $[11,12]$

$$
\mathbb{E}_{\mathrm{CE}}\left(\mathrm{N}, \mathrm{r}_{\mathrm{d}}\right)=\frac{-0.87553}{0.0908+r_{\mathrm{sn}}}+\frac{\left[\frac{0.87553}{0.0908+r_{\mathrm{sn}}}+\mathrm{a}_{\mathrm{P}} \times L n\left(r_{\mathrm{sn}}\right)+\mathrm{b}_{\mathrm{P}}\right]}{1+0.03847728 \times r_{\mathrm{sn}}^{1.67378876}}
$$

where $a_{P}=2[1-\operatorname{Ln}(2)] / \pi^{2}$ and $b_{P}=-0.093288$. Then, due to such the HDE, the effective electron mass can be approximated by $[11,12]$

$$
\mathrm{m}_{\mathrm{n}}^{\mathrm{HDE}}\left(\mathrm{N}, \mathrm{r}_{\mathrm{d}}\right)=\left(1+\frac{4 \gamma \times \mathrm{r}_{\mathrm{sn}}}{3 \pi\left[1+\mathrm{R}_{\mathrm{sn}}^{2}\right]^{2}}\right) \times \mathrm{m}_{\mathrm{n}} .
$$

HDE on $\mathbb{E}_{g i}$

In the degenerate case, the optical band gap is defined by

$$
\mathbb{E}_{\mathrm{gn} 1}\left(\mathrm{~N}, \mathrm{~T}, \mathrm{r}_{\mathrm{d}}\right) \equiv \mathbb{E}_{\mathrm{gn} 2}\left(\mathrm{~N}, \mathrm{~T}, \mathrm{r}_{\mathrm{d}}\right)+\mathbb{E}_{\mathrm{Fn}}(\mathrm{N}, \mathrm{T})
$$

where $\mathbb{E}_{\mathrm{Fn}}$ is the Fermi energy determined at any $\mathrm{N}$ and $\mathrm{T}$ in Eq. (C.1) of the Appendix C, with an accuracy equal to: $2.11 \times 10^{-4}$, and $\mathbb{E}_{\mathrm{gn} 2}$ is the reduced band gap defined as

$$
\mathbb{E}_{\mathrm{gn} 2}\left(\mathrm{~N}, \mathrm{~T}, r_{\mathrm{d}}\right) \equiv \mathbb{E}_{\mathrm{gi}}\left(\mathrm{T}, r_{\mathrm{d}}\right)-\mathrm{BGN}\left(\mathrm{N}, r_{\mathrm{d}}\right),
$$

where the intrinsic band gap $\mathbb{E}_{\mathrm{gi}}\left(\mathrm{T}, r_{\mathrm{d}}\right)$ is determined in Eq. (3) and the band gap narrowing (BGN) is determined below.

In our recent paper [12], an accurate formula for the BGN was investigated, being expressed in the following spinpolarized chemical potential-energy contributions, as: the exchange energy of an effective electron gas, the majority-electron correlation energy of an effective electron gas,

(iii) the minority-hole correlation energy,

(iv) the majority electron-ionized donor interaction screened Coulomb potential energy, and finally

(v) the minority hole-ionized donor interaction screened Coulomb potential energy.

It should be noted that the two last contributions (iv) and (v) are found to be the most important ones. Therefore, an approximate form for the BGN can be proposed by

$$
\mathrm{BGN}\left(\mathrm{N}, \mathrm{r}_{\mathrm{d}}\right) \simeq \mathrm{C}_{\mathrm{n}} \times\left(\frac{\mathrm{N}}{10^{18} \mathrm{~cm}^{-3}}\right)^{1 / 2} \times\left(\frac{11.4}{\varepsilon_{\mathrm{n}}\left(\mathrm{r}_{\mathrm{d}}\right)}\right)^{1 / 2} \times\left(\frac{\mathrm{m}_{\mathrm{n}}}{\mathrm{m}_{\mathrm{n}}^{\mathrm{HDE}}\left(\mathrm{N}, \mathrm{r}_{\mathrm{d}}\right)}\right)^{1 / 2} \times\left[1+\left(\frac{\mathrm{m}_{\mathrm{n}}^{\mathrm{HDE}}\left(\mathrm{N}, \mathrm{r}_{\mathrm{d}}\right)}{\mathrm{m}_{\mathrm{p}}}\right)^{1 / 2}\right],
$$

which is a very simplified form compared with our previous complicated expression for BGN [12].

Here, the values of effective dielectric constant $\varepsilon_{n}\left(r_{d}\right)$ are given in Table 1 and the electron effective mass $m_{n}^{H D E}\left(N, r_{d}\right)$, due to the heavy doping effect, is determined in Eq. (8). Further, the empirical parameter $\mathrm{C}_{\mathrm{n}}=8.5 \times 10^{-3}(\mathrm{eV})$ has been chosen so that the absolute maximal relative error $|\mathrm{MRE}|$ of our result (9), calculated using the optical band-gap $\left(\mathbb{E}_{\text {gn1 }}\right)$-data for P-Si systems at $20 \mathrm{~K}$ obtained by Wagner, [7] are found to be minimized.

In a degenerate P-Si system, with use of the next Eq. (43), obtained for the definition of effective density of free electrons given in the conduction band, $\mathrm{N}^{*} \simeq \mathrm{N}-\mathrm{N}_{\mathrm{c}(\mathrm{P})}$, where the value of $\mathrm{N}_{\mathrm{c}(\mathrm{P})}$ is given in Table $\mathrm{I}$, our present results of $\mathbb{E}_{\mathrm{gn} 1}\left(\mathrm{~N}^{*}, \mathrm{~T}=20 \mathrm{~K}, \mathrm{r}_{\mathrm{P}}\right)$, computed using Eqs. (9, $11)$, and their absolute relative errors $|R E s|$, calculated using the $\mathbb{E}_{\text {gn } 1}$-data at $20 \mathrm{~K}$ [12], are obtained and reported in Table 2 , in which our previous accurate $\mathbb{E}_{\mathrm{gn} 1}\left(\mathrm{~N}^{*}\right)$-results and their |REs| are also included [12], for a comparison.

Table 2. Numerical results of optical band gap at $T=20 \mathrm{~K}, \mathbb{E}_{g n 1}\left(N^{*}\right)$, expressed in $\mathrm{eV}$, being investigated in our recent paper [12], and determined in Eq. (9), and finally their absolute relative errors $|R E|$, calculated using the $\mathbb{E}_{\text {gn } 1 \text {-data [7]. }}$

\begin{tabular}{lllllll}
\hline $\mathbf{N}\left(\mathbf{1 0}^{\mathbf{1 8}} \mathbf{~ c m}^{-\mathbf{3}}\right)$ & $\mathbf{4}$ & $\mathbf{8 . 5}$ & $\mathbf{1 5}$ & $\mathbf{5 0}$ & $\mathbf{8 0}$ & $\mathbf{1 5 0}$ \\
\hline $\mathbb{E}_{\text {gn } 1}$-data & 1.138 & 1.133 & 1.129 & 1.131 & 1.132 & 1.133 \\
$\mathbb{E}_{\text {gn } 1}\left(\mathrm{~N}^{*}\right)[12]$ & 1.149 & 1.138 & 1.134 & 1.126 & 1.123 & 1.119 \\
$|\mathrm{RE}|(\%)$ & 0.9 & 0.5 & 0.5 & 0.4 & 0.8 & 1.2 \\
$\mathbb{E}_{\text {gn } 1}\left(\mathrm{~N}^{*}\right)$, Eq. $(9)$ & 1.160 & 1.147 & 1.139 & 1.123 & 1.118 & 1.113 \\
$|\mathrm{RE}|(\%)$ & 1.9 & 1.3 & 0.9 & 0.7 & 1.2 & 1.7 \\
\hline
\end{tabular}

The underlined $|\mathrm{RE}|$-value is the maximal one.

This table indicates that the maximal value of $|R E s|$, obtained from our present $\mathbb{E}_{\mathrm{gn} 1}\left(\mathrm{~N}^{*}\right)$-result, is found to be equal to $1.7 \%$, which can be compared with that equal to $1.2 \%$ obtained from our previous $\mathbb{E}_{\mathrm{gn} 1}\left(\mathrm{~N}^{*}\right)$-result [12].

HDE conditions

Finally, in degenerate d-Si systems, the energy parameter $\eta_{\mathrm{n}}$, being characteristic of the exponential conduction-band tail, is determined in Eq. (B.4) of the Appendix B as

$$
\eta_{\mathrm{n}}\left(\mathrm{N}, r_{\mathrm{d}}\right) \equiv \sqrt{2 \pi \mathrm{N}} \times \mathrm{q}^{2} \mathrm{k}_{\mathrm{sn}}^{-1 / 2} \varepsilon_{\mathrm{n}}^{-1}
$$

where $\mathrm{k}_{\mathrm{sn}}^{-1 / 2}$ is determined in Eq. (4). Moreover, in highly degenerate case $\left(\mathrm{N} \gg \mathrm{N}_{\mathrm{c}(\mathrm{d})}\right)$ or in the Thomas-Fermi approximation, $\mathrm{k}_{\mathrm{sn}}^{-1 / 2} \simeq \mathrm{k}_{\mathrm{snTF}}^{-1 / 2}$, determined in Eq. (5), $\eta_{\mathrm{n}}$ is found to be proportional to $\mathrm{N}^{5 / 12}$.

Then, from Eq. (12) and next Eq. (15), we can obtain another heavy doping condition as

$$
\frac{\eta_{\mathrm{n}}}{\mathbb{E}_{\mathrm{Fno}}}<1
$$

being proportional to $\mathrm{N}^{-1 / 4}$ in this highly degenerate case.

In summary, in the highly degenerate case $\left(\mathrm{N} \gg \mathrm{N}_{\mathrm{c}(\mathrm{d})}\right)$ and from Eqs. $(2,4,13)$, one has

$$
\frac{\mathrm{k}_{\mathrm{Fn}}^{-1}}{a_{\mathrm{B}}}<\frac{\eta_{\mathrm{n}}}{\mathbb{E}_{\mathrm{Fno}}}<\frac{\mathrm{k}_{\mathrm{Fn}}^{-1}}{\mathrm{k}_{\mathrm{Sn}}^{-1}}<1,
$$

where $\mathbb{E}_{\text {Fno }}$ is the Fermi energy at $0 \mathrm{~K}$, defined by

$$
\mathbb{E}_{\mathrm{Fno}}(\mathrm{N}) \equiv \frac{\hbar^{2} \times \mathrm{k}_{\mathrm{Fn}}^{2}(\mathrm{~N})}{2 \times \mathrm{m}^{*}} .
$$

In Eq. (15), $\mathrm{m}^{*}$ is the electron effective mass, defined in Eq. (1), and in this highly degenerate case one has a low $\mathrm{T}$ condition as: $\mathrm{T} \ll \mathrm{T}_{\mathrm{D}} \equiv \mathbb{E}_{\mathrm{Fno}}(\mathrm{N}) / \mathrm{k}_{\mathrm{B}}, \mathrm{T}_{\mathrm{D}}$ and $\mathrm{k}_{\mathrm{B}}$ being the 
degeneracy temperature and the Boltzmann's constant, respectively.

\section{Effective Autocorrelation Function and its Applications}

In the degenerate d-Si systems, the total screened Coulomb impurity potential energy due to the attractive interaction between an electron charge, $-q$, at position $\vec{r}$ and an ionized donor charge: $+q$ at position $\overrightarrow{\mathrm{R}_{\mathrm{j}}}$ randomly distributed throughout the Si crystal, is defined by

$$
\mathrm{V}(\mathrm{r}) \equiv \sum_{\mathrm{j}=1}^{\mathcal{N}} \mathrm{v}_{\mathrm{j}}(\mathrm{r})+\mathrm{V}_{\mathrm{o}}
$$

where $\mathcal{N}$ is the total number of ionized donors, $V_{0}$ is a constant potential energy, and $v_{j}(r)$ is a screened Coulomb potential energy for each d-Si system, defined as

$$
\mathrm{v}_{\mathrm{j}}(\mathrm{r}) \equiv-\frac{\mathrm{q}^{2} \times \exp \left(-\mathrm{k}_{\mathrm{sn}} \times\left|\overrightarrow{\mathrm{r}}-\overrightarrow{\mathrm{R}_{\mathrm{j}}}\right|\right)}{\varepsilon_{\mathrm{n}} \times\left|\overrightarrow{\mathrm{r}}-\overrightarrow{\mathrm{R}_{\mathrm{j}}}\right|}
$$

Further, using a Fourier transform, the $\mathrm{v}_{\mathrm{j}}$-representation in wave vector $\overrightarrow{\mathrm{k}}$-espace is given by

$$
\mathrm{v}_{\mathrm{j}}(\overrightarrow{\mathrm{k}})=-\frac{\mathrm{q}^{2}}{\varepsilon_{\mathrm{n}}} \times \frac{4 \pi}{\Omega} \times \frac{1}{\mathrm{k}^{2}+\mathrm{k}_{\mathrm{sn}}^{2}},
$$

where $\Omega$ is the total Si-crystal volume and $\mathrm{k}_{\mathrm{sn}}$ is the inverse screening length determined in Eq. (4). Moreover, in Eqs. $(16,17), \mathrm{V}_{\mathrm{o}}$ is defined as a constant so that $\langle\mathrm{V}(\mathrm{r})\rangle=0$, reflecting a charge neutrality, where the notation $\langle\ldots\rangle$ denotes the configuration average $[25,58]$. In fact, from Eq. (17), one has

$$
\left\langle\sum_{\mathrm{j}=1}^{\mathcal{N}} \mathrm{v}_{\mathrm{j}}(\mathrm{r})\right\rangle=(\mathcal{N} / \Omega) \int_{0}^{\infty} \mathrm{v}_{\mathrm{j}}(\mathrm{r}) \times 4 \pi \mathrm{r}^{2} \mathrm{dr}=-4 \pi \mathrm{Nq}^{2} \mathrm{k}_{\mathrm{sn}(\mathrm{sp})}^{-2} \varepsilon_{\mathrm{n}(\mathrm{p})}^{-1} \equiv-\mathrm{V}_{\mathrm{o}}, \mathrm{N} \equiv \mathcal{N} / \Omega
$$

indicating that from Eq. (16) one obtains: $\langle\mathrm{V}(\mathrm{r})\rangle=0$.

Therefore, the effective autocorrelation function for potential fluctuations can thus be defined by $[25,58]$

$$
\mathrm{W}_{\mathrm{n}}\left(\left|\overrightarrow{\mathrm{r}}-\overrightarrow{\mathrm{r}^{\prime}}\right|\right) \equiv\left\langle\mathrm{V}(\mathrm{r}) \mathrm{V}\left(\mathrm{r}^{\prime}\right)\right\rangle \equiv\langle\mathrm{V}(\mathrm{r})\rangle \times\left\langle\mathrm{V}\left(\mathrm{r}^{\prime}\right)\right\rangle+\left\langle\left\langle\mathrm{V}(\mathrm{r}) \mathrm{V}\left(\mathrm{r}^{\prime}\right)\right\rangle\right\rangle=\left\langle\left\langle\mathrm{V}(\mathrm{r}) \mathrm{V}\left(\mathrm{r}^{\prime}\right)\right\rangle\right\rangle,
$$

where $\left\langle\left\langle\mathrm{V}(\mathrm{r}) \mathrm{V}\left(\mathrm{r}^{\prime}\right)\right\rangle\right\rangle$ denotes the effective second-order cumulant, and $\overrightarrow{\mathrm{r}(\mathrm{t})}$ and $\overrightarrow{\mathrm{r}^{\prime}\left(\mathrm{t}^{\prime}\right)}$ are the electron positions at the times $t$ and $t^{\prime}$, noting that the cumulant is just the average potential energy, which may be absorbed by a redefinition of the zero energy. Then, the expression for $W_{n}$ is determined in Eq. (B.6) of the Appendix B, as

$$
\mathrm{W}_{\mathrm{n}}\left(v_{\mathrm{n}}, \mathrm{N}, \mathrm{r}_{\mathrm{d}}\right) \equiv\left\langle\mathrm{V}(\mathrm{r}) \mathrm{V}\left(\mathrm{r}^{\prime}\right)\right\rangle=\eta_{\mathrm{n}}^{2} \times \exp \left(\frac{-\mathcal{H}_{\mathrm{n}} \times \mathrm{R}_{\mathrm{sn}}}{2 \sqrt{\left|v_{\mathrm{n}}\right|}}\right) .
$$

Here, $R_{\mathrm{sn}}(\mathrm{N})$ is given in Eq. (4), $\eta_{\mathrm{n}}$ is determined in Eq. (12), the constant $\mathcal{H}_{\mathrm{n}}$ will be chosen in next Section $\mathrm{V}$ as: $\mathcal{H}_{\mathrm{n}}=5.4370$, such that the determination of the density of electrons localized in the conduction-band tail would be accurate, and finally $v_{\mathrm{n}} \equiv \frac{-\mathbb{E}}{\mathbb{E}_{\mathrm{Fno}}}$, where $\mathbb{E}$ is the total electron energy and $\mathbb{E}_{\mathrm{Fno}}$ is the Fermi energy at $0 \mathrm{~K}$, determined in Eq. (15).

Now, we calculate the ensemble average of the function:

$$
\left\langle(\mathbb{E}-\mathrm{V})^{\mathrm{a}-\frac{1}{2}}\right\rangle_{\mathrm{KIM}} \equiv\left\langle\mathbb{E}_{\mathrm{k}}^{\mathrm{a}-\frac{1}{2}}\right\rangle_{\mathrm{KIM}}=\int_{-\infty}^{\mathbb{E}}(\mathbb{E}-\mathrm{V})^{\mathrm{a}-\frac{1}{2}} \times \mathrm{P}(\mathrm{V}) \mathrm{dV}, \text { for } \mathrm{a} \geq 1 .
$$

Then, by variable changes: $s=(\mathbb{E}-V) / \sqrt{\mathrm{w}_{\mathrm{n}}}$ and $\mathrm{x}=-\mathbb{E} / \sqrt{\mathrm{W}_{\mathrm{n}}}$, and using an identity [15]:

$$
\int_{0}^{\infty} \mathrm{s}^{\mathrm{a}-\frac{1}{2}} \times \exp \left(-\mathrm{xs}-\frac{\mathrm{s}^{2}}{2}\right) \mathrm{ds} \equiv \Gamma\left(a+\frac{1}{2}\right) \times \exp \left(\mathrm{x}^{2} / 4\right) \times \mathrm{D}_{-\mathrm{a}-\frac{1}{2}}(\mathrm{x})
$$

where $\mathrm{D}_{-\mathrm{a}-\frac{1}{2}}(\mathrm{x})$ is the parabolic cylinder function, $\Gamma\left(a+\frac{1}{2}\right)$ is the Gamma function, one thus finds

$$
\left\langle\mathbb{E}_{\mathrm{k}}^{\mathrm{a}-\frac{1}{2}}\right\rangle_{\mathrm{KIM}}=\frac{\exp \left(-\mathrm{x}^{2} / 4\right) \times \mathrm{W}_{\mathrm{n}}^{\frac{2 \mathrm{a}-1}{4}}}{\sqrt{2 \pi}} \times \Gamma\left(a+\frac{1}{2}\right) \times \mathrm{D}_{-\mathrm{a}-\frac{1}{2}}(\mathrm{x}) .
$$

This result (20) will used to study the optical, electrical, and thermoelectric properties of various degenerate d-Si systems, depending on $\mathrm{W}_{\mathrm{n}}$ defined in Eq. (19) and the variable $\mathrm{x}$, expressed also in terms of $\mathrm{W}_{\mathrm{n}}$, as 


$$
\mathrm{x}=\frac{-\mathbb{E}}{\sqrt{\mathrm{W}_{\mathrm{n}}}} \equiv \mathrm{A}_{\mathrm{n}} \times v_{\mathrm{n}} \times \exp \left(\frac{\mathcal{H}_{\mathrm{n}} \times \mathrm{R}_{\mathrm{Sn}}}{4 \times \sqrt{\left|v_{\mathrm{n}}\right|}}\right), \mathrm{A}_{\mathrm{n}} \equiv \frac{\mathbb{E}_{\mathrm{Fno}}}{\eta_{\mathrm{n}}}, v_{\mathrm{n}} \equiv \frac{-\mathbb{E}}{\mathbb{E}_{\mathrm{Fno}}}
$$

where $\mathbb{E}_{\mathrm{Fno}}$ and $\eta_{\mathrm{n}}$ are determined in Eqs. $(15,12)$, respectively. Therefore, the effective autocorrelation function for potential fluctuations $W_{n}$, defined in Eq. (19), is thus a central result of the present paper.

\subsection{Feynman Path-Integral Method}

In the Feynman path-integral method (FPIM), the ensemble average of $(\mathbb{E}-V)^{\mathrm{a}-\frac{1}{2}}$ is defined by

$$
\left\langle(\mathbb{E}-\mathrm{V})^{\mathrm{a}-\frac{1}{2}}\right\rangle_{\mathrm{FPIM}} \equiv\left\langle\mathbb{E}_{\mathrm{k}}^{\mathrm{a}-\frac{1}{2}}\right\rangle_{\mathrm{FPIM}} \equiv \frac{\hbar^{\mathrm{a}-\frac{1}{2}}}{2^{3 / 2} \times \sqrt{2 \pi}} \times \frac{\Gamma\left(\mathrm{a}+\frac{1}{2}\right)}{\Gamma\left(\frac{3}{2}\right)} \times \int_{-\infty}^{\infty}(i \mathrm{t})^{-\mathrm{a}-\frac{1}{2}} \times \exp \left\{\frac{i \mathbb{E t}}{\hbar}-\frac{\left(\mathrm{t} \sqrt{\mathrm{W}_{\mathrm{n}}}\right)^{2}}{2 \hbar^{2}}\right\} \mathrm{dt}, \mathrm{i}^{2}=-1,
$$

noting that as $\mathrm{a}=1$, (it) $)^{-\frac{3}{2}} \times \exp \left\{-\frac{\left(\mathrm{t} \sqrt{\mathrm{W}_{\mathrm{n}}}\right)^{2}}{2 \hbar^{2}}\right\}$ is found to be proportional to the averaged Feynman propagator given the dense donors [16].

Then, by variable changes: $t=\frac{\hbar}{\sqrt{W_{n}}}$ and $x=-\mathbb{E} / \sqrt{W_{n}}$ and then using an identity [15]:

$$
\int_{-\infty}^{\infty}(i s)^{-\mathrm{a}-\frac{1}{2}} \times \exp \left\{i \mathrm{xs}-\frac{\mathrm{s}^{2}}{2}\right\} \mathrm{ds} \equiv 2^{3 / 2} \times \Gamma(3 / 2) \times \exp \left(-\mathrm{x}^{2} / 4\right) \times \mathrm{D}_{-\mathrm{a}-\frac{1}{2}}(\mathrm{x}),
$$

one finally obtains: $\left\langle\mathbb{E}_{\mathrm{k}}^{\mathrm{a}-\frac{1}{2}}\right\rangle_{\mathrm{FPIM}} \equiv\left\langle\mathbb{E}_{\mathrm{k}}^{\mathrm{a}-\frac{1}{2}}\right\rangle_{\mathrm{KIM}}$, where $\left\langle\mathbb{E}_{\mathrm{k}}^{\mathrm{a}-\frac{1}{2}}\right\rangle_{\mathrm{KIM}}$ is determined in Eq. (20).

In the following, with use of asymptotic forms for $\mathrm{D}_{-\mathrm{a}-\frac{1}{2}}(\mathrm{x})[15]$, those given for $\left\langle(\mathbb{E}-\mathrm{V})^{\mathrm{a}-\frac{1}{2}}\right\rangle_{\mathrm{KIM}}$ will be obtained in the two cases: $\mathbb{E} \geq 0$ and $\mathbb{E} \leq 0$.

$\mathbb{E} \geq 0$-case

As $\mathbb{E} \rightarrow+\infty$, from Eq. (21), one has: $v_{\mathrm{n}} \rightarrow-\infty$ and $\mathrm{x} \rightarrow-\infty$. In this case, one gets [15]:

$$
\mathrm{D}_{-\mathrm{a}-\frac{1}{2}}(\mathrm{x} \rightarrow-\infty) \approx \frac{\sqrt{2 \pi}}{\Gamma\left(\mathrm{a}+\frac{1}{2}\right)} \times e^{\frac{\mathrm{x}^{2}}{4}} \times(-\mathrm{x})^{\mathrm{a}-\frac{1}{2}}
$$

Therefore, Eq. (20) becomes

$$
\left\langle\mathbb{E}_{\mathrm{k}}^{\mathrm{a}-\frac{1}{2}}\right\rangle_{\mathrm{KIM}} \approx \mathbb{E}^{\mathrm{a}-\frac{1}{2}}
$$

Further, as $\mathbb{E} \rightarrow+0$, from Eq. (21), one has: $v_{\mathrm{n}} \rightarrow-0$ and $\mathrm{x} \rightarrow-\infty$. Therefore, one gets [15]

$$
\mathrm{D}_{-\mathrm{a}-\frac{1}{2}}(\mathrm{x} \rightarrow-\infty) \simeq \beta(\mathrm{a}) \times \exp \left(\left(\sqrt{\mathrm{a}}+\frac{1}{16 \mathrm{a}^{\frac{3}{2}}}\right) \mathrm{x}-\frac{\mathrm{x}^{2}}{16 \mathrm{a}}+\frac{\mathrm{x}^{3}}{24 \sqrt{\mathrm{a}}}\right) \rightarrow 0, \beta(\mathrm{a})=\frac{\sqrt{\pi}}{\left.2^{\frac{2 a+1}{4}} \Gamma\left(\frac{\mathrm{a}}{2}+\frac{3}{4}\right)\right]} .
$$

Thus, as $\mathbb{E} \rightarrow+0$, from Eq. (20), one gets:

$$
\left\langle\mathbb{E}_{\mathrm{k}}^{\mathrm{a}-\frac{1}{2}}\right\rangle_{\mathrm{KIM}} \rightarrow 0
$$

being in good agreement with our result obtained in Eq. (A3) of the Appendix A.

In summary, from Eqs. $(22,23)$ and for $\underline{\mathbb{E} \geq 0}$, the expression of $\left\langle\mathbb{E}_{\mathrm{k}}^{\mathrm{a}-\frac{1}{2}}\right\rangle_{\mathrm{KIM}}$ can be approximated by:

$$
\left\langle\mathbb{E}_{\mathrm{k}}^{\mathrm{a}-\frac{1}{2}}\right\rangle_{\mathrm{KIM}} \cong \mathbb{E}^{\mathrm{a}-\frac{1}{2}}
$$

$\mathbb{E} \leq 0$-case

Here, from Eqs. $(19,21)$, Eq. (20) can be rewritten as

$$
\begin{gathered}
\left\langle\mathbb{E}_{\mathrm{k}}^{\mathrm{a}-\frac{1}{2}}\right\rangle_{\mathrm{KIM}}=\frac{\exp \left(-\mathrm{x}^{2} / 4\right) \times \mathrm{W}_{\mathrm{n}}^{\frac{2 \mathrm{a}-1}{4}}}{\sqrt{2 \pi}} \times \Gamma\left(a+\frac{1}{2}\right) \times \mathrm{D}_{-\mathrm{a}-\frac{1}{2}}(\mathrm{x}), \\
=\frac{\exp \left(-\mathrm{x}^{2} / 4\right) \times \eta_{\mathrm{n}}^{\mathrm{a}-\frac{1}{2}}}{\sqrt{2 \pi}} \times \exp \left(-\frac{\mathcal{H}_{\mathrm{n}} R_{\mathrm{Sn}} \times(2 \mathrm{a}-1)}{8 \times \sqrt{\left|v_{\mathrm{n}}\right|}}\right) \times \Gamma\left(\mathrm{a}+\frac{1}{2}\right) \times \mathrm{D}_{-\mathrm{a}-\frac{1}{2}}(\mathrm{x}) .
\end{gathered}
$$

As $\mathbb{E} \rightarrow-0$, from Eq. (21), one has: $v_{\mathrm{n}} \rightarrow+0$ and $\mathrm{x} \rightarrow+\infty$. Thus, one obtains, for any $\mathrm{a} \geq 1,[15]$ 


$$
\begin{gathered}
\mathrm{D}_{-\mathrm{a}-\frac{1}{2}}(\mathrm{x} \rightarrow \infty) \simeq \beta(\mathrm{a}) \times \exp \left[-\left(\sqrt{a}+\frac{1}{16 \mathrm{a}^{\frac{3}{2}}}\right) \mathrm{x}-\frac{\mathrm{x}^{2}}{16 \mathrm{a}}-\frac{\mathrm{x}^{3}}{24 \sqrt{\mathrm{a}}}\right] \rightarrow 0, \beta(\mathrm{a})=\frac{\sqrt{\pi}}{2^{\left.\frac{2 a+1}{4} \Gamma\left(\frac{\mathrm{a}}{2}+\frac{3}{4}\right)\right]} \text {, noting that }} \\
\beta(1)=\frac{\sqrt{\pi}}{2^{\frac{3}{4}} \times \Gamma(5 / 4)} \text { and } \beta(5 / 2)=\frac{\sqrt{\pi}}{2^{3 / 2}} .
\end{gathered}
$$

Then, putting $\mathrm{f}(\mathrm{a}) \equiv \frac{\eta_{\mathrm{n}}-\frac{1}{2}}{\sqrt{2 \pi}} \times \Gamma\left(\mathrm{a}+\frac{1}{2}\right) \times \beta(\mathrm{a})$, Eq. (25) yields

$$
\mathrm{H}_{\mathrm{n}}\left(v_{\mathrm{n}} \rightarrow 0, \mathrm{r}_{\mathrm{d}}, \mathrm{a}\right)=\frac{\left\langle\mathbb{E}_{\mathrm{k}}^{\mathrm{a}-\frac{1}{2}}\right\rangle_{\mathrm{KIM}}}{\mathrm{f}(\mathrm{a})}=\exp \left[-\frac{\mathcal{F}_{\mathrm{n}} \mathrm{R}_{\mathrm{sn}} \times(2 \mathrm{a}-1)}{8 \times \sqrt{\left|\mathrm{v}_{\mathrm{n}}\right|}}-\left(\sqrt{\mathrm{a}}+\frac{1}{16 \mathrm{a}^{\frac{3}{2}}}\right) \mathrm{x}-\left(\frac{1}{4}+\frac{1}{16 \mathrm{a}}\right) \mathrm{x}^{2}-\frac{\mathrm{x}^{3}}{24 \sqrt{\mathrm{a}}}\right] \rightarrow 0,
$$

which is in good accordance with that given in Eq. (A3) of the Appendix A. In particular, as $v_{n} \rightarrow 0$, the first term of $\operatorname{lnH}_{\mathrm{n}}\left(v_{\mathrm{n}} \rightarrow 0, \mathrm{r}_{\mathrm{d}}, \mathrm{a}=1\right)$ given in Eq. (26), $-\frac{\mathcal{H}_{\mathrm{n}} \mathrm{R}_{\mathrm{sn}}}{8 \times \sqrt{\left|v_{\mathrm{n}}\right|}}$, can be compared with the third one given in Eq. (A3), $-4 \mathrm{~B} c^{2} \mathrm{R}_{\mathrm{sn}} \times$ $\left|v_{\mathrm{n}}\right|^{-\frac{1}{2}}$. Moreover, as noted in Eqs. (B.5, B.6) of the Appendix B, when the small time approximation (STA) is used: $\Delta \mathrm{r} \simeq 0$ $[17,21,22,29,30], \mathrm{W}_{\mathrm{n}}\left(v_{\mathrm{n}}, \mathrm{N}\right) \simeq \eta_{\mathrm{n}}^{2}$. Therefore, Eq. (25) now yields [21, 29, 30]:

$$
\mathrm{H}_{\mathrm{n}(\mathrm{STA})}\left(v_{\mathrm{n}} \rightarrow 0, \mathrm{r}_{\mathrm{d}}, \mathrm{a}\right)=\frac{\left\langle\mathbb{E}_{\mathrm{k}}^{\mathrm{a}-\frac{1}{2}}\right\rangle_{\text {KIM }}}{\mathrm{f}(\mathrm{a})}=\exp \left[\left(\sqrt{\mathrm{a}}+\frac{1}{16 \mathrm{a}^{\frac{3}{2}}}\right) \times \frac{\mathbb{E}}{\eta_{\mathrm{n}}}\right], \mathbb{E} \leq 0,
$$

being equal to 1 for $\mathbb{E}=-0$, which is not correct, since we must have: $H_{n}\left(\mathbb{E} \rightarrow-0, r_{d}, a\right) \rightarrow 0$, as obtained in Eq. (26), due correctly to the Heisenberg uncertainty relation given in Eq. (B.5): $\Delta r \gg 0$ as $\mathbb{E} \rightarrow-0$. Finally, we also remark that, in the full ground-state case and deep-tail approximation, the exponential conduction- band tail, obtained by Sa-yakamit et al. [23], was also equal to a constant at $\mathbb{E}=-0$, being not correct.

Further, from Eq. (21), as $\mathbb{E} \rightarrow-\infty$, one has: $v_{\mathrm{n}} \rightarrow+\infty$ and $\mathrm{x} \rightarrow \infty$. Thus, one gets [15]:

$\mathrm{D}_{-\mathrm{a}-\frac{1}{2}}(\mathrm{x} \rightarrow \infty) \approx \mathrm{x}^{-\mathrm{a}-\frac{1}{2}} \times e^{-\frac{\mathrm{x}^{2}}{4}} \rightarrow 0$. Therefore, Eq. (25) yields

$$
\mathrm{K}_{\mathrm{n}}\left(v_{\mathrm{n}} \rightarrow+\infty, \mathrm{r}_{\mathrm{d}}, \mathrm{a}\right) \equiv \frac{\left\langle\mathbb{E}_{\mathrm{k}}^{\mathrm{a}} \mathrm{-}^{\frac{1}{2}}\right\rangle_{\mathrm{KIM}}}{\mathrm{f}(\mathrm{a})} \simeq \frac{1}{\beta(\mathrm{a})} \times \exp \left(-\frac{\left(\mathrm{A}_{\mathrm{n}} \times v_{\mathrm{n}}\right)^{2}}{2}\right) \times\left(\mathrm{A}_{\mathrm{n}} \times v_{\mathrm{n}}\right)^{-\mathrm{a}-\frac{1}{2}} \rightarrow 0,
$$

being in perfect agreement with a well-known semi-classical Kane's result [14].

It should be noted that, as $\mathbb{E} \leq 0$, the ratios (26) and (27) can be taken in an approximate form as

$$
\mathrm{F}_{\mathrm{n}}\left(v_{\mathrm{n}}, \mathrm{r}_{\mathrm{d}}, \mathrm{a}\right)=\mathrm{K}_{\mathrm{n}}\left(v_{\mathrm{n}}, \mathrm{r}_{\mathrm{d}}, \mathrm{a}\right)+\left[\mathrm{H}_{\mathrm{n}}\left(v_{\mathrm{n}}, \mathrm{r}_{\mathrm{d}}, \mathrm{a}\right)-\mathrm{K}_{\mathrm{n}}\left(v_{\mathrm{n}}, \mathrm{r}_{\mathrm{d}}, \mathrm{a}\right)\right] \times \exp \left[-\mathrm{c}_{1} \times\left(\mathrm{A}_{\mathrm{n}} v_{\mathrm{n}}\right)^{\mathrm{c}_{2}}\right],
$$

so that: $F_{n}\left(v_{n}, r_{d}, a\right) \rightarrow H_{n}\left(v_{n}, r_{d}, a\right)$ for $0 \leq v_{n} \leq 16$, and $\mathrm{F}_{\mathrm{n}}\left(v_{\mathrm{n}}, \mathrm{r}_{\mathrm{d}}, \mathrm{a}\right) \rightarrow \mathrm{K}_{\mathrm{n}}\left(v_{\mathrm{n}}, \mathrm{r}_{\mathrm{d}}, \mathrm{a}\right)$ for $v_{\mathrm{n}} \geq 16$. For that, in next sections $\mathrm{V}$ and $\mathrm{VI}$, the constants $\mathrm{c}_{1}$ and $\mathrm{c}_{2}$ may be respectively chosen as: $c_{1}=10^{-40}$ and $c_{2}=80$ when $\mathrm{a}=1$, being used to the study of reduced density of exponential conduction-band-tail states, and $c_{1}=20^{-150}$ and $c_{2}=300$ when $a=5 / 2$, for the study of reduced optical absorption coefficient and exponential tails of electrical conductivity.

Here, one remarks that, from Eqs. (26-28) and for a given value of a, since, as $v_{\mathrm{n}} \rightarrow+0$ and $+\infty$, $\mathrm{F}_{\mathrm{n}}\left(v_{\mathrm{n}}, \mathrm{r}_{\mathrm{d}}, \mathrm{a}\right) \rightarrow 0$, the maximum of this function thus exists, occurring at $v_{\mathrm{n}}=v_{\mathrm{n}(\mathrm{M})}$. Hence, in various degenerate d-Si systems, in which $\mathrm{N}=5 \times 10^{20} \mathrm{~cm}^{-3}$ and $\mathrm{T}=0 \mathrm{~K}$, for example, using Eq. (28), we can study the behaviors of the function $\ln \left[\mathrm{F}_{\mathrm{n}}\left(v_{\mathrm{n}}, \mathrm{r}_{\mathrm{d}}, \mathrm{a}\right)\right]<0$, for given $\mathrm{a}$, which can take its approximate form determined by: $\operatorname{AF}\left(v_{\mathrm{n}}, \mathrm{r}_{\mathrm{d}}, v_{1}, v_{2}, \mathrm{z}, \mathrm{f}\right)<0$, obtained in small $v_{\mathrm{n}}$-intervals: $v_{1} \leq v_{\mathrm{n}} \leq v_{2}$, as

$$
\operatorname{AF}\left(v_{n}, r_{d}, v_{1}, v_{2}, z, f\right)=e\left(r_{d}, v_{1}, v_{2}, z\right) \times v_{n}^{z}+f .
$$

Here, $\mathrm{e}\left(\mathrm{r}_{\mathrm{d}}, v_{1}, v_{2}, \mathrm{z}\right)$ is the slope of this AF-curve, defined by

$$
\mathrm{e}\left(\mathrm{r}_{\mathrm{d}}, v_{1}, v_{2}, \mathrm{z}\right) \equiv \frac{\ln _{\mathrm{n}}\left(v_{2}, \mathrm{r}_{\mathrm{d}}, \mathrm{a}\right)-\ln \mathrm{F}_{\mathrm{n}}\left(v_{1}, \mathrm{r}_{\mathrm{d}}, \mathrm{a}\right)}{v_{2}^{\mathrm{z}}-v_{1}^{\mathrm{z}}},
$$

which is negative for $v_{\mathrm{n}}>v_{\mathrm{n}(\mathrm{M})}$ and positive for $v_{\mathrm{n}}<v_{\mathrm{n}(\mathrm{M})}$, noting that for $v_{\mathrm{n}}>v_{\mathrm{n}(\mathrm{M})}$ or in particular $v_{\mathrm{n}} \rightarrow+\infty$, from our above results $(27,28)$, one has: $\mathrm{z}=2$. So, for $v_{\mathrm{n}}>v_{\mathrm{n}(\mathrm{M})}$ the values of exponent $\mathrm{z}=1,1 / 2,1 / 3$ and $1 / 4$, and for $v_{\mathrm{n}}<v_{\mathrm{n}(\mathrm{M})}$ those of exponent $z=2,1$, for $1 / 2,1 / 3$ and $1 / 4$ could be considered in next Sections V-VII. Moreover, as $v_{\mathrm{n}}>v_{\mathrm{n}(\mathrm{M})}$, according to $\mathrm{e}\left(\mathrm{r}_{\mathrm{d}}, v_{1}, v_{2}, \mathrm{z}=1\right)<0$, the energy parameter characteristic of $\left(-|\mathrm{e}| \times v_{\mathrm{n}}\right)$-linear exponential tail states of the function $\mathrm{F}_{\mathrm{n}}\left(v_{\mathrm{n}}, \mathrm{r}_{\mathrm{d}}\right)$ can be defined by

$$
\mathbb{E}_{\mathrm{no}}\left(\mathrm{N}, \mathrm{r}_{\mathrm{d}}, v_{1}, v_{2}\right) \equiv \frac{\mathbb{E}_{\mathrm{Fno}}(\mathrm{N})}{\left|\mathrm{e}\left(\mathrm{r}_{\mathrm{d}}, v_{1}, v_{2}, \mathrm{z}=1\right)\right|},
$$

as observed in next Figs. 2, 5, and 8.

It should be noted that the important results (20) obtained for any $\mathbb{E}$-values, (24) for $\mathbb{E} \geq 0$, and (28-31) for $\mathbb{E} \leq 0$, can be used to determine the density of states and the optical, 
electrical and thermoelectric functions in Sections V-VIII, respectively.

\section{Low Temperature Effect, Due to the Fermi-Dirac Distribution Function}

The Fermi-Dirac distribution function (FDDF) is given by

$$
\left\langle\mathbb{E}^{\mathrm{p}}\right\rangle_{\mathrm{FDDF}} \equiv \mathrm{G}_{\mathrm{p}}\left(\mathbb{E}_{\mathrm{Fn}}\right) \times \mathbb{E}_{\mathrm{Fn}}^{\mathrm{p}} \equiv \int_{-\infty}^{\infty} \mathbb{E}^{\mathrm{p}} \times\left(-\frac{\partial \mathrm{f}}{\partial \mathbb{E}}\right) \mathrm{d} \mathbb{E},-\frac{\partial \mathrm{f}}{\partial \mathbb{E}}=\frac{1}{\mathrm{k}_{\mathrm{B}} \mathrm{T}} \times \frac{\mathrm{e}^{\gamma}}{\left(1+\mathrm{e}^{\gamma}\right)^{2}}
$$

Further, one remarks that, at $0 \mathrm{~K},-\frac{\partial \mathrm{f}}{\partial \mathbb{E}}=\delta\left(\mathbb{E}-\mathbb{E}_{\mathrm{Fno}}\right), \delta\left(\mathbb{E}-\mathbb{E}_{\mathrm{Fno}}\right)$ being the Dirac delta $(\delta)$-function and $\mathbb{E}_{\mathrm{Fno}}$ is the Fermi energy at $\mathrm{T}=0 \mathrm{~K}$ defined in Eq. (15). Therefore, $\mathrm{G}_{\mathrm{p}}\left(\mathbb{E}_{\mathrm{Fno}}\right)=1$.

Then, at low $\mathrm{T}$, by a variable change $\gamma \equiv\left(\mathbb{E}-\mathbb{E}_{\mathrm{F}}\right) /\left(\mathrm{k}_{\mathrm{B}} \mathrm{T}\right)$, Eq. (32) yields

$$
\mathrm{G}_{\mathrm{p}}\left(\mathbb{E}_{\mathrm{Fn}}\right) \equiv 1+\mathbb{E}_{\mathrm{Fn}}^{-\mathrm{p}} \times \int_{-\infty}^{\infty} \frac{\mathrm{e}^{\gamma}}{\left(1+\mathrm{e}^{\gamma}\right)^{2}} \times\left(\mathrm{k}_{\mathrm{B}} \mathrm{T} \gamma+\mathbb{E}_{\mathrm{Fn}}\right)^{\mathrm{p}} \mathrm{d} \gamma=1+\sum_{\mu=1,2, \ldots}^{\mathrm{p}} \mathrm{C}_{\mathrm{p}}^{\beta} \times\left(\mathrm{k}_{\mathrm{B}} \mathrm{T}\right)^{\beta} \times \mathbb{E}_{\mathrm{Fn}}^{-\beta} \times \mathrm{I}_{\beta},
$$

where $C_{\mathrm{p}}^{\beta} \equiv \mathrm{p}(\mathrm{p}-1) \ldots(\mathrm{p}-\beta+1) / \beta$ ! and the integral $\mathrm{I}_{\beta}$ is given by

$$
\mathrm{I}_{\beta}=\int_{-\infty}^{\infty} \frac{\gamma^{\beta} \times \mathrm{e}^{\gamma}}{\left(1+\mathrm{e}^{\gamma}\right)^{2}} \mathrm{~d} \gamma=\int_{-\infty}^{\infty} \frac{\gamma^{\beta}}{\left(\mathrm{e}^{\gamma / 2}+\mathrm{e}^{-\gamma / 2}\right)^{2}} \mathrm{~d} \gamma,
$$

vanishing for old values of $\beta$. Then, for even values of $\beta=2 \mathrm{n}$, with $\mathrm{n}=1,2, \ldots$, one obtains

$$
\mathrm{I}_{2 \mathrm{n}}=2 \int_{0}^{\infty} \frac{\gamma^{2 \mathrm{n}} \times \mathrm{e}^{\gamma}}{\left(1+\mathrm{e}^{\gamma}\right)^{2}} \mathrm{~d} \gamma
$$

Now, using an identity [15]: $\left(1+\mathrm{e}^{\gamma}\right)^{-2} \equiv \sum_{\mathrm{s}=1}^{\infty}(-1)^{\mathrm{s}+1} \mathrm{~s} \times \mathrm{e}^{\gamma(s-1)}$, a variable change: $\mathrm{s} \gamma=-\mathrm{t}$, the Gamma function: $\int_{0}^{\infty} \mathrm{t}^{2 \mathrm{n}} \mathrm{e}^{-\mathrm{t}} \mathrm{dt} \equiv \Gamma(2 n+1)=(2 n)$ !, and also the definition of the Riemann's zeta function [15]: $\zeta(2 \mathrm{n}) \equiv 2^{2 \mathrm{n}-1} \pi^{2 \mathrm{n}}\left|\mathrm{B}_{2 \mathrm{n}}\right| /$ $(2 n)$ !,$B_{2 n}$ being the Bernoulli numbers, one finally gets: $I_{2 n}=\left(2^{2 n}-2\right) \times \pi^{2 n} \times\left|B_{2 n}\right|$. So, from Eq. (32), we get in the degenerate case the following ratio:

$$
\mathrm{G}_{\mathrm{p}}\left(\mathbb{E}_{\mathrm{Fn}}\right) \equiv \frac{\left\langle\mathbb{E}^{\mathrm{p}}\right\rangle_{\mathrm{FDDF}}}{\mathbb{E}_{\mathrm{Fn}}^{\mathrm{p}}}=1+\sum_{\mathrm{n}=1}^{\mathrm{p}} \frac{\mathrm{p}(\mathrm{p}-1) \ldots(\mathrm{p}-2 \mathrm{n}+1)}{(2 \mathrm{n}) !} \times\left(2^{2 \mathrm{n}}-2\right) \times\left|\mathrm{B}_{2 \mathrm{n}}\right| \times \mathrm{y}^{2 \mathrm{n}} \equiv \mathrm{G}_{\mathrm{p}}(\mathrm{y}), \mathrm{y}=\frac{\pi \mathrm{k}_{\mathrm{B}} \mathrm{T}}{\mathbb{E}_{\mathrm{Fn}}} \simeq \frac{\pi \mathrm{k}_{\mathrm{B}} \mathrm{T}}{\mathbb{E}_{\mathrm{Fno}}} .
$$

It should be noted that our previous expression for $\mathrm{G}_{\mathrm{p}}(x)$ [58] can now be corrected, replacing $\beta$ by $2 \mathrm{n}$ and the Bernoulli numbers $B_{\beta / 2}$ by $\left|B_{2 n}\right|$. Further, Jaffe [49] proposed the following result:

$$
G_{p(J a f f e)}\left(\mathbb{E}_{F n}, T\right)=1+\mathbb{E}_{F n}^{-p} \times \sum_{n=1}^{p}(-1)^{2 n+1} \times c_{2 n} \times\left(k_{B} T\right)^{2 n} \times\left(\frac{d^{2 n}}{d \mathbb{E}^{2 n}} \mathbb{E}^{p}\right)_{\mathbb{E}=\mathbb{E}_{F n}}
$$

where $c_{2 n}=\frac{\left(2-2^{2 n}\right) \times \pi^{2 n} \times\left|B_{2 n}\right|}{(2 n) !}$. Now, using an identity:

$$
\left(\frac{d^{2 n}}{d_{E^{2 n}}} \mathbb{E}^{p}\right)_{\mathbb{E}=\mathbb{E}_{F n}} \equiv p(p-1) \ldots(p-2 n+1) \times \mathbb{E}_{\mathrm{Fn}}^{p-2 n}
$$

Eq. (35) is found to be identical to our above result (34), which is a more practical result. Then, some usual results of $\mathrm{G}_{\mathrm{p}}(\mathrm{y})$ are given in Table 3.

Table 3. The values of absolute Bernoulli numbers $\left|B_{2 n}\right|[15]$, and some expressions for $G_{p}(y)$, obtained from Eq. (34) at low $T$ and for $p \geq 3 / 2$. Here, $y=\frac{\pi k_{B} T}{\mathbb{E}_{F n}} \simeq \frac{\pi k_{B} T}{\mathbb{E}_{F n o}}$.

\begin{tabular}{llllll}
\hline $\mathbf{2 n}$ & $\mathbf{2}$ & $\mathbf{4}$ & $\mathbf{6}$ & $\mathbf{8}$ & $\mathbf{1 0}$ \\
\hline$\left|\mathrm{B}_{2 \mathrm{n}}\right|$ & $1 / 6$ & $|-1 / 30|$ & $1 / 42$ & $|-1 / 30|$ & $5 / 66$ \\
\hline $\mathrm{G}_{\frac{3}{2}}(\mathrm{y})=1+\frac{\mathrm{y}^{2}}{8}+\frac{7 \mathrm{y}^{4}}{640}, \mathrm{G}_{2}(\mathrm{y})=1+\frac{\mathrm{y}^{2}}{3}, \mathrm{G}_{\frac{5}{2}}(\mathrm{y})=1+\frac{5 \mathrm{y}^{2}}{8}-\frac{7 \mathrm{y}^{4}}{384}, \mathrm{G}_{3}(\mathrm{y})=1+\mathrm{y}^{2}, \mathrm{G}_{\frac{7}{2}}(\mathrm{y})=1+\frac{35 \mathrm{y}^{2}}{24}+\frac{49 \mathrm{y}^{4}}{384}, \mathrm{G}_{4}(\mathrm{y})=1+2 \mathrm{y}^{2}+\frac{7 \mathrm{y}^{4}}{15}, \mathrm{G}_{\frac{9}{2}}(\mathrm{y})=1+\frac{21 \mathrm{y}^{2}}{8}+\frac{147 \mathrm{y}^{4}}{128}, \ldots$
\end{tabular}

These functions $G_{p}(y)$ obtained in Table 3 will be applied to determine the electrical and thermoelectric properties of the degenerate d-Si systems, being given in Sections 7 and 8, respectively. 


\section{Determination of Critical Donor Density}

In degenerate d-Si systems at $\mathrm{T}=0 \mathrm{~K}$, due to the heavy doping effect (HDE), using Eq. (20) for a $=1,\left\langle\mathbb{E}_{\mathrm{k}}^{\frac{1}{2}}\right\rangle_{\mathrm{KIM}}$, the density of states $\mathcal{D}(\mathbb{E})$ is given by:

$$
\left\langle\mathcal{D}\left(\mathbb{E}_{\mathrm{k}}\right)\right\rangle_{\mathrm{KIM}} \equiv \frac{\mathrm{g}_{\mathrm{c}}}{2 \pi^{2}}\left(\frac{2 \mathrm{~m}_{\mathrm{n}}^{\mathrm{HDE}}(\mathrm{N})}{\hbar^{2}}\right)^{\frac{3}{2}} \times\left\langle\mathbb{E}_{\mathrm{k}}^{\frac{1}{2}}\right\rangle_{\mathrm{KIM}}=\frac{\mathrm{g}_{\mathrm{c}}}{2 \pi^{2}}\left(\frac{2 \mathrm{~m}_{\mathrm{n}}^{\mathrm{HDE}}(\mathrm{N})}{\hbar^{2}}\right)^{\frac{3}{2}} \times \frac{\exp \left(-\frac{\mathrm{x}^{2}}{4}\right) \times \mathrm{w}_{\mathrm{n}}^{\frac{1}{4}}}{\sqrt{2 \pi}} \times \Gamma\left(\frac{3}{2}\right) \times \mathrm{D}_{-\frac{3}{2}}(\mathrm{x})=\mathcal{D}(\mathbb{E}),
$$

where $\mathrm{m}_{\mathrm{n}}^{\mathrm{HDE}}(\mathrm{N})$ is the electron effective mass, due to the HDE, determined in Eq. (8), and the variable $\mathrm{x}$ is defined in Eq. (21), as

$$
\mathrm{x}=\frac{-\mathbb{E}}{\sqrt{\mathrm{W}_{\mathrm{n}}}} \equiv \mathrm{A}_{\mathrm{n}} \times v_{\mathrm{n}} \times \exp \left(\frac{\mathcal{F}_{\mathrm{n}} \times \mathrm{R}_{\mathrm{Sn}}}{4 \times \sqrt{\left|\mathrm{v}_{\mathrm{n}}\right|}}\right), \mathrm{A}_{\mathrm{n}} \equiv \frac{\mathbb{E}_{\mathrm{Fno}}}{\eta_{\mathrm{n}}}, v_{\mathrm{n}}(\mathbb{E}, \mathrm{N}) \equiv \frac{-\mathbb{E}}{\mathbb{E}_{\mathrm{Fno}}} .
$$

Here, $\mathbb{E}_{\mathrm{Fno}}$ is determined in Eq. (15) for $\mathrm{m}^{*}=\mathrm{m}_{\mathrm{n}}^{\mathrm{HDE}}(\mathrm{N}), \mathrm{m}_{\mathrm{n}}^{\mathrm{HDE}}(\mathrm{N})$ being the electron effective mass due to the HDE and determined in Eq. (8), and the value of Heisenberg empirical parameter $\mathcal{H}_{\mathrm{n}(\mathrm{p})}$ was defined in the Appendix $\mathrm{B}$ and proposed here as: $\mathcal{H}_{\mathrm{n}(\mathrm{p})}=5.4370$, so that the following determination of the critical density of electrons localized in the exponential conduction-band tail would be accurate. Further, from Eq. (24), one also has

$$
\mathcal{D}(\mathbb{E} \geq 0)=\frac{\mathrm{g}_{\mathrm{c}}}{2 \pi^{2}}\left(\frac{2 \mathrm{~m}_{\mathrm{n}}^{\mathrm{HDE}}(\mathrm{N})}{\hbar^{2}}\right)^{\frac{3}{2}} \times \sqrt{\mathbb{E}}
$$

Going back to the functions: $H_{n}, K_{n}$ and $F_{n}$, given respectively in Eqs. (26-28), in which the factor $\frac{\left\langle\mathbb{E}_{k}^{2}\right\rangle_{K I M}}{f(a=1)}$ is now replaced by:

$$
\frac{\left\langle\frac{1}{\mathbb{E}_{\mathrm{k}}^{2}}\right)_{\mathrm{KIM}}}{\mathrm{f}(\mathrm{a}=1)}=\frac{\mathcal{D}(\mathbb{E} \leq 0)}{\mathcal{D}_{\mathrm{o}}}=\mathrm{F}_{\mathrm{n}}\left(v_{\mathrm{n}}, \mathrm{r}_{\mathrm{d}}, \mathrm{a}=1\right), \mathcal{D}_{\mathrm{o}}=\frac{\mathrm{g}_{\mathrm{c}} \times\left(m_{\mathrm{n}}^{\mathrm{HDE}}\right)^{3 / 2} \times \sqrt{\eta_{\mathrm{n}}}}{2 \pi^{2} \hbar^{3}} \times \beta(\mathrm{a}=1), \beta(\mathrm{a}=1)=\frac{\sqrt{\pi}}{2^{\frac{3}{4}} \times \Gamma(5 / 4)},
$$

where the reduced density of exponential-tail states: $F_{n}\left(v_{n}, r_{d}, a=1\right) \equiv F_{n(1)}\left(v_{n}, r_{d}\right)$, for a simplicity of presentation, is determined in Eq. (28). Then, in d-Si systems at $0 \mathrm{~K}$ and for $\mathrm{N}=5 \times 10^{20} \mathrm{~cm}^{-3}$, our results of the functions $\mathrm{F}_{\mathrm{n}(1)}\left(v_{\mathrm{n}}, \mathrm{r}_{\mathrm{d}}\right)$ obtained for each $\mathrm{r}_{\mathrm{d}}$-value, are plotted as functions of $v_{\mathrm{n}}$ in Figure 1.

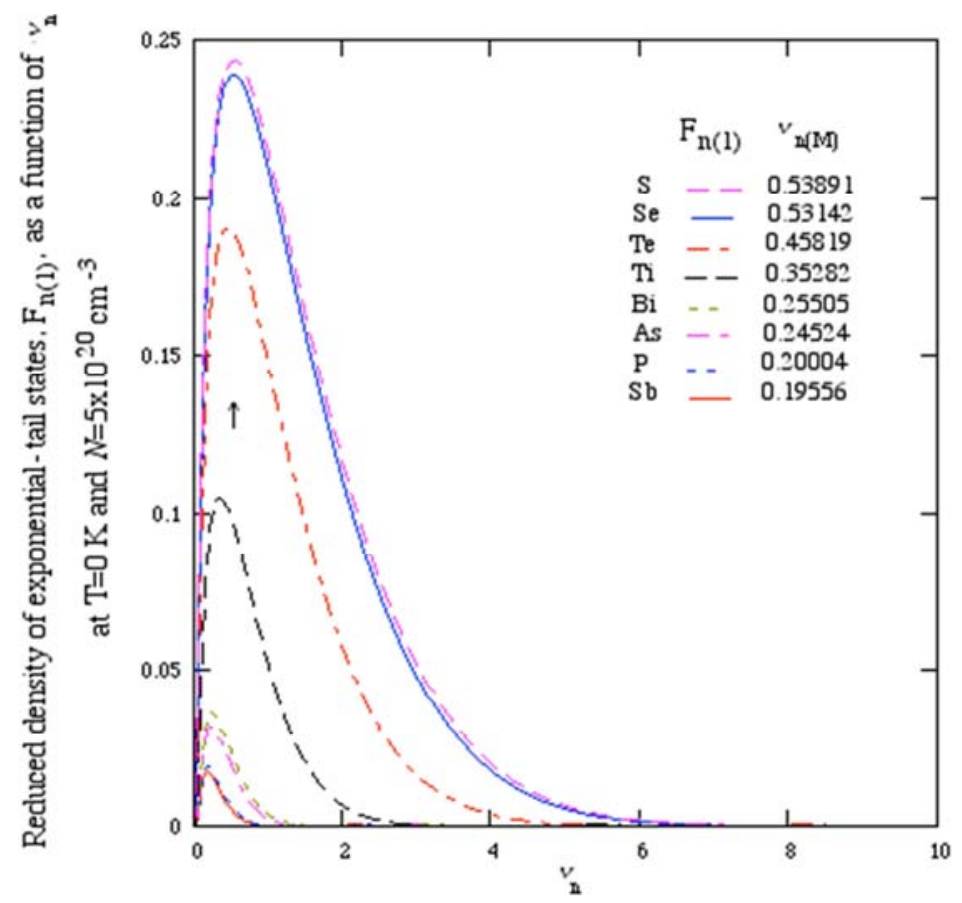

Figure 1. Our results of $F_{n(1)}$ increase with increasing $r_{d}$ for a given $v_{n}$, due to the donor-size effect, and present the maxima at $v_{n}=v_{n(M)}$ and go to zero as $v_{n} \rightarrow 0$ and $\infty$. 
Figure 1 shows that:

(i) our results of $F_{n(1)}$ increase with increasing $r_{d}$ for a given $v_{\mathrm{n}}$, due to the donor-size effect, and

(ii) present the maxima at $v_{\mathrm{n}}=v_{\mathrm{n}(\mathrm{M})}$ and go to zero as $v_{\mathrm{n}} \rightarrow 0$ and $\infty$, being found to be in good agreement with theoretical results obtained by Lifshitz [18], Friedberg and Luttinger [20], our results given in Eq. (A.3) of the Appendix $\mathrm{A}$, and in particular with an asymptotic form for exponential conduction-band tail, obtained for $0 \lesssim v_{\mathrm{n}} \lesssim \infty$, by Halperin and Lax [19], using the minimum counting methods.

Further, our numerical results of functions $\ln \left[\mathrm{F}_{\mathrm{n}}\left(v_{\mathrm{n}}, \mathrm{r}_{\mathrm{d}}, \mathrm{a}=1\right)\right]<0$, which can take their approximate forms as: $\operatorname{AF}\left(v_{\mathrm{n}}, \mathrm{r}_{\mathrm{d}}, v_{1}, v_{2}, \mathrm{z}, \mathrm{f}\right)=\mathrm{e}\left(\mathrm{r}_{\mathrm{d}}, v_{1}, v_{2}, \mathrm{z}\right) \times v_{\mathrm{n}}^{\mathrm{z}}+\mathrm{f}<$ 0 , obtained in small $v_{\mathrm{n}}$-intervals: $v_{1} \leq v_{\mathrm{n}} \leq v_{2}$, using Eqs. $(29,30)$, are tabulated in Table 4.

Table 4. In the d-Si systems at $T=0 \mathrm{~K}$ and for $N=5 \times 10^{20} \mathrm{~cm}^{-3}$, using the reduced density of state, $F_{n}\left(v_{n}, r_{d}, a=1\right)$, determined in Eq. (38), the numerical results of $\ln \left[F_{n}\left(v_{n}, r_{d}, a=1\right)\right]$ and its approximate form obtained for $a=1$ : AF $\left(v_{n} ; r_{d}, v_{1}, v_{2}, z, f\right)=e\left(r_{d}, v_{1}, v_{2}, z\right) \times v_{n}^{z}+f$, determined in Eqs. (29, 30) for small $v_{n}$-intervals: $v_{1} \leq v_{n} \leq v_{2}$, and also those of absolute relative errors defined by: $|R E| \equiv 1-\frac{A F\left(v_{n}, r_{d}, v_{1}, v_{2}, z, f\right)}{\ln \left[F_{n}\left(v_{n}, r_{d}, a=1\right)\right]}$, are evaluated and tabulated below.

\begin{tabular}{|c|c|c|c|c|c|c|c|c|}
\hline Donor & Sb & $\mathbf{P}$ & As & Bi & Ti & Te & Se & $\mathbf{S}$ \\
\hline $\boldsymbol{v}_{\mathrm{n}(\mathrm{M})}$ & 0.19556 & 0.20004 & 0.24524 & 0.25505 & 0.35282 & 0.45819 & 0.53142 & 0.53891 \\
\hline \multicolumn{9}{|c|}{ For $1.20 \leq v_{\mathrm{n}} \leq 1.25, \mathrm{AF}=\left(\mathrm{e} \times v_{\mathrm{n}}+\mathrm{f}\right)$ is accurate to within $2.2 \times 10^{-4}$, where } \\
\hline$-\mathrm{e}$ & 10.312 & 9.433 & 5.642 & 5.037 & 1.846 & 0.854 & 0.567 & 0.546 \\
\hline f & 1.387 & 1.016 & -0.374 & -0.552 & -1.118 & -1.056 & -0.994 & -0.988 \\
\hline |RE $\mid$ & $8.1 \times 10^{-5}$ & $9.9 \times 10^{-5}$ & $6.3 \times 10^{-5}$ & $1.2 \times 10^{-4}$ & $2.2 \times 10^{-4}$ & $1.0 \times 10^{-4}$ & $5.4 \times 10^{-5}$ & $6.3 \times 10^{-5}$ \\
\hline \multicolumn{9}{|c|}{ For $1.10 \leq v_{\mathrm{n}} \leq 1.20, \mathrm{AF}=\left(\mathrm{e} \times v_{\mathrm{n}}^{1 / 2}+\mathrm{f}\right)$ is accurate to within $6.6 \times 10^{-4}$, where } \\
\hline$-\mathrm{e}$ & 21.192 & 19.400 & 11.654 & 10.413 & 3.825 & 1.759 & 1.159 & 1.114 \\
\hline f & 12.233 & 10.953 & 5.624 & 4.813 & 0.857 & -0.154 & -0.405 & -0.423 \\
\hline |RE & $6.6 \times 10^{-4}$ & $5.8 \times 10^{-4}$ & $5.6 \times 10^{-4}$ & $5.5 \times 10^{-4}$ & $3.6 \times 10^{-4}$ & $4.4 \times 10^{-4}$ & $5.3 \times 10^{-4}$ & $4.7 \times 10^{-4}$ \\
\hline \multicolumn{9}{|c|}{ For $1.07 \leq v_{\mathrm{n}} \leq 1.09, \mathrm{AF}=\left(\mathrm{e} \times v_{\mathrm{n}}^{1 / 3}+\mathrm{f}\right)$ is accurate to within $3.1 \times 10^{-4}$, where } \\
\hline$-\mathrm{e}$ & 29.952 & 27.445 & 16.549 & 14.795 & 5.442 & 2.484 & 1.619 & 1.555 \\
\hline f & 20.921 & 18.933 & 10.483 & 9.162 & 2.462 & 0.566 & 0.510 & 0.014 \\
\hline |RE $\mid$ & $3.8 \times 10^{-5}$ & $7.9 \times 10^{-5}$ & $3.5 \times 10^{-5}$ & $3.2 \times 10^{-5}$ & $1.7 \times 10^{-4}$ & $3.1 \times 10^{-4}$ & $4.9 \times 10^{-5}$ & $2.7 \times 10^{-5}$ \\
\hline \multicolumn{9}{|c|}{ For $v_{\mathrm{n}(\mathrm{M})}<1.00 \leq v_{\mathrm{n}} \leq 1.05, \mathrm{AF}=\left(\mathrm{e} \times v_{\mathrm{n}}{ }^{1 / 4}+\mathrm{f}\right)$ is accurate to within $3.2 \times 10^{-4}$, where } \\
\hline$-\mathrm{e}$ & 37.375 & 34.267 & 20.721 & 18.533 & 6.815 & 3.084 & 1.989 & 1.908 \\
\hline f & 28.308 & 25.723 & 14.636 & 12.883 & 3.829 & 1.162 & 0.419 & 0.365 \\
\hline |RE $\mid$ & $2.6 \times 10^{-4}$ & $2.3 \times 10^{-4}$ & $2.1 \times 10^{-4}$ & $2.3 \times 10^{-4}$ & $2.3 \times 10^{-4}$ & $2.2 \times 10^{-4}$ & $3.2 \times 10^{-4}$ & $2.7 \times 10^{-4}$ \\
\hline \multicolumn{9}{|c|}{ For $0.090 \leq v_{\mathrm{n}} \leq 0.095<v_{\mathrm{n}(\mathrm{M})}, \mathrm{AF}=\left(\mathrm{e} \times v_{\mathrm{n}}{ }^{1 / 4}+\mathrm{f}\right)$ is accurate to within $3.5 \times 10^{-4}$, where } \\
\hline e & 16.603 & 17.281 & 19.424 & 19.467 & 15.283 & 11.155 & 9.666 & 9.554 \\
\hline $\mathrm{f}$ & -13.968 & -14.322 & -15.240 & -15.172 & -11.807 & -8.815 & -7.728 & -7.646 \\
\hline$|\mathrm{RE}|$ & $2.9 \times 10^{-4}$ & $2.7 \times 10^{-4}$ & $3.0 \times 10^{-4}$ & $2.4 \times 10^{-4}$ & $3.5 \times 10^{-4}$ & $2.2 \times 10^{-4}$ & $3.3 \times 10^{-4}$ & $1.3 \times 10^{-4}$ \\
\hline \multicolumn{9}{|c|}{ For $0.088 \leq v_{\mathrm{n}} \leq 0.090, \mathrm{AF}=\left(\mathrm{e} \times v_{\mathrm{n}}{ }^{1 / 3}+\mathrm{f}\right)$ is accurate to within $1.9 \times 10^{-4}$, where } \\
\hline $\mathrm{e}$ & 16.618 & 17.279 & 19.346 & 19.376 & 15.067 & 10.876 & 9.372 & 9.258 \\
\hline f & -12.322 & -12.601 & -13.271 & -13.193 & -10.188 & -7.579 & -6.634 & -6.562 \\
\hline |RE $\mid$ & $9.5 \times 10^{-5}$ & $1.1 \times 10^{-4}$ & $1.0 \times 10^{-4}$ & $1.5 \times 10^{-4}$ & $1.5 \times 10^{-4}$ & $1.6 \times 10^{-4}$ & $1.9 \times 10^{-4}$ & $1.1 \times 10^{-4}$ \\
\hline \multicolumn{9}{|c|}{ For $0.080 \leq v_{\mathrm{n}} \leq 0.083, \mathrm{AF}=\left(\mathrm{e} \times v_{\mathrm{n}}{ }^{1 / 2}+\mathrm{f}\right)$ is accurate to within $2.8 \times 10^{-4}$, where } \\
\hline e & 20.696 & 21.486 & 23.925 & 23.934 & 18.238 & 12.825 & 10.903 & 10.758 \\
\hline $\mathrm{f}$ & -11.049 & -11.269 & -11.741 & -11.652 & -8.881 & -6.537 & -5.692 & -5.628 \\
\hline |RE $\mid$ & $1.5 \times 10^{-4}$ & $2.2 \times 10^{-4}$ & $2.2 \times 10^{-4}$ & $1.9 \times 10^{-4}$ & $1.4 \times 10^{-4}$ & $2.7 \times 10^{-4}$ & $2.8 \times 10^{-4}$ & $1.4 \times 10^{-4}$ \\
\hline \multicolumn{9}{|c|}{ For $0.061 \leq v_{\mathrm{n}} \leq 0.064, \mathrm{AF}=\left(\mathrm{e} \times v_{\mathrm{n}}+\mathrm{f}\right)$ is accurate to within $6.4 \times 10^{-4}$, where } \\
\hline $\mathrm{e}$ & 81.678 & 84.899 & 95.187 & 95.220 & 69.115 & 44.628 & 36.206 & 35.580 \\
\hline $\mathrm{f}$ & -11.286 & -11.520 & -12.064 & -11.976 & -8.887 & -6.265 & -5.341 & -5.271 \\
\hline |RE| & $4.8 \times 10^{-4}$ & $6.4 \times 10^{-4}$ & $5.2 \times 10^{-4}$ & $5.4 \times 10^{-4}$ & $4.4 \times 10^{-4}$ & $4.3 \times 10^{-4}$ & $3.3 \times 10^{-4}$ & $2.9 \times 10^{-4}$ \\
\hline \multicolumn{9}{|c|}{ For $0.054 \leq v_{\mathrm{n}} \leq 0.056, \mathrm{AF}=\left(\mathrm{e} \times v_{\mathrm{n}}^{2}+\mathrm{f}\right)$ is accurate to within $4.9 \times 10^{-4}$, where } \\
\hline e & 1119.900 & 1167.630 & 1327.600 & 1330.280 & 948.984 & 585.600 & 462.692 & 453.624 \\
\hline f & -10.322 & -10.531 & -11.015 & -10.934 & -8.074 & -5.648 & -4.799 & -4.735 \\
\hline |RE & $3.4 \times 10^{-4}$ & $3.8 \times 10^{-4}$ & $4.7 \times 10^{-4}$ & $4.9 \times 10^{-4}$ & $4.6 \times 10^{-4}$ & $3.7 \times 10^{-4}$ & $2.5 \times 10^{-4}$ & $2.5 \times 10^{-4}$ \\
\hline
\end{tabular}

The underlined $|R E|$-value is the maximal one for each donor-Si system.

Table 4 suggests that: (i) our results of $\mathrm{AF}\left(v_{\mathrm{n}}, \mathrm{r}_{\mathrm{d}}, v_{1}, v_{2}, \mathrm{z}, \mathrm{f}\right)$ given for $(\mathrm{z}=1)$-exponent agree with the Urbach law obtained from linear exponential conductionband-tail behaviors by some workers [21, 29, 30, 37], (ii) ours for $(\mathrm{z}=1 / 2)$-exponent and $v_{\mathrm{n}}>v_{\mathrm{n}(\mathrm{M})}$ agree with other theoretical results $[19,37]$, and finally (iii) ours for $(z=1 / 3$, 1/4)-exponents when $v_{\mathrm{n}}>v_{\mathrm{n}(\mathrm{M})}$, and for $(\mathrm{z}=1 / 4,1 / 3,1 / 2,1$, 2)-exponents when $v_{\mathrm{n}}<v_{\mathrm{n}(\mathrm{M})}$ may thus be new.

Finally, our numerical results of energy parameter, $\mathbb{E}_{\mathrm{no}}\left(\mathrm{N} ; \mathrm{r}_{\mathrm{d}}, \mathrm{a}=1\right)$, obtained in the small interval: $1.2 \leq v_{\mathrm{n}} \leq$ 1.25, using Eq. (31), are plotted as functions of $\mathrm{N}$ in Figures $2 \mathrm{a}$ and $2 \mathrm{~b}$, indicating that, for a given $\mathrm{N}, \mathbb{E}_{\text {no }}$ increases with increasing $r_{d}$-values, due to the donor-size effect. 


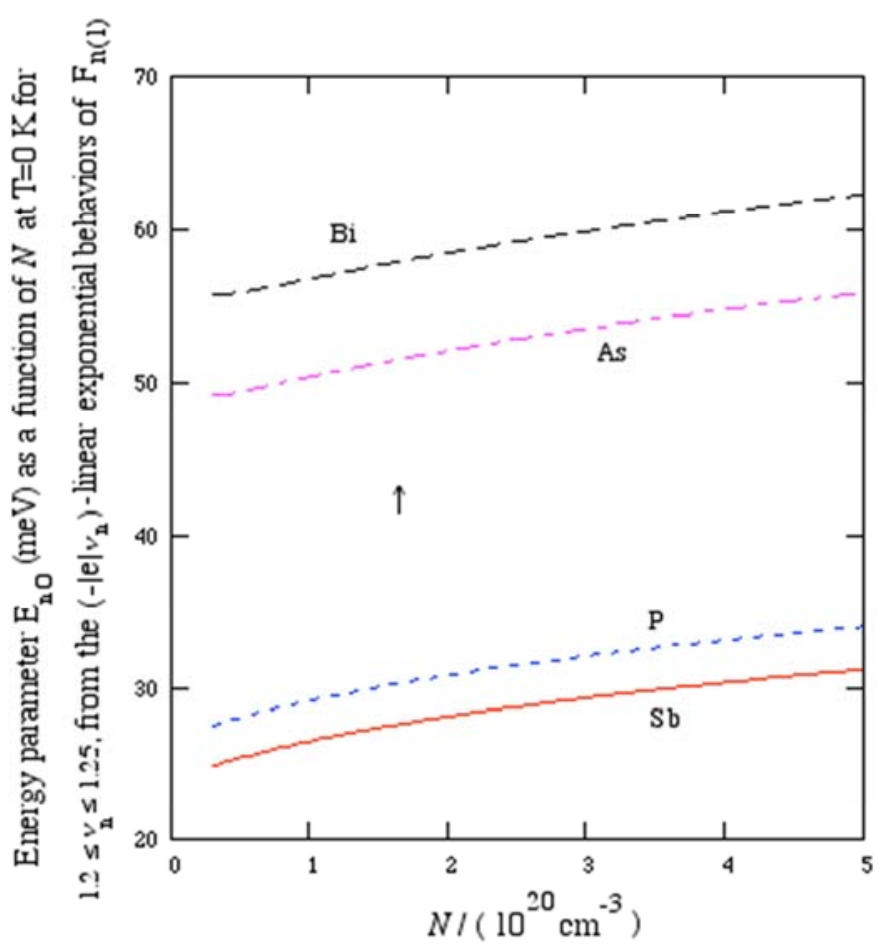

FIG. 2a

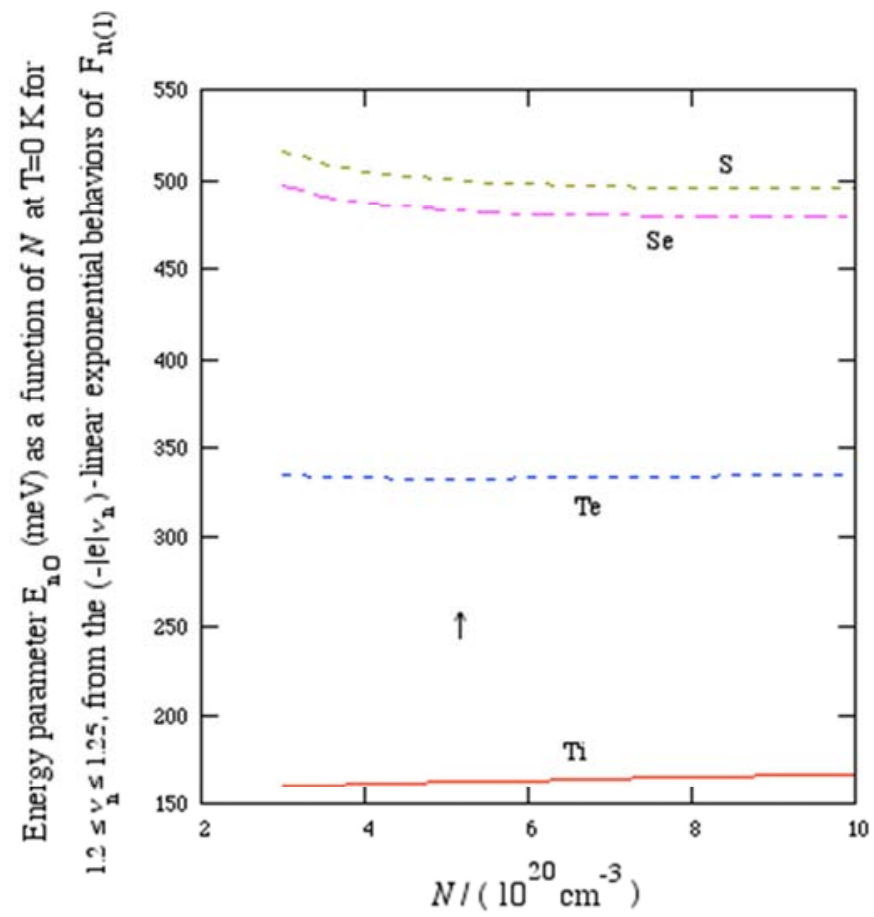

FIG. 2b

Figures 2. Our results of energy parameter, $\mathbb{E}_{n o}\left(N ; r_{d}, a=1\right)$, are plotted as functions of $N$, indicating that, for a given $N$, $\mathbb{E}_{n o}$ increases with increasing $r_{d}-$ values, due to the donor-size effect.

Now, for $\mathbb{E} \leq 0$, using Eqs. $(27,28)$ for the functions $K_{n}$ and $F_{n}$ as a=1, the density of electrons localized in the exponential band tail (EBT) is given by

$$
\mathrm{N}_{\mathrm{d}}^{\mathrm{EBT}}\left(\mathrm{N}, \mathrm{r}_{\mathrm{d}}\right)=\int_{-\infty}^{0} \mathcal{D}(\mathbb{E} \leq 0) \mathrm{d} \mathbb{E}
$$

where $\mathcal{D}(\mathbb{E} \leq 0)$ is determined in Eq. (38). 
Then, by a variable change: $v_{\mathrm{n}} \equiv \frac{-\mathbb{E}}{\mathbb{E}_{\mathrm{Fno}}}$, Eq. (39) yields

$$
\mathrm{N}_{\mathrm{d}, \boldsymbol{b}}^{\mathrm{EBT}}\left(\mathrm{N}, \mathrm{r}_{\mathrm{d}}\right)=\frac{\mathrm{g}_{\mathrm{c}} \times\left(m_{\mathrm{n}}^{\mathrm{HDE}}\right)^{3 / 2} \sqrt{\eta_{\mathrm{n}}} \times \mathbb{E}_{\mathrm{Fno}}}{2 \pi^{2} \hbar^{3}} \times b \times\left\{\int_{0}^{16} \beta(\mathrm{a}=1) \times \mathrm{F}_{\mathrm{n}}\left(v_{\mathrm{n}}, \mathrm{r}_{\mathrm{d}}, \mathrm{a}=1\right) \mathrm{d} v_{\mathrm{n}}+\mathrm{I}_{\mathrm{n}}\right\},
$$

where

$$
\mathrm{I}_{\mathrm{n}} \equiv \int_{16}^{\infty} \beta(\mathrm{a}=1) \times \mathrm{K}_{\mathrm{n}}\left(v_{\mathrm{n}}, \mathrm{r}_{\mathrm{d}}, \mathrm{a}=1\right) \mathrm{d} v_{\mathrm{n}}=\int_{16}^{\infty} e^{\frac{-\left(\mathrm{A}_{\mathrm{n}} \nu_{\mathrm{n}}\right)^{2}}{2}} \times\left(\mathrm{A}_{\mathrm{n}} v_{\mathrm{n}}\right)^{-3 / 2} \mathrm{~d} v_{\mathrm{n}} .
$$

Here, $\beta(\mathrm{a}=1)=\frac{\sqrt{\pi}}{2^{\frac{3}{4}} \times \Gamma(5 / 4)}$ and $b$ is normally equal to 1 , but it can be an empirical parameter, being chosen as: $b=b_{0}=$ 1.0028637416 such that the obtained values of $\mathrm{N}_{\mathrm{n}}^{\mathrm{EBT}}$ would be accurate.

Then, by another variable change: $t=\left[\mathrm{A}_{\mathrm{n}} v_{\mathrm{n}} / \sqrt{2}\right]^{2}$, the integral $\mathrm{I}_{\mathrm{n}}$ yields [15]

$$
\mathrm{I}_{\mathrm{n}}=\frac{1}{2^{5 / 4} A_{\mathrm{n}}} \times \int_{y_{\mathrm{n}}}^{\infty} t^{\mathrm{b}-1} e^{-t} d t \equiv \frac{\Gamma\left(\mathrm{b}, y_{\mathrm{n}}\right)}{2^{5 / 4} \times \mathrm{A}_{\mathrm{n}}}
$$

where $b=-1 / 4, y_{n}=\left[16 A_{n} / \sqrt{2}\right]^{2}$, with $A_{n}$ being defined in Eq. (38), and $\Gamma\left(b, y_{n}\right)$ is the incomplete Gamma function, defined by [15]

$$
\Gamma\left(\mathrm{b}, \mathrm{y}_{\mathrm{n}}\right) \simeq \mathrm{y}_{\mathrm{n}}^{\mathrm{b}-1} \times e^{-\mathrm{y}_{\mathrm{n}}}\left[1+\sum_{\mathrm{j}=1}^{16} \frac{(\mathrm{b}-1)(\mathrm{b}-2) \ldots(\mathrm{b}-\mathrm{j})}{\mathrm{y}_{\mathrm{n}}^{\mathrm{j}}}\right]
$$

Finally, Eq. (40) now yields

$$
\mathrm{N}_{\mathrm{d}, b}^{\mathrm{EBT}}\left(\mathrm{N}, \mathrm{r}_{\mathrm{d}}\right)=\frac{\mathrm{g}_{\mathrm{c}} \times\left(m_{\mathrm{n}}^{\mathrm{HDE}}\right)^{3 / 2} \sqrt{\eta_{\mathrm{n}}} \times \mathbb{E}_{\mathrm{Fno}}}{2 \pi^{2} \hbar^{3}} \times b \times\left\{\int_{0}^{16} \beta(\mathrm{a}=1) \times \mathrm{F}_{\mathrm{n}}\left(v_{\mathrm{n}}, \mathrm{r}_{\mathrm{d}}, \mathrm{a}=1\right) \mathrm{d} v_{\mathrm{n}}+\frac{\Gamma\left(\mathrm{b}, y_{\mathrm{n}}\right)}{2^{5 / 4} \times \mathrm{A}_{\mathrm{n}}}\right\}
$$

being the density of electrons localized in the exponential conduction-band tail.

Hence, in the degenerate $\mathrm{d}-\mathrm{Si}$ system, replacing $\mathrm{N}$, given in the parabolic conduction band of an effective electron gas, by the effective density of free electrons defined here by: $\mathrm{N}^{*}=\mathrm{N}-\mathrm{N}_{\mathrm{d}, b}^{\mathrm{EBT}} \geq 0$. So, in this system, the Fermi energy given in Eq. (15) is now rewritten as

$$
\mathbb{E}_{\mathrm{Fno}}\left(\mathrm{N}^{*}\right) \equiv \frac{\hbar^{2} \times \mathrm{k}_{\mathrm{Fn}}^{2}\left(\mathrm{~N}^{*}\right)}{2 \times \mathrm{m}_{\mathrm{n}}^{\mathrm{HDE}}\left(\mathrm{N}^{*}\right)}, \mathrm{N} \geq \mathrm{N}_{\mathrm{d}, \ell}^{\mathrm{EBT}},
$$

where the Fermi wave number $\mathrm{k}_{\mathrm{Fn}}$ and $\mathrm{m}_{\mathrm{n}}^{\mathrm{HDE}}$ are respectively determined in Eqs. $(2,8)$. One notes here that $\mathbb{E}_{\text {Fno }}\left(\mathrm{N}^{*}\right)$ vanishes at $\mathrm{N}^{*}=0$, or at the critical donor density defined by: $\mathrm{N}=\mathrm{N}_{\mathrm{c}(\mathrm{d}), b}^{\mathrm{EBT}} \equiv \mathrm{N}_{\mathrm{d}, b}^{\mathrm{EBT}}\left(\mathrm{N}=\mathrm{N}_{\mathrm{c}(\mathrm{d}), b}^{\mathrm{EBT}}, \mathrm{r}_{\mathrm{d}}\right)$, at which the metal-insulator transition thus occurs. Then, the numerical results of $\mathrm{N}_{\mathrm{c}(\mathrm{d}), b}^{\mathrm{EBT}}$, for $b=1$ and $b_{\mathrm{o}}=$ 1.0028637416 , and their absolute relative errors $|\mathrm{RE}|$, calculated using the $\mathrm{N}_{\mathrm{c}(\mathrm{d})}$-data given in Table I, are obtained and also reported in this Table 1, indicating that those of $\mathrm{N}_{\mathrm{c}(\mathrm{d}), b_{\mathrm{o}}}^{\mathrm{EBT}}$ and $\mathrm{N}_{\mathrm{c}(\mathrm{d}), 1}^{\mathrm{EBT}}$ are obtained respectively with accuracies of the orders of $1.1 \times 10^{-4}$ and $3 \times 10^{-3}$. Hence, these results of $\mathrm{N}_{\mathrm{c}(\mathrm{d}), b_{0}}^{\mathrm{EBT}}$ thus confirm our above choice of Heisenberg parameter value: $\mathcal{H}_{\mathrm{n}}=5.4370$, as that proposed in Eq. (19) and also in the Appendix B. Furthermore, our numerical calculation indicates that, in all the d-Si systems for $\mathrm{N} \geq 1.15 \times \mathrm{N}_{\mathrm{c}(\mathrm{d})}$, if defining the absolute relative deviations between $\mathrm{N}-\mathrm{N}_{\mathrm{c}(\mathrm{d}), b_{\mathrm{o}}}^{\mathrm{EBT}}$ and $\mathrm{N}-\mathrm{N}_{\mathrm{c}(\mathrm{d})}$ by: $|\mathrm{RD}| \equiv$ $\left|1-\frac{\mathrm{N}_{\mathrm{c}(\mathrm{d}), b_{0}}^{\mathrm{EBT}}}{\mathrm{N}-\mathrm{N}_{\mathrm{c}(\mathrm{d})}}\right|$, the maximal $|\mathrm{RD}|$-values, which occur at $\mathrm{N}=1.15 \times \mathrm{N}_{\mathrm{c}(\mathrm{d})}$, are approximately equal to $3.2 \%$. So, $\mathrm{N}^{*}$ given in the parabolic conduction band of the degenerate $\mathrm{d}-\mathrm{Si}$ systems can be approximated by [22]

$$
\mathrm{N}^{*} \equiv \mathrm{N}-\mathrm{N}_{\mathrm{c}(\mathrm{d}), b_{\mathrm{o}}}^{\mathrm{EBT}} \simeq \mathrm{N}-\mathrm{N}_{\mathrm{c}(\mathrm{d})} .
$$

Here, this notion of effective density of free electrons $\mathrm{N}^{*}$ defined by Eq. (43) should be equivalent to that of $\left(\mathrm{N}_{d}-\mathrm{N}_{\mathrm{a}}\right)$ given in the n-type compensated $\mathrm{Si}$, in which $\mathrm{N}_{\mathrm{d}}$ is the total density of donors (or majority electrons) and $\mathrm{N}_{\mathrm{a}}$ is the total density of acceptors (or minority holes), assuming that all the impurities are ionized [22]. Finally, in degenerate d-Si systems, in which $\mathrm{N}>\mathrm{N}_{\mathrm{c}(\mathrm{d})}$ and $\mathrm{T} \leq 77 \mathrm{~K}$ or $\mathrm{T} \ll \mathrm{T}_{\mathrm{D}}, \mathrm{T}_{\mathrm{D}}$ being the degeneracy temperature defined in Eq. (15), this result (43) will be used in all the following Sections.

\section{Optical Properties}

The problem of exponential optical absorption-coefficient tails has by now a rather long history. We will limit our study here to the degenerate $\mathrm{d}-\mathrm{Si}$ systems, although the band structure of random alloys and amorphous materials is a problem with many common features [41].

Optical properties of any medium can be described by the complex refraction index $\mathbb{N}$ and the complex dielectric function $\varepsilon$, defined by: $\mathbb{N} \equiv n-i \kappa$ and $\varepsilon \equiv \varepsilon_{1}-i \varepsilon_{2}$, where $i^{2}=-1$ and $\varepsilon \equiv \mathbb{N}^{2}$, and by the optical absorption coefficient $\alpha$, which is related to the imaginary part of $\varepsilon$ : $\varepsilon_{2}$, the refraction index $n$, the extinction coefficient $\kappa$, and the conductivity $\sigma_{0}$, due to the electro-optical effect, as [29-48]

$$
\alpha(E) \equiv \frac{\hbar q^{2} \times|v(E)|^{2}}{n(E) \times \varepsilon_{0} c E} \times J(E)=\frac{E \times \varepsilon_{2}(E)}{\hbar c n(E)}=\frac{2 E \times \kappa(E)}{\hbar c}=\frac{4 \pi \times \sigma_{O}(E)}{\operatorname{cn}(E) \times \varepsilon_{o}} .
$$


One remarks that the real part of $\varepsilon$ is defined by

$$
\varepsilon_{1}(\mathrm{E}) \equiv \mathrm{n}(\mathrm{E})^{2}-\kappa(\mathrm{E})^{2},
$$

and the normal-incidence reflectance $\mathrm{R}(\mathrm{E})$, by

$$
R(E)=\frac{[n(E)-1]^{2}+\kappa(E)^{2}}{[n(E)+1]^{2}+\kappa(E)^{2}}
$$

which are the optical dispersion relations since in general the values of those optical functions are expressed as functions of the multi-photon energy [46], $\mathrm{E} \equiv \hbar \omega, 2 \hbar \omega, 3 \hbar \omega$, $4 \hbar \omega, \ldots$. In the present work, we only focus our attention to the case of photon energy $\mathrm{E} \equiv \hbar \omega$. Here, $-q, \hbar,|v(E)|, \omega, \varepsilon_{o}$, $c$ and $\mathrm{J}(E)$ respectively represent the electron charge, Dirac's constant, matrix elements of the velocity operator between valence-and-conduction bands in n-type semiconductors, photon frequency, permittivity of free space, velocity of light, and joint density of states (JDOS). One remarks here that: (i) if some optical functions are known such as: $\left(\mathrm{J}, \mathrm{n},|\mathrm{v}|^{2}\right)$, $(n, \kappa)$, or $\left(\varepsilon_{1}, \varepsilon_{2}\right)$, then, all other ones are determined, and (ii) in n-type semiconductors, all the optical functions will be expressed in terms of the total energy of the electron, defined by:

$$
\mathbb{E} \equiv \mathrm{E}-\mathbb{E}_{\mathrm{gn}}
$$

where the band gap given in the degenerate d-Si systems, $\mathbb{E}_{\text {gn }}$, can be equal to: $\mathbb{E}_{\text {gi }}, \mathbb{E}_{\text {gn } 1}$ and $\mathbb{E}_{\text {gn } 2}$, defined in Eqs. (3, $9,10)$, respectively.
Now, we determine the accurate expressions for the optical functions obtained in band-to-band transitions at $\mathrm{E} \geq \mathbb{E}_{\mathrm{gn}}$, and for the exponential optical absorption-coefficient tails and also their behaviors at $E \leq \mathbb{E}_{\mathrm{gn}}$, due to the effects of temperature, donor size and heavy doping, being also compared with corresponding experimental and theoretical results.

\subsection{Optical Functions Obtained in Band-to-Band Transitions at $E \geq \mathbb{E}_{\text {gn }}$ or $\mathbb{E} \geq 0$}

First of all, one remarks from Eq. (37) that if replacing the density-of-states effective mass, $\mathrm{g}_{\mathrm{c}}^{2 / 3} \times \mathrm{m}_{\mathrm{n}}^{\mathrm{HDE}}$, by the reduced effective mass $m_{r}=0.171 \times m_{o}$, defined in Eq. (1), the density of state $\mathcal{D}(\mathbb{E} \geq 0)$ becomes the joint density of states, given in Eq. (44), as

$$
J(E)=\frac{1}{2 \pi^{2}} \times\left(\frac{2 m_{\mathrm{r}}}{\hbar^{2}}\right)^{3 / 2} \times\left(\mathbb{E} \equiv \mathrm{E}-\mathbb{E}_{\mathrm{gn}}\right)^{(1 / 2)} .
$$

Then, we use a transformation, replacing $(\mathbb{E})^{1 / 2}$ by: $\frac{1}{\mathbb{E}_{\mathrm{Fno}}^{\mathrm{a}-1}} \times(\mathbb{E})^{(1 / 2)+(\mathrm{a}-1)=s=\mathrm{a}-\frac{1}{2}}$. So, $\mathrm{J}(\mathrm{E})$ yields for $\mathrm{a} \geq 1$ as

$$
J(E, a)=\frac{1}{2 \pi^{2}} \times\left(\frac{2 m_{\mathrm{r}}}{\hbar^{2}}\right)^{3 / 2} \times \frac{1}{\mathbb{E}_{\mathrm{Fno}}^{\mathrm{a}-1}} \times\left(\mathrm{E}-\mathbb{E}_{\mathrm{gn}}\right)^{\mathrm{s}=\mathrm{a}-\frac{1}{2}}
$$

and from Eq. (44), one gets

$$
\alpha\left(E \geq \mathbb{E}_{\mathrm{gn}}\right) \equiv \frac{\hbar \mathrm{q}^{2} \times|\mathrm{v}(\mathrm{E})|^{2}}{\mathrm{n}(\mathrm{E}) \times \varepsilon_{\mathrm{o}} \mathrm{cE}} \times \frac{1}{2 \pi^{2}} \times\left(\frac{2 m_{\mathrm{r}}}{\hbar^{2}}\right)^{3 / 2} \times \frac{1}{\mathbb{E}_{\mathrm{Fno}}^{\mathrm{a}-1}} \times\left(\mathrm{E}-\mathbb{E}_{\mathrm{gn}}\right)^{\mathrm{s}=\mathrm{a}-\frac{1}{2}}
$$

Further, for any E or $\mathbb{E}$, using Eq. (20), Eq. (48) becomes

$$
\alpha(\mathbb{E}, \mathrm{a}) \equiv \frac{\mathrm{q}^{2} \times|\mathrm{v}(\mathrm{E})|^{2}}{\mathrm{n}(\mathrm{E}) \times \varepsilon_{\mathrm{o}} \mathrm{cE}} \times \frac{\mathrm{m}_{\mathrm{r}}^{3 / 2}}{\pi^{5 / 2} \times \hbar^{2}} \times \frac{\exp \left(-\mathrm{x}^{2} / 4\right) \times \mathrm{W}_{\mathrm{n}}^{\frac{2 \mathrm{a}-1}{4}}}{\mathbb{E}_{\mathrm{Fno}}^{\mathrm{a}-1}} \times \Gamma\left(\mathrm{a}+\frac{1}{2}\right) \times \mathrm{D}_{-\mathrm{a}-\frac{1}{2}}(\mathrm{x}),
$$

where $x$ is defined in Eq. (21), as $x=\frac{-\mathbb{E}}{\sqrt{W_{n}}} \equiv A_{n} \times v_{n} \times$ $\exp \left(\frac{\mathcal{H}_{\mathrm{n}} \times \mathrm{R}_{\mathrm{Sn}}}{4 \times \sqrt{\left|v_{\mathrm{n}}\right|}}\right), \mathrm{A}_{\mathrm{n}} \equiv \frac{\mathbb{E}_{\mathrm{Fno}}}{\eta_{\mathrm{n}}}, v_{\mathrm{n}} \equiv \frac{-\mathbb{E}}{\mathbb{E}_{\mathrm{Fno}}}$. Here, the Fermi energy $\mathbb{E}_{\mathrm{Fno}}$ is determined in Eq. (15), in which $\mathrm{m}^{*}=m_{\mathrm{r}}=$ $0.171 \times \mathrm{m}_{\mathrm{o}}$, noting that for $\mathrm{E} \geq \mathbb{E}_{\text {gn }}$ or $\mathbb{E} \geq 0$ and from Eq. (22), the result (49) is reduced to Eq. (48). Here, the values of $\mathrm{a}=1,2,5 / 2,7 / 2$ and $9 / 2$ correspond to the allowed-direct [2931]: $\mathbb{S}=\frac{1}{2}$, forbidden-direct [31]: $\mathbb{S}=\frac{3}{2}$, allowed-indirect [31, $46,47]: \mathbb{s}=2$, forbidden-indirect [46, 47]: $\mathbb{s}=3$, and forbidden-forbidden-indirect transitions [46, 47]: $\mathbb{S}=$ 4 , respectively.

Then, one also remarks that:

(i) when $\mathrm{a}=1$, according to allowed direct transitions for $\mathrm{n}$ type (GaAs, GaSb, InP, InAs and InSb)-semiconductors [31], $\alpha\left(E \geq \mathbb{E}_{\mathrm{gn}}, \mathrm{a}=1\right)$, being thus expressed in terms of $(\mathrm{E}-$ $\left.\mathbb{E}_{\mathrm{gn}}\right)^{1 / 2}$, is identical to those obtained by Lukes et Somaratna [29], and Van Cong [30], and

(ii) when $a=5 / 2$, according to allowed indirect transitions for n-type ( $\mathrm{Si}, \mathrm{Ge}$ and $\mathrm{GaP})$-semiconductors [31], $\alpha\left(E \geq \mathbb{E}_{\text {gn }}, \mathrm{a}=5 / 2\right)$ is now expressed in terms of $\left(\mathrm{E}-\mathbb{E}_{\mathrm{gn}}\right)^{2}$. In 1984, Forouhi- Bloomer (FB) [40] proposed in his FB-method (FB-M) a familiar four-term expression for extinction coefficient, $\kappa(\mathrm{E}, 5 / 2)$, expressed in terms of $\left(E-\mathbb{E}_{\mathrm{gn}}\right)^{2}$ for both direct-and-indirect bandgap semiconductors, being thus correct only in indirect band-gap ones. Further, their result is not correct when $\mathrm{E} \rightarrow \infty$ since one must have: $\kappa(\mathrm{E} \rightarrow \infty) \rightarrow 0[36,41]$. Furthermore, in the d-Si systems, from Eqs. $(44,48)$ one can determine the extinction coefficient $\kappa$, obtained for $\mathrm{a}=5 / 2$, as

$$
\kappa\left(E \geq \mathbb{E}_{\mathrm{gn}}\right) \equiv \frac{\mathrm{q}^{2} \times \mathrm{m}_{\mathrm{r}}^{3 / 2}}{\sqrt{2} \times \pi^{2} \times \hbar \times \mathrm{n}(\mathrm{E}) \times \varepsilon_{0} \times \mathbb{E}_{\mathrm{Fno}}^{3 / 2}} \times|\mathrm{v}(\mathrm{E})|^{2} \times \frac{\left(\mathrm{E}-\mathbb{E}_{\mathrm{gn}}\right)^{2}}{\mathrm{E}^{2}}
$$

We now propose an improved FB-M (IFB-M).

First, if putting $f(E) \equiv \sum_{i=1}^{4} \frac{A_{i(F B)} \times E^{2}}{E^{2}-B_{i(F B)} E+C_{i(F B)}}$, where the values of empirical parameters: $A_{i(F B)}, B_{i(F B)}$ and $C_{i(F B)}$, are given in the $\mathrm{FB}-\mathrm{M}$ for the $\mathrm{Si}$ [40], and simply replacing the band-gap energy $\mathbb{E}_{\mathrm{g}}=1.06 \mathrm{eV}$ [40] by $\mathbb{E}_{\text {gn }}$, which can be equal to: $\mathbb{E}_{\text {gi }}, \mathbb{E}_{\mathrm{gn} 1}$ and $\mathbb{E}_{\mathrm{gn} 2}$, which are determined respectively in Eqs. $(3,10,11)$, we can now propose, as that done by O'Leary et al. for very large values of $E$, [39] 
$\kappa_{I F B-M}\left(E \geq E_{g n}\right)=f(E) \times \frac{\left(E-\mathbb{E}_{g n}\right)^{2}}{E^{2}} \times\left(\frac{6 \mathrm{eV}}{E}\right)^{3}$, for $E \geq 6 \mathrm{eV}$,

$$
=f(E) \times \frac{\left(E-E_{g n}\right)^{2}}{E^{2}}, \text { for } \mathbb{E}_{g n} \leq E \leq 6 \mathrm{eV}
$$

so that $\kappa_{\mathrm{IFB}-\mathrm{M}}(\mathrm{E} \rightarrow \infty)$ goes to 0 as $\mathrm{E}^{-3}$, in good accordance with both experimental [36] and theoretical [41] results.

Secondly, by putting

$$
\Delta \mathrm{n}\left(\mathrm{E}, \mathrm{A}_{\mathrm{i}(\mathrm{FB})}, \mathrm{B}_{\mathrm{i}(\mathrm{FB})}, \mathrm{C}_{\mathrm{i}(\mathrm{FB})}, \mathrm{E}_{\mathrm{gn}}\right) \equiv \sum_{\mathrm{i}=1}^{4} \frac{\mathrm{B}_{\mathrm{oi}} \mathrm{E}+\mathrm{C}_{\mathrm{oi}}}{\mathrm{E}^{2}-\mathrm{B}_{\mathrm{i}(\mathrm{FB})} \mathrm{E}+\mathrm{C}_{\mathrm{i}(\mathrm{FB})}} \equiv \Delta \mathrm{n},
$$

for a simplicity of presentation, where the empirical parameters, $B_{o i}\left(A_{i(F B)}, B_{i(F B)}, C_{i(F B)}, \mathbb{E}_{g n}\right)$ and $\mathrm{C}_{\mathrm{oi}}\left(\mathrm{A}_{\mathrm{i}(\mathrm{FB})}, \mathrm{B}_{\mathrm{i}(\mathrm{FB})}, \mathrm{C}_{\mathrm{i}(\mathrm{FB})}, \mathbb{E}_{\mathrm{gn}}\right)$, are determined respectively in the FB-M [40], in which we now replace $\mathbb{E}_{\mathrm{g}}=1.06 \mathrm{eV}$ by $\mathbb{E}_{\mathrm{gn}}$ for our IFB-M, we can further propose

$$
\begin{gathered}
\mathrm{n}_{\mathrm{IFB}-\mathrm{M}}(\mathrm{E})=\mathrm{n}_{\infty}+\mathrm{n}_{\mathrm{o}} \times \Delta \mathrm{n}, \text { for } \mathrm{E} \geq 6 \mathrm{eV}, \mathrm{n}_{\infty} \equiv \sqrt{\varepsilon_{\mathrm{n}}} \\
=1.93+\Delta \mathrm{n}, \text { for } \mathbb{E}_{\mathrm{gn}} \leq \mathrm{E} \leq 6 \mathrm{eV}, \\
=1.93+\Delta \mathrm{n}\left(\mathbb{E}_{\mathrm{gn}}, \mathrm{A}_{\mathrm{i}(\mathrm{FB})}, \mathrm{B}_{\mathrm{i}(\mathrm{FB})}, \mathrm{C}_{\mathrm{i}(\mathrm{FB})}, \mathbb{E}_{\mathrm{gn}}\right), \text { for } \mathrm{E} \leq \mathbb{E}_{\mathrm{gn}},
\end{gathered}
$$

so that $\mathrm{n}_{\mathrm{IFB}-\mathrm{M}}(\mathrm{E} \rightarrow \infty) \rightarrow \sqrt{\varepsilon_{\mathrm{n}}}$, where the values of $\varepsilon_{\mathrm{n}}$ are given in Table I, giving a correct asymptotic behavior of $\mathrm{n}_{\mathrm{IFB}-\mathrm{M}}(\mathrm{E})$. Here, $\mathrm{n}_{\mathrm{o}}$ is the factor to be determined so that the function $\mathrm{n}_{\mathrm{IFB}-\mathrm{M}}(\mathrm{E})$ for $\mathrm{E} \geq 6 \mathrm{eV}$ is continuous at $\mathrm{E}=6 \mathrm{eV}$, depending on $\mathrm{T}$, $r_{\mathrm{d}}$, and $\mathrm{N}$.

For example, in intrinsic d-Si systems at $298 \mathrm{~K}$, in which $\mathbb{E}_{\mathrm{gn}}=\mathbb{E}_{\mathrm{gi}}\left(\mathrm{T}=298 \mathrm{~K}, r_{\mathrm{d}}\right)=1.125 \mathrm{eV}$ is determined in Eq. (3), the values of $n_{o}\left(r_{d}\right)$ are evaluated and tabulated in Table 5 .

Table 5. In intrinsic donor-Si systems at $298 \mathrm{~K}$, the numerical results of Factor $n_{o}\left(r_{d}\right)$, being due to the donor-size effect and expressed as functions of donorradius $r_{d}$, are determined so that the function $n_{I F B-M}(E)$ given in $E q$. (52) for $E \geq 6 \mathrm{eV}$ is continuous at $E=6 \mathrm{eV}$.

\begin{tabular}{llllllll}
\hline Donor & Sb & P & As & Bi & Ti & Te & Se \\
\hline $\mathrm{n}_{\mathrm{o}}\left(\mathrm{r}_{\mathrm{d}}\right)$ & 2.571289 & 2.482479 & 2.032121 & 1.944450 & 1.290620 & 0.805033 & 0.430750 \\
\hline
\end{tabular}

As noted in Eqs. (44-46), if from Eqs. $(51,52)$ the values of $\kappa_{\mathrm{IFB}-\mathrm{M}}(\mathrm{E})$ and $\mathrm{n}_{\mathrm{IFB}-\mathrm{M}}(\mathrm{E})$ are evaluated, all other optical functions can thus be determined. So, at $298 \mathrm{~K}$ and $1.5 \leq \mathrm{E}(\mathrm{eV}) \leq 6$, in the intrinsic P-Si systems, in which $\mathbb{E}_{\mathrm{gn}}=$ $\mathbb{E}_{\mathrm{gi}}\left(\mathrm{T}=298 \mathrm{~K}, r_{\mathrm{d}}\right)=1.125 \mathrm{eV}$ is evaluated using Eq. (3), our results of all the optical functions and the corresponding ones obtained from the FB-M, and the absolute errors of those, calculated using the optical-function data obtained by Aspnes and

\begin{tabular}{|c|c|c|c|c|c|c|c|}
\hline MRE & $\mathbf{E}(\mathbf{e V})$ & $\varepsilon_{1}-\mid$ MRE $\mid$ & $\varepsilon_{2}-\mid$ MRE $\mid$ & n-|MRE| & К-|MRE| & R-|MRE| & $\alpha-\mid$ MRE $\mid$ \\
\hline FB-M & 1.5 & & & & & & \\
\hline \multirow[t]{3}{*}{$\left(\mathrm{n}_{\infty}=1.95, \mathrm{E}_{\mathrm{g}}=1.06 \mathrm{eV}\right)$} & 2.2 & & 0.57 & & 0.58 & & 0.58 \\
\hline & 4.2 & 0.66 & & & & & \\
\hline & 5.0 & & & 0.06 & & & \\
\hline Our IFB-M & 1.5 & & 0.40 & & & 0.07 & \\
\hline \multirow[t]{2}{*}{$\left(\mathrm{n}_{\infty}=\sqrt{11.4}, \mathrm{E}_{\mathrm{gi}}=1.125 \mathrm{eV}\right)$} & 2.6 & & & & 0.41 & & 0.40 \\
\hline & $\begin{array}{l}4.3 \\
5.0\end{array}$ & 0.30 & & 0.08 & & & \\
\hline
\end{tabular}
Studna [33], are tabulated in the Table 6.

Table 6. In intrinsic P-Si systems at $298 \mathrm{~K}$ and for $1.5 \leq E(\mathrm{eV}) \leq 6$, our numerical results of all the optical functions (OF) are calculated, using Eqs. (44-46, 51, 52) obtained in our IFB-M, and using the OF-data obtained by Aspnes and Studna [33], their absolute maximal relative errors (|MREs|) determined at the photon energy $E(\mathrm{eV})$ are also evaluated and tabulated in this Table, in which the corresponding $|M R E S|$ obtained in FB-M are also included.

The underlined $|M R E|$-value is the maximal one for each optical function.

Table 6. In intrinsic P-Si systems at $298 \mathrm{~K}$ and for $1.5 \leq E(\mathrm{eV}) \leq 6$, our numerical results of all the optical functions (OF) are calculated, using Eqs. (44-46, 51, 52) obtained in our IFB-M, and using the OF-data obtained by Aspnes and Studna [33], their absolute maximal relative errors (|MREs $\mid)$ determined at the photon energy $E(e V)$ are also evaluated and tabulated in this Table, in which the corresponding |MREs| obtained in FB-M are also included.

Table 6 indicates that our results given in our IFB-M are found to be more accurate than those obtained in the FB-M.
Further, our numerical calculation indicates that, for a given $\mathrm{E}$, since $\kappa_{\mathrm{IFB}-\mathrm{M}}(\mathrm{E})$ given in Eq. (51) is expressed in terms of $\left(\mathrm{E}-\mathbb{E}_{\mathrm{gn}}\right)^{2}$, if $\mathbb{E}_{\mathrm{gn}}$ increases (decreases), then other functions such as: $\left(E-\mathbb{E}_{\text {gn }}\right)^{2}, \quad \kappa_{\text {IFB-M }}(E), \quad \varepsilon_{2(\mathrm{IFB}-\mathrm{M})}(\mathrm{E})$ and $\varepsilon_{1(\mathrm{IFB}-\mathrm{M})}(\mathrm{E})$ decrease (increase), respectively. This useful remark will be used in our IFB-M to explain all the following results.

In the intrinsic P-Si system, $\mathbb{E}_{\mathrm{gn}} \equiv \mathbb{E}_{\mathrm{gi}}\left(\mathrm{T}, \mathrm{r}_{\mathrm{P}}\right)$, calculated from Eq. (3), decreases with increasing T. So, for a given $\mathrm{E}$, our results of $\left[\mathrm{E}-\mathbb{E}_{\mathrm{gi}}\left(\mathrm{T}, \mathrm{r}_{\mathrm{P}}\right)\right]^{2}$ and $\varepsilon_{1(2)(\mathrm{IFB}-\mathrm{M})}(\mathrm{E})$, obtained in absolute values, increase with increasing $\mathrm{T}$, in good 
accordance with experimental results $[32,38,44,48]$, as observed in the following Figure $3 \mathrm{a}$.

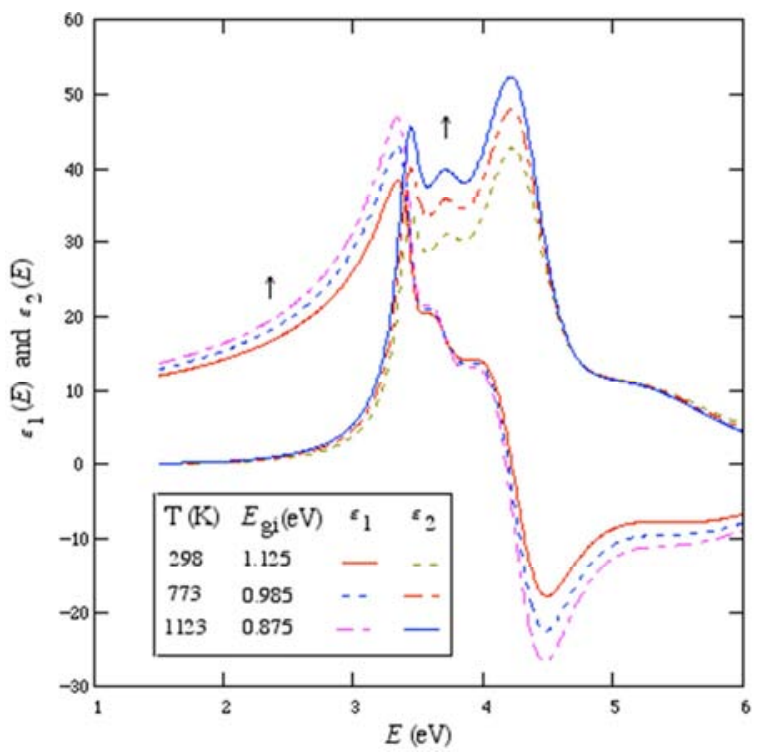

Figure $3 a$. In the intrinsic $P-S i$ system, our results of $\varepsilon_{1(2)(I F B-M)}(E)$, obtained in absolute values, increase with increasing $T$.

In intrinsic donor-Si systems, $\mathbb{E}_{\text {gn }} \equiv \mathbb{E}_{\text {gi }}\left(r_{d}, T=298 \mathrm{~K}\right)$, calculated from Eq. (3), increases with increasing $r_{d}$, as seen in Table 1. Thus, for a given $\mathrm{E}$, our results of $[\mathrm{E}-$ $\left.\mathbb{E}_{\mathrm{gi}}\left(\mathrm{r}_{\mathrm{d}}, \mathrm{T}=298 \mathrm{~K}\right)\right]^{2}$ and $\varepsilon_{1(2)(\mathrm{IFB}-\mathrm{M})}(\mathrm{E})$, in absolute values, decrease with increasing $r_{d}$, as obtained in the following Figure $3 b$, in which we also observe the correct asymptotic results: $\varepsilon_{1(\mathrm{IFB}-\mathrm{M})}(E \rightarrow \infty) \rightarrow \varepsilon_{\mathrm{n}}$, being identical to the values of $\varepsilon_{\mathrm{n}}$ given in Table 1 , and $\varepsilon_{2(\mathrm{IFB}-\mathrm{M})}(\mathrm{E} \rightarrow \infty) \rightarrow 0$.

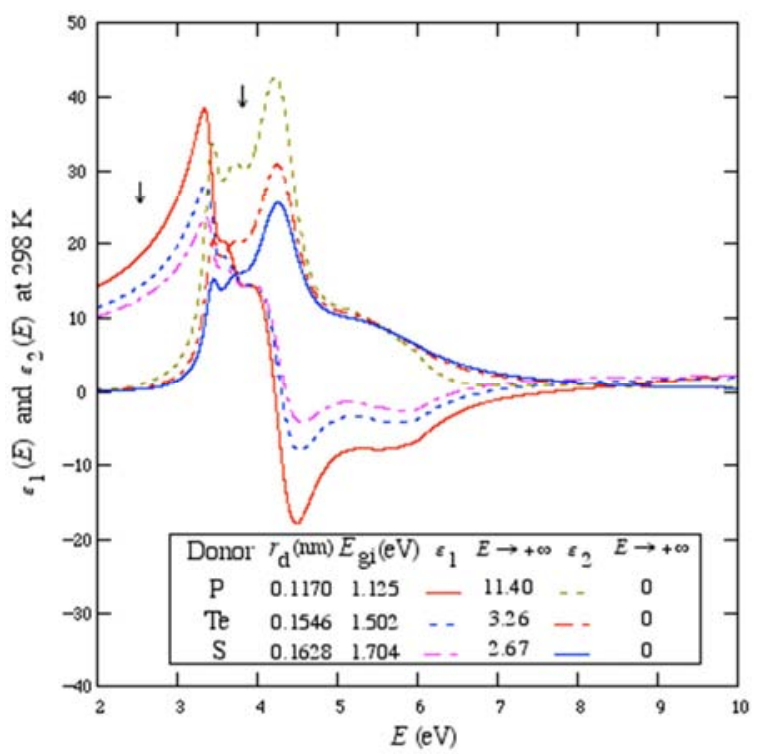

Figure 3b. In intrinsic donor-Si systems, our results of $\varepsilon_{1(2)(I F B-M)}(E)$, in absolute values, decrease with increasing $r_{d}$.

In degenerate $\mathrm{P}-\mathrm{Si}$ systems at $\mathrm{T}=4.2 \mathrm{~K}$, in which $\mathbb{E}_{\text {gn }} \equiv$ $\mathbb{E}_{\text {gn1 }}(\mathrm{N})$, being the optical band gap determined in Eq. (9), increases with increasing $\mathrm{N}$, due to the heavy-doping effect.
So, for a given $\mathrm{E}$, the absolute values of $\left[\mathrm{E}-\mathrm{E}_{\mathrm{gn} 1}(\mathrm{~N})\right]^{2}$ and $\varepsilon_{1(2)(\mathrm{IFB}-\mathrm{M})}(\mathrm{E})$ decrease with increasing $\mathrm{N}$, in good accordance with experiments by Aspnes et al. [34], and Vina and Cardona [35], as seen in the following Figure 3c.

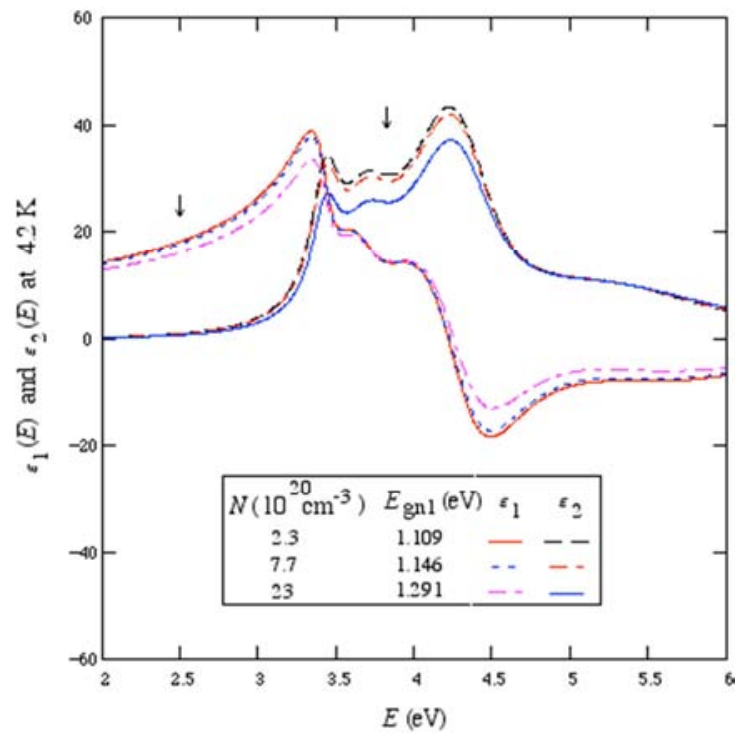

Figure 3c. In degenerate P-Si systems, our results of $\varepsilon_{1(2)(I F B-M)}(E)$, in absolute values, decrease with increasing $N$.

Finally, in degenerate $\mathrm{P}-\mathrm{Si}$ systems, in which $\mathbb{E}_{\text {gn }} \equiv$ $\mathbb{E}_{\text {gn2 }}(\mathrm{N})$, being the reduced band gap determined in Eq. (10), decreases with increasing $\mathrm{N}$, due to the heavy-doping effect. Consequently, for a given $\mathrm{E}$, the absolute values of [E$\left.\mathbb{E}_{\text {gn2 }}(\mathrm{N})\right]^{2}$ and $\varepsilon_{1(2)(\mathrm{IFB}-\mathrm{M})}(\mathrm{E})$ increase with increasing $\mathrm{N}$.

Now, identifying our above results $(50,51)$ and using Eq. (52), we can propose an useful expression for $|\mathrm{v}(\mathrm{E})|^{2}$ as

$$
\begin{gathered}
|v(E)|^{2}=\frac{\sqrt{2} \times \pi^{2} \times \hbar \times n_{\text {IFB-M }}(E) \times \varepsilon_{0} \times \mathbb{E}_{\mathrm{Fno}}^{3 / 2} \times f(E)}{\mathrm{q}^{2} \times m_{\mathrm{r}}^{3 / 2}} \times\left(\frac{6 \mathrm{eV}}{\mathrm{E}}\right)^{3}, \text { for } \mathrm{E} \geq 6 \mathrm{eV}, \\
=\frac{\sqrt{2} \times \pi^{2} \times \hbar \times n_{\mathrm{IFB}-\mathrm{M}}(\mathrm{E}) \times \varepsilon_{\mathrm{o}} \times \mathbb{E}_{\mathrm{Fno}}^{3 / 2} \times \mathrm{f}(\mathrm{E})}{\mathrm{q}^{2} \times m_{\mathrm{r}}{ }^{3 / 2}}, \text { for } \mathbb{E}_{\mathrm{gn}} \leq \mathrm{E} \leq 6 \mathrm{eV}, \\
=\frac{\sqrt{2} \times \pi^{2} \times \hbar \times \mathrm{n}_{\mathrm{IFB}-\mathrm{M}}\left(\mathbb{E}_{\mathrm{gn}}\right) \times \varepsilon_{\mathrm{o}} \times \mathbb{E}_{\mathrm{Fno}}^{3 / 2} \times \mathrm{f}\left(\mathbb{E}_{\mathrm{gn}}\right)}{\mathrm{q}^{2} \times m_{\mathrm{r}}{ }^{3 / 2}}, \text { for } \mathrm{E} \leq \mathbb{E}_{\mathrm{gn}} \text { or for } \\
\mathbb{E} \leq 0 .
\end{gathered}
$$

\subsection{Behaviors of Optical Functions Obtained for $E \leq \mathbb{E}_{g n}$ or $\mathbb{E} \leq \mathbf{0}$}

Here, going back to the functions: $H_{n}, K_{n}$ and $F_{n}$, given respectively in Eqs. (26-28) for $\mathrm{a}=5 / 2$, in which the factor $\frac{\left\langle\mathbb{E}_{\mathrm{k}}^{2}\right\rangle_{\mathrm{KIM}}}{\mathrm{f}(\mathrm{a}=5 / 2)} \quad$ is $\quad$ now replaced by: $\quad \frac{\left\langle\mathbb{E}_{\mathrm{k}}^{2}\right\rangle_{\mathrm{KIM}}}{\mathrm{f}(\mathrm{a}=5 / 2)}=\frac{\alpha(\mathbb{E} \leq 0)}{\alpha_{\mathrm{o}}\left(\mathrm{E}=\mathbb{E}_{\mathrm{gn}}\right)}=$ $\mathrm{F}_{\mathrm{n}}\left(v_{\mathrm{n}}, \mathrm{r}_{\mathrm{d}}, \mathrm{a}=5 / 2\right) \equiv \mathrm{F}_{\mathrm{n}\left(\frac{5}{2}\right)}\left(v_{\mathrm{n}}, \mathrm{r}_{\mathrm{d}}\right)$ calculated using Eq. (28), for a simplicity of presentation, $\alpha_{\mathrm{o}}\left(\mathrm{E}=\mathbb{E}_{\mathrm{gn}}\right)$ being determined from Eqs. $(26,49,53)$ as: $\alpha_{\mathrm{o}}=\frac{\mathrm{f}\left(\mathbb{E}_{\mathrm{gn}}\right) \times \eta_{\mathrm{n}}^{2}\left(\mathrm{~N}^{*}, \mathrm{r}_{\mathrm{d}}\right)}{\mathrm{c} \times \hbar \times \mathbb{E}_{\mathrm{gn}}}$, then our numerical results of reduced optical absorption coefficient given in degenerate d-Si systems at $0 \mathrm{~K}$ and for $\mathrm{N}=5 \times 10^{20} \mathrm{~cm}^{-3}, \mathrm{~F}_{\mathrm{n}\left(\frac{5}{2}\right)}\left(v_{\mathrm{n}}, \mathrm{r}_{\mathrm{d}}\right)$, are plotted in Figure 4 , as functions of $v_{n}$. 


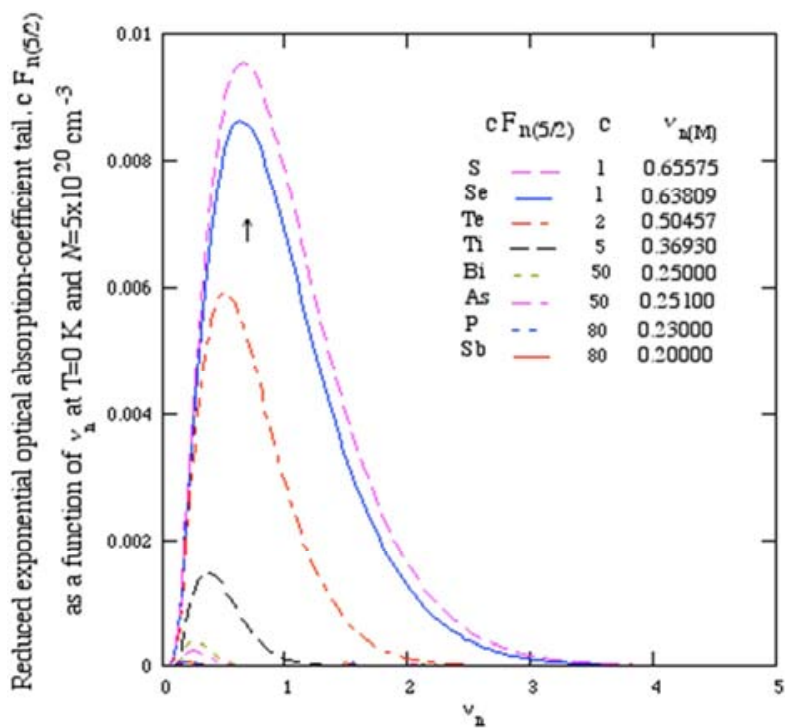

Figure 4. Our results of $F_{n\left(\frac{5}{2}\right)}$ increase with increasing $r_{d}$ for a given $v_{n}$, due to the donor-size effect, and present the maxima at $v_{n}=v_{n(M)}$ and go to zero as $v_{n} \rightarrow 0$ and $\infty$
Figure 4 shows that:

(i) our results of $\mathrm{F}_{\mathrm{n}\left(\frac{5}{2}\right)}$ increase with increasing $\mathrm{r}_{\mathrm{d}}$ for a given $v_{\mathrm{n}}$, due to the donor-size effect, and

(ii) present the maxima at $v_{\mathrm{n}}=v_{\mathrm{n}(\mathrm{M})}$ and go to zero as $v_{\mathrm{n}} \rightarrow 0$ and $\infty$, being found to be in good agreement with theoretical results obtained by Lifshitz [18], Friedberg and Luttinger [20], our results given in Eq. (A.3) of the Appendix A, and in particular with an asymptotic form for exponential conduction-band tail, obtained for $0 \lesssim v_{\mathrm{n}} \lesssim$ $\infty$, by Halperin and Lax [19], using the minimum counting methods.

Then, in degenerate $\mathrm{d}-\mathrm{Si}$ systems at $0 \mathrm{~K}$ and $\mathrm{N}=5 \times$ $10^{20} \mathrm{~cm}^{-3}$, our numerical results of $\ln \left[\mathrm{F}_{\mathrm{n}}\left(v_{\mathrm{n}}, \mathrm{r}_{\mathrm{d}}, \mathrm{a}=\right.\right.$ $5 / 2)]<0$, which can take its approximate form, obtained in small $v_{\mathrm{n}}$-intervals: $v_{1} \leq v_{\mathrm{n}} \leq v_{2}$, by: $\ln \left[\mathrm{F}_{\mathrm{n}}\left(v_{\mathrm{n}}, \mathrm{r}_{\mathrm{d}}, \mathrm{a}=\right.\right.$ $5 / 2)] \simeq \mathrm{AF}\left(v_{\mathrm{n}}, \mathrm{r}_{\mathrm{d}}, v_{1}, v_{2}, \mathrm{z}, \mathrm{f}\right)=\mathrm{e}\left(\mathrm{r}_{\mathrm{d}}, v_{1}, v_{2}, \mathrm{z}\right) \times v_{\mathrm{n}}^{\mathrm{z}}+\mathrm{f}<0$, as those given in Eqs. $(29,30)$, are tabulated in Table 7.

Table 7. In the $d$-Si systems at $T=0 \mathrm{~K}$ and for $N=5 \times 10^{20} \mathrm{~cm}^{-3}$, using the reduced optical absorption coefficient determined in Eq. (28), $F_{n}\left(v_{n}, r_{d}, a=5 /\right.$ $2)$, the numerical results of $\ln \left[F_{n}\left(v_{n}, r_{d}, a=5 / 2\right)\right]$ and its approximate form for $a=5 / 2: A F\left(v_{n}, r_{d}, v_{1}, v_{2}, z, f\right)=e\left(r_{d}, v_{1}, v_{2}, z\right) \times v_{n}^{z}+f$, determined in Eqs. $(29,30)$ for small $v_{n}$-intervals: $v_{1} \leq v_{n} \leq v_{2}$, and those of absolute relative errors defined by: $|R E| \equiv 1-\frac{A F\left(v_{n}, r_{d}, v_{1}, v_{2}, z_{f}\right)}{\ln \left[F_{n}\left(v_{n}, r_{d}, a=5 / 2\right)\right]}$, are calculated and tabulated below.

\begin{tabular}{|c|c|c|c|c|c|c|c|c|}
\hline Donor & Sb & $\mathbf{P}$ & As & $\mathbf{B i}$ & $\mathbf{T i}$ & Te & $\mathrm{Se}$ & $\mathbf{S}$ \\
\hline$v_{n(M)}$ & 0.20000 & 0.23000 & 0.25100 & 0.25000 & 0.36930 & 0.50457 & 0.63809 & 0.65575 \\
\hline \multicolumn{9}{|c|}{ For $1.20 \leq v_{\mathrm{n}} \leq 1.25, \mathrm{AF}=\left(\mathrm{e} \times v_{\mathrm{n}}+\mathrm{f}\right)$ is accurate to within $1.5 \times 10^{-4}$, where } \\
\hline$-\mathrm{e}$ & 41.048 & 37.467 & 22.309 & 19.884 & 6.995 & 2.809 & 1.455 & 1.344 \\
\hline$f$ & 8.817 & 7.066 & 0.610 & -0.268 & -3.580 & -3.690 & -3.498 & -3.476 \\
\hline |RE $\mid$ & $1.5 \times 10^{-4}$ & $9.5 \times 10^{-5}$ & $1.4 \times 10^{-4}$ & $8.4 \times 10^{-5}$ & $7.7 \times 10^{-5}$ & $9.4 \times 10^{-5}$ & $7.2 \times 10^{-5}$ & $7.7 \times 10^{-5}$ \\
\hline \multicolumn{9}{|c|}{ For $1.10 \leq v_{\mathrm{n}} \leq 1.20, \mathrm{AF}=\left(\mathrm{e} \times v_{\mathrm{n}}^{1 / 2}+\mathrm{f}\right)$ is accurate to within $7.8 \times 10^{-4}$, where } \\
\hline$-e$ & 83.727 & 76.598 & 45.797 & 40.849 & 14.399 & 5.729 & 2.905 & 2.672 \\
\hline$f$ & 51.300 & 46.035 & 24.020 & 20.630 & 3.803 & -0.784 & -2.061 & -2.161 \\
\hline |RE $\mid$ & $7.8 \times 10^{-4}$ & $7.0 \times 10^{-4}$ & $5.8 \times 10^{-4}$ & $5.6 \times 10^{-4}$ & $3.9 \times 10^{-4}$ & $3.1 \times 10^{-4}$ & $2.7 \times 10^{-4}$ & $2.4 \times 10^{-4}$ \\
\hline \multicolumn{9}{|c|}{ For $1.07 \leq v_{\mathrm{n}} \leq 1.09, \mathrm{AF}=\left(\mathrm{e} \times v_{\mathrm{n}}{ }^{1 / 3}+\mathrm{f}\right)$ is accurate to within $6.7 \times 10^{-5}$, where } \\
\hline -e & 117.594 & 107.704 & 64.640 & 57.691 & 20.350 & 8.001 & 3.950 & 3.614 \\
\hline$f$ & 84.856 & 76.863 & 42.706 & 37.332 & 9.706 & 1.466 & -1.031 & -1.233 \\
\hline |RE $\mid$ & $4.0 \times 10^{-5}$ & $4.4 \times 10^{-5}$ & $3.6 \times 10^{-5}$ & $2.7 \times 10^{-5}$ & $5.6 \times 10^{-5}$ & $6.7 \times 10^{-5}$ & $1.1 \times 10^{-5}$ & $1.5 \times 10^{-5}$ \\
\hline \multicolumn{9}{|c|}{ For $v_{\mathrm{n}(\mathrm{M})}<1.00 \leq v_{\mathrm{n}} \leq 1.05, \mathrm{AF}=\left(\mathrm{e} \times v_{\mathrm{n}}{ }^{1 / 4}+\mathrm{f}\right)$ is accurate to within $2.5 \times 10^{-4}$, where } \\
\hline$-\mathrm{e}$ & 146.037 & 133.830 & 80.538 & 71.909 & 25.343 & 9.835 & 4.719 & 4.294 \\
\hline$f$ & 113.151 & 102.853 & 58.526 & 51.481 & 14.674 & 3.288 & -0.269 & -0.561 \\
\hline |RE $\mid$ & $2.5 \times 10^{-4}$ & $2.5 \times 10^{-4}$ & $2.1 \times 10^{-4}$ & $2.0 \times 10^{-4}$ & $1.4 \times 10^{-4}$ & $1.3 \times 10^{-4}$ & $1.7 \times 10^{-4}$ & $7.5 \times 10^{-5}$ \\
\hline \multicolumn{9}{|c|}{ For $0.090 \leq v_{\mathrm{n}} \leq 0.095<v_{\mathrm{n}(\mathrm{M})}, \mathrm{AF}=\left(\mathrm{e} \times v_{\mathrm{n}}^{1 / 4}+\mathrm{f}\right)$ is accurate to within $2.5 \times 10^{-4}$, where } \\
\hline e & 61.911 & 64.563 & 73.471 & 73.821 & 58.071 & 40.661 & 33.954 & 33.436 \\
\hline f & -51.196 & -52.643 & -56.888 & -56.805 & -44.514 & -32.149 & -27.297 & -26.916 \\
\hline |RE & $2.3 \times 10^{-4}$ & $2.1 \times 10^{-4}$ & $2.5 \times 10^{-4}$ & $2.5 \times 10^{-4}$ & $2.4 \times 10^{-4}$ & $1.6 \times 10^{-4}$ & $1.6 \times 10^{-4}$ & $1.6 \times 10^{-4}$ \\
\hline \multicolumn{9}{|c|}{ For $0.088 \leq v_{\mathrm{n}} \leq 0.090, \mathrm{AF}=\left(\mathrm{e} \times v_{\mathrm{n}}{ }^{1 / 3}+\mathrm{f}\right)$ is accurate to within $7.8 \times 10^{-5}$, where } \\
\hline e & 61.933 & 64.532 & 73.219 & 73.525 & 57.271 & 39.554 & 32.765 & 32.240 \\
\hline f & -45.044 & -46.203 & -49.462 & -49.324 & -38.375 & -27.605 & -23.384 & -23.052 \\
\hline |RE $\mid$ & $4.7 \times 10^{-5}$ & $5.4 \times 10^{-5}$ & $6.8 \times 10^{-5}$ & $5.6 \times 10^{-5}$ & $7.5 \times 10^{-5}$ & $3.6 \times 10^{-5}$ & $4.3 \times 10^{-5}$ & $7.8 \times 10^{-5}$ \\
\hline \multicolumn{9}{|c|}{ For $0.080 \leq v_{\mathrm{n}} \leq 0.083, \mathrm{AF}=\left(\mathrm{e} \times v_{\mathrm{n}}{ }^{1 / 2}+\mathrm{f}\right)$ is accurate to within $1.5 \times 10^{-4}$, where } \\
\hline
\end{tabular}




\begin{tabular}{|c|c|c|c|c|c|c|c|c|}
\hline Donor & Sb & $\mathbf{P}$ & As & $\mathbf{B i}$ & Ti & Te & Se & $\mathbf{S}$ \\
\hline$v_{n(M)}$ & 0.20000 & 0.23000 & 0.25100 & 0.25000 & 0.36930 & 0.50457 & 0.63809 & 0.65575 \\
\hline e & 77.110 & 80.266 & 90.763 & 91.957 & 69.455 & 46.413 & 37.693 & 37.021 \\
\hline$f$ & -40.295 & -41.231 & -43.731 & -43.546 & -33.443 & -23.746 & -19.967 & -19.670 \\
\hline$|\mathrm{RE}|$ & $1.3 \times 10^{-4}$ & $6.7 \times 10^{-4}$ & $1.7 \times 10^{-4}$ & $1.7 \times 10^{-4}$ & $1.5 \times 10^{-4}$ & $1.3 \times 10^{-4}$ & $1.2 \times 10^{-4}$ & $1.1 \times 10^{-4}$ \\
\hline \multicolumn{9}{|c|}{ For $0.061 \leq v_{\mathrm{n}} \leq 0.064, \mathrm{AF}=\left(\mathrm{e} \times v_{\mathrm{n}}+\mathrm{f}\right)$ is accurate to within $5.1 \times 10^{-4}$, where } \\
\hline e & 306.576 & 319.993 & 366.932 & 368.556 & 267.210 & 159.872 & 120.930 & 117.973 \\
\hline$f$ & -41.333 & -42.369 & -45.358 & -45.205 & -33.739 & -22.646 & -18.456 & -18.129 \\
\hline |RE $\mid$ & $3.9 \times 10^{-4}$ & $4.3 \times 10^{-4}$ & $4.9 \times 10^{-4}$ & $5.1 \times 10^{-4}$ & $2.3 \times 10^{-4}$ & $3.2 \times 10^{-4}$ & $2.8 \times 10^{-4}$ & $2.4 \times 10^{-4}$ \\
\hline \multicolumn{9}{|c|}{ For $0.054 \leq v_{\mathrm{n}} \leq 0.056, \mathrm{AF}=\left(\mathrm{e} \times v_{\mathrm{n}}^{2}+\mathrm{f}\right)$ is accurate to within $8.7 \times 10^{-4}$, where } \\
\hline $\mathrm{e}$ & 4254.38 & 4420.99 & 5198.02 & 5318.51 & 3719.15 & 2095.41 & 1520.14 & 1476.98 \\
\hline $\mathrm{f}$ & -37.877 & -38.706 & -41.581 & -41.708 & -30.766 & -20.430 & -16.560 & -16.260 \\
\hline |RE & $3.9 \times 10^{-4}$ & $4.3 \times 10^{-4}$ & $5.5 \times 10^{-4}$ & $8.7 \times 10^{-4}$ & $4.2 \times 10^{-4}$ & $3.0 \times 10^{-4}$ & $2.3 \times 10^{-4}$ & $2.3 \times 10^{-4}$ \\
\hline
\end{tabular}

The underlined $|R E|$-value is the maximal one for each donor-Si system.

Table 7 suggests that: (i) our results of $\operatorname{AF}\left(v_{n}, r_{d}, v_{1}, v_{2}, z, f\right)$ given for $(\mathrm{z}=1)$-exponent agree with the Urbach law obtained from linear exponential conductionband tail-behaviors by some workers [21, 29, 30, 37], (ii) ours for $(\mathrm{z}=1 / 2)$-exponent and $v_{\mathrm{n}}>v_{\mathrm{n}(\mathrm{M})}$ agree with other theoretical results $[19,37]$, and finally (iii) ours for $(z=1 / 3$, 1/4)-exponents when $v_{\mathrm{n}}>v_{\mathrm{n}(\mathrm{M})}$, and for $(\mathrm{z}=1 / 4,1 / 3,1 / 2,1$, 2)-exponents when $v_{\mathrm{n}}<v_{\mathrm{n}(\mathrm{M})}$ may thus be new.

Finally, our numerical results of energy parameter, $\mathbb{E}_{\text {no }}\left(\mathrm{N} ; \mathrm{r}_{\mathrm{d}}, \mathrm{a}=5 / 2\right)$, obtained in the small interval: $1.2 \leq$ $v_{\mathrm{n}} \leq 1.25$, using Eq. (31), are plotted as functions of $\mathrm{N}$ in Figures $5 \mathrm{a}$ and $5 \mathrm{~b}$, indicating that, for a given $\mathrm{N}, \mathbb{E}_{\text {no }}$ increases with increasing $r_{d}$-values, due to the donor-size effect.

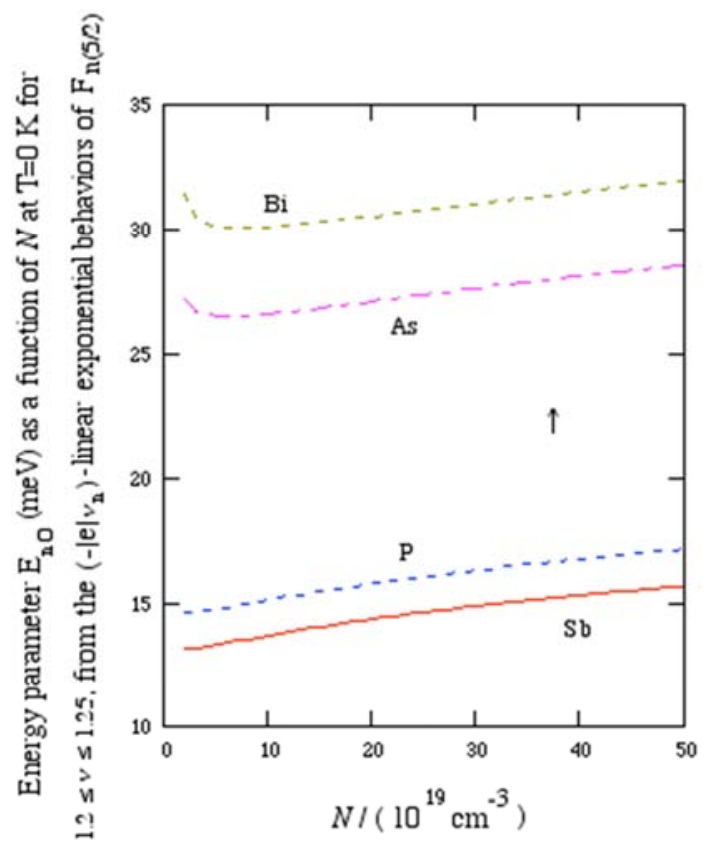

FIG. 5a

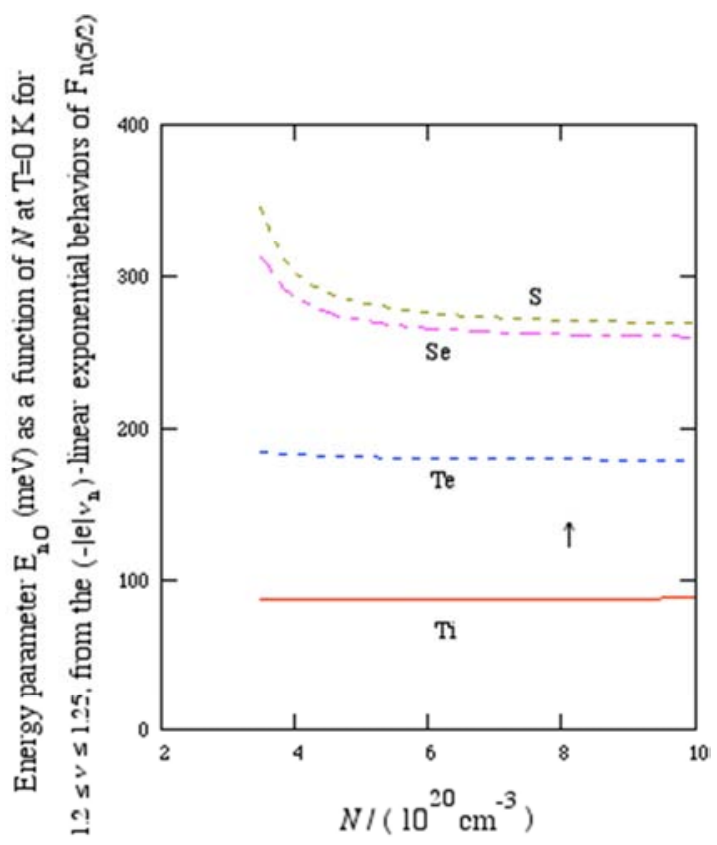

FIG. 5b

Figures 5. Our results of energy parameter, $\mathbb{E}_{n o}\left(N ; r_{d}, a=5 / 2\right)$ are plotted as functions of $N$, indicating that, for a given $N, \mathbb{E}_{\text {no }}$ increases with increasing $r_{d}$-values, due to the donor-size effect.

\section{Electrical Properties}

Here, $\mathrm{m}^{*} \equiv \mathrm{m}_{\text {cond. }}=0.26 \times \mathrm{m}_{\mathrm{o}}$. Then, the electrical functions, obtained in the two cases: $\mathbb{E} \geq 0$ and $\mathbb{E} \leq 0$, will be considered as follows.

\subsection{Electrical Functions Obtained as $\mathbb{E} \geq 0$}

In the effective electron gas at $0 \mathrm{~K}$ [66], denoting the relaxation time by $\tau$, the mobility is defined by

$$
\mu \equiv \frac{\mathrm{q} \times \tau}{\mathrm{m}_{\text {cond. }}}
$$

the conductivity $\sigma$ (or resistivity $\rho \equiv 1 / \sigma$ ), given in the Drude model, by 


$$
\sigma \equiv \mathrm{q} \times \mathrm{N} \times \mu=\mathrm{q}^{2} \times \mathrm{N} \times \frac{\tau}{\mathrm{m}_{\text {cond. }}},
$$

the Hall conductivity $\sigma_{\mathrm{H}}$, by

$$
\sigma_{\mathrm{H}} \equiv-\sigma \times \mu=-\frac{\mathrm{q}^{3} \times \mathrm{N} \times \tau^{2}}{\left(\mathrm{~m}_{\text {cond. }}\right)^{2}}<0,
$$

and finally, from Eqs. $(55,56)$, the Hall coefficient at $0 \mathrm{~K}$, by

$$
\mathrm{R}_{\mathrm{H}}(\mathrm{N}) \equiv \frac{\left\langle\sigma_{\mathrm{H}}\right\rangle}{\langle\sigma\rangle^{2}}=-\frac{1}{\mathrm{~N} \times \mathrm{q}} \times \frac{\left\langle\tau^{2}\right\rangle}{\langle\tau\rangle^{2}}<0, \frac{\left\langle\tau^{2}\right\rangle}{\langle\tau\rangle^{2}} \equiv 1
$$

This result (57) is not correct for the degenerate donor (d)$\mathrm{Si}$ systems at low temperatures, where $\mathrm{N}$ may be replaced by the total effective density of free electrons given in the conduction band, $\mathrm{N}^{*} \simeq \mathrm{N}-\mathrm{N}_{\mathrm{c}(\mathrm{d})}$, as that given in Eq. (43), in which the values of critical donor density $\mathrm{N}_{\mathrm{c}(\mathrm{d})}$ are given in Table I. In those degenerate d-Si systems, the relaxation time can be defined by

$$
\frac{1}{\tau(\mathrm{k})}=\mathrm{N}^{*} \times \frac{\hbar \mathrm{k}}{\mathrm{m}_{\text {cond. }}} \times \pi(\mathrm{C} \times \mathrm{k})^{-2} \times \prod_{\mathrm{i}=1}^{\mathrm{J}} \mathrm{x}_{\mathrm{i}},
$$

where $\hbar \mathrm{k} /\left(\mathrm{m}_{\text {cond. }} \times \mathrm{m}\right)$ is the electron velocity, $\mathrm{C}$ is an empirical parameter, $\pi(\mathrm{C} \times \mathrm{k})^{-2}$ is the scattering cross section, and finally the factors $x_{i}$ are included to represent the high donor-density conditions when $\mathrm{k}=\mathrm{k}_{\mathrm{Fn}}$, as those given in Eq. (14), such that $\frac{1}{\tau\left(\mathrm{k}_{\mathrm{Fn}}\right)}<1$.

We now report and discuss the results of $\tau$, being obtained by Van Cong and Mesnard method (VCMM) [58] and also by Yussouff and Zittarz [59], as follows.

By a Green function (G)-method, assuming that the Gaussian ensemble average of GG as: $\langle G G\rangle \equiv\langle G\rangle \times\langle G\rangle+$ $\Delta G \simeq\langle G\rangle \times\langle G\rangle$, Van Cong and Mesnard obtained [58]

$$
\begin{aligned}
\frac{1}{\tau\left(\mathrm{k}_{\mathrm{Fn}}\right)}=\mathrm{N}^{*} \times \frac{\hbar \mathrm{k}_{\mathrm{Fn}}}{\mathrm{m}_{\text {cond. }}} \times \pi\left(\sqrt{\frac{4 \sqrt{\pi}}{3}} \times \mathrm{k}_{\mathrm{Fn}}\right)^{-2} \times \frac{\eta_{\mathrm{n}}}{\mathbb{E}_{\mathrm{Fno}}}<1,(59) \quad(61) \text { are now performed as } \\
\mu_{\mathrm{PVCMM}}\left(\mathrm{N}^{*}, \mathrm{~T}, \mathrm{r}_{\mathrm{d}}\right) \simeq \mu_{\mathrm{VCMM}} \times\left\{\mathrm{G}_{\frac{3}{2}}(\mathrm{y})+\Delta_{\mathrm{PVCMM}} \times \mathrm{G}_{1}(\mathrm{y})\right\}, \\
\sigma_{\mathrm{PVCMM}}\left(\mathrm{N}^{*}, \mathrm{~T}, \mathrm{r}_{\mathrm{d}}\right) \simeq \sigma_{\mathrm{VCMM}} \times\left\{\mathrm{G}_{\frac{3}{2}}(\mathrm{y})+\Delta_{\mathrm{PVCMM}} \times \mathrm{G}_{1}(\mathrm{y})\right\},
\end{aligned}
$$

which can be replaced into Eqs. $(54,55)$, respectively, to obtain

$$
\begin{gathered}
\mu_{\mathrm{VCMM}} \simeq \frac{4}{3 \sqrt{\pi}} \times \frac{\mathrm{q} \times \mathrm{k}_{\mathrm{Fn}}}{\mathrm{N}^{*} \hbar} \times \frac{\mathbb{E}_{\mathrm{Fno}}}{\eta_{\mathrm{n}}}, \\
\sigma_{\mathrm{VCMM}} \simeq \frac{4}{3 \sqrt{\pi}} \times \frac{\mathrm{q}^{2} \times \mathrm{k}_{\mathrm{Fn}}}{\hbar} \times \frac{\mathbb{E}_{\mathrm{Fno}}}{\eta_{\mathrm{n}}},
\end{gathered}
$$

which is proportional to $\mathbb{E}_{\mathrm{Fno}}^{3 / 2}$, where the Fermi energy $\mathbb{E}_{\mathrm{Fno}}\left(\mathrm{N}^{*}\right)$ is determined in Eq. (42).

Furthermore, by qualitative arguments, based on the diagram method, then for the lowest order in inverse screening length $\mathrm{k}_{\mathrm{sn}}$, Yussouff and Zittarz [59] obtained

$$
\frac{1}{\tau\left(\mathrm{k}_{\mathrm{Fn}}\right)}=\alpha_{\mathrm{YZ}} \times \frac{\mathrm{k}_{\mathrm{Fn}}^{-1}}{\mathrm{k}_{\mathrm{sn}}^{-1}} \times \frac{\eta_{\mathrm{n}}}{\mathbb{E}_{\mathrm{Fno}}} \times \frac{\eta_{\mathrm{n}}}{\hbar}<1,
$$

where $\alpha_{Y Z}$ is the dimensionless function, being not well determined. However, this qualitative argument method is useful to investigate the accurate $\tau$-result, as that given below.

Our numerical calculation indicates that the $(\mu, \sigma)$-results, obtained from Eqs. $(60,61)$ do not well agree with the corresponding experimental ones $[50,54,60]$. Thus, there is a need of performing those results.

In this performed VCM-method (PVCMM), proposing the total correction:

$$
\Delta_{\mathrm{PVCMM}}=-0.01 \times \frac{\mathrm{k}_{\mathrm{Fn}}^{-1}}{\mathrm{k}_{\mathrm{sn}}^{-1}}-0.125 \times \frac{\mathrm{k}_{\mathrm{Fn}}^{-1}}{a_{\mathrm{B}}\left(\mathrm{r}_{\mathrm{d}}, \mathrm{m}_{\text {cond. }}\right)},
$$

being proportional to $\mathbb{E}_{\mathrm{Fno}}^{-1 / 2}$, where $a_{\mathrm{B}}$ is the effective Bohr radius determined in Eq. (1), and also using our result (34) for $G_{p}\left(\mathbb{E}_{\text {Fno }}\right) \equiv \frac{\left\langle\mathbb{E}^{p}\right\rangle_{\mathrm{FDDF}}}{\mathbb{E}_{\mathrm{Fno}}^{\mathrm{p}}}$ with $\mathrm{p}=3 / 2$, then the results $(60)$ and

where $\mu_{\mathrm{VCMM}}$ and $\sigma_{\mathrm{VCMM}}$ are respectively determined in Eqs. $(60,61)$ and the function $\mathrm{G}_{\frac{3}{2}}(\mathrm{y})$ is given in Table III, with $\mathrm{y}=\frac{\pi \mathrm{k}_{\mathrm{B}} \mathrm{T}}{\mathbb{E}_{\mathrm{Fn}}} \simeq \frac{\pi \mathrm{k}_{\mathrm{B}} \mathrm{T}}{\mathbb{E}_{\mathrm{Fno}}}$, noting that $\mathrm{G}_{1}(\mathrm{y})=1$.

Further, the Hall coefficient is defined by

$$
\mathrm{R}_{\mathrm{H}(\mathrm{PVCMM})}\left(\mathrm{N}^{*}, \mathrm{~T}, \mathrm{r}_{\mathrm{d}}\right) \equiv \frac{-\left\langle\sigma_{\mathrm{PVCMM}} \times \mu_{\mathrm{PVCMM}}\right\rangle}{\left\langle\sigma_{\mathrm{PVCMM}}\right\rangle^{2}}=-\frac{1}{\mathrm{~N}^{*} \times \mathrm{q}} \times \mathrm{r}_{\mathrm{H}(\mathrm{PVCMM})}<0,
$$

where the Hall factor is found to be given by

$$
\mathrm{r}_{\mathrm{H}(\mathrm{PVCMM})}\left(\mathrm{N}^{*}, \mathrm{~T}, \mathrm{r}_{\mathrm{d}}\right) \equiv \frac{\left\langle\tau^{2}\right\rangle}{\langle\tau\rangle^{2}}=\frac{\mathrm{G}_{3}(\mathrm{y})+\Delta_{\mathrm{PVCMM}}^{2} \times \mathrm{G}_{2}(\mathrm{y})+2 \times \Delta_{\mathrm{PVCMM}} \times \mathrm{G}_{5 / 2}(\mathrm{y})}{\left(\mathrm{G}_{\frac{3}{2}}(\mathrm{y})+\Delta_{\mathrm{PVCMM}}\right)^{2}} .
$$

Furthermore, the Hall mobility is given by

$$
\mu_{\mathrm{H}(\mathrm{PVCMM})}\left(\mathrm{N}^{*}, \mathrm{~T}, \mathrm{r}_{\mathrm{d}}\right)=\mu_{\mathrm{PVCMM}} \times \mathrm{r}_{\mathrm{H}(\mathrm{PVCMM})} .
$$

We now propose our present method (PM) to determine all the electrical functions as follows.

First of all, one remarks that in Section 6 all the optical functions, given in Eq. (44) and obtained in d-Si systems, are found to be proportional to $\mathbb{E}^{2}$ or to $\mathbb{E}_{\mathrm{Fno}}^{2}$, as $\mathbb{E}=\mathbb{E}_{\mathrm{Fno}}$. Then, in the PM, we propose both principal parts of $\mu$ and $\sigma$, being 
found to be proportional to $\mathbb{E}_{\text {Fno }}^{2}$. Further, using now the total correction given by: $\Delta_{\mathrm{PM}}=0.04 \times \frac{\mathrm{k}_{\mathrm{Fn}}^{-1}}{\mathrm{k}_{\mathrm{sn}}^{-1}}+0.2 \times$ $\frac{\mathrm{k}_{\mathrm{Fn}}^{-1}}{\mathrm{a}_{\mathrm{B}}\left(r_{\mathrm{d}}, \mathrm{m}_{\text {cond. }}\right)}-0.03 \times \sqrt{\frac{\eta_{\mathrm{n}}}{\mathbb{E}_{\mathrm{Fno}}}}$, which is proportional to $\mathbb{E}_{\mathrm{Fno}}^{-1 / 2}$,

$$
\mu_{\mathrm{PM}}\left(\mathrm{N}^{*}, \mathrm{~T}, \mathrm{r}_{\mathrm{d}}\right) \simeq \frac{(0.85)^{2}}{\pi} \times \frac{\mathrm{q} \times \mathrm{k}_{\mathrm{Fn}}}{\mathrm{N} \hbar} \times \frac{\mathrm{a}_{\mathrm{B}}}{\mathrm{k}_{\mathrm{Fn}}^{-1}} \times \frac{\mathrm{k}_{\mathrm{sn}}^{-1}}{\mathrm{k}_{\mathrm{Fn}}^{-1}} \times \sqrt{\frac{\mathbb{E}_{\mathrm{Fno}}}{\eta_{\mathrm{n}}}} \times\left\{\mathrm{G}_{2}(\mathrm{y})+\Delta_{\mathrm{PM}} \times \mathrm{G}_{\frac{3}{2}}(\mathrm{y})\right\},
$$

where $(0.85)^{2}$ is the empirical parameter chosen to minimize the absolute deviations between the numerical results of $\mu_{\mathrm{PM}}$ and the corresponding $\mu$-data, and the functions $G_{2}(y)$ and $\mathrm{G}_{\frac{3}{2}}(\mathrm{y})$ are given in Table III. Then, the expression for electrical conductivity is given by

$$
\sigma_{\mathrm{PM}}\left(\mathrm{N}^{*}, \mathrm{~T}, \mathrm{r}_{\mathrm{d}}\right) \simeq \sigma_{\mathrm{o}}\left(\mathbb{E}_{\mathrm{Fno}}\right) \times\left\{\mathrm{G}_{2}(\mathrm{y})+\Delta_{\mathrm{PM}} \times \mathrm{G}_{\frac{3}{2}}(\mathrm{y})\right\},
$$

where

$$
\sigma_{\mathrm{o}}\left(\mathbb{E}_{\mathrm{Fno}}\right)=\frac{(0.85)^{2}}{\pi} \times \frac{\mathrm{q}^{2} \times \mathrm{k}_{\mathrm{Fn}}}{\hbar} \times \frac{\mathrm{a}_{\mathrm{B}}}{\mathrm{k}_{\mathrm{Fn}}^{-1}} \times \frac{\mathrm{k}_{\mathrm{Sn}}^{-1}}{\mathrm{k}_{\mathrm{Fn}}^{-1}} \times \sqrt{\frac{\mathbb{E}_{\mathrm{Fno}}}{\eta_{\mathrm{n}}}},
$$

being proportional to $\mathbb{E}_{\text {Fno }}^{2}$.

Further, the Hall coefficient is defined by

$$
\mathrm{R}_{\mathrm{H}(\mathrm{PM})}\left(\mathrm{N}^{*}, \mathrm{~T}, \mathrm{r}_{\mathrm{d}}\right) \equiv \frac{-\left\langle\sigma_{\mathrm{PM}} \times \mu_{\mathrm{PM}}\right\rangle}{\left\langle\sigma_{\mathrm{PM}}\right\rangle^{2}}=-\frac{1}{\mathrm{~N}^{*} \times \mathrm{q}} \times \mathrm{r}_{\mathrm{H}(\mathrm{PM})}<0,
$$

where the Hall factor is given by

$$
\mathrm{r}_{\mathrm{H}(\mathrm{PM})}\left(\mathrm{N}^{*}, \mathrm{~T}, \mathrm{r}_{\mathrm{d}}\right) \equiv \frac{\left\langle\tau^{2}\right\rangle}{\langle\tau\rangle^{2}}=\frac{\mathrm{G}_{4}(\mathrm{y})+\Delta_{\mathrm{PM}}^{2} \times \mathrm{G}_{3}(\mathrm{y})+2 \times \Delta_{\mathrm{PM}} \times \mathrm{G}_{7 / 2}(\mathrm{y})}{\left[\mathrm{G}_{2}(\mathrm{y})+\Delta_{\mathrm{PM}} \times \mathrm{G}_{3 / 2}(\mathrm{y})\right]^{2}} .
$$

Furthermore, the Hall mobility yields

$$
\mu_{\mathrm{H}(\mathrm{PM})}\left(\mathrm{N}^{*}, \mathrm{~T}, \mathrm{r}_{\mathrm{d}}\right)=\mu_{\mathrm{PM}} \times \mathrm{r}_{\mathrm{H}(\mathrm{PM})} .
$$

Our numerical calculation indicates that in degenerate d-Si systems the $\mathrm{r}_{\mathrm{H}}$-behaviors obtained in PVCMM and PM, using Eqs. $(65,70)$, are almost the same. So, in the PM, our numerical results of Hall factors $\mathrm{r}_{\mathrm{H}}$ obtained in various d-Si systems at $77 \mathrm{~K}$, using Eq. (70), are plotted as functions of $\mathrm{N}$ in Figures $6 \mathrm{a}$ and $6 \mathrm{~b}$.

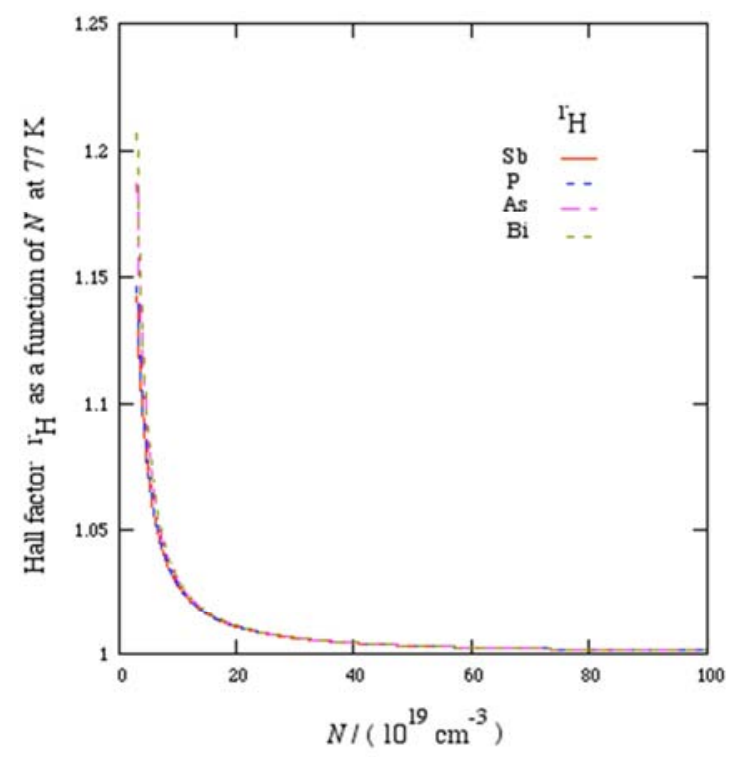

FIG. 6a and also using our result (34) for $\mathrm{G}_{\mathrm{p}}\left(\mathbb{E}_{\mathrm{Fno}}\right) \equiv \frac{\left\langle\mathbb{E}^{\mathrm{p}}\right\rangle_{\mathrm{FDDF}}}{\mathbb{E}_{\mathrm{Fno}}^{\mathrm{p}}}$, given for $\mathrm{p}=2$ and $\mathrm{p}=3 / 2$, we propose the expression for electron mobility, obtained for $\mathrm{p}=2$ and $\mathrm{p}=3 / 2$, as

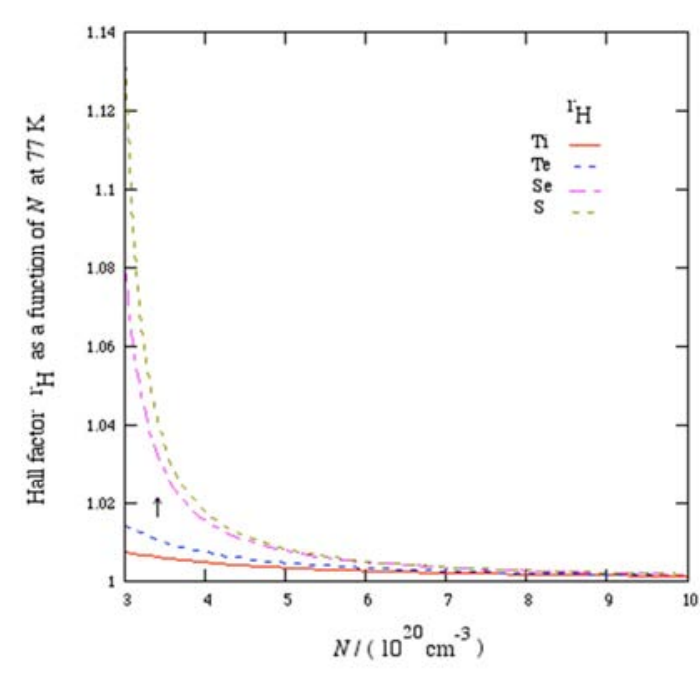

FIG. 6b

Figures 6. In the PM, our results of Hall factors $r_{H}$ obtained in various d-Si systems are plotted as functions of $N$, decreasing with increasing $N$, increasing with increasing $r_{d}$ for a given $N$, and tend towards 1 at very high $N$.

Figures $6 a$ and $6 b$ indicate that those results of $r_{H}$ are positive, decrease with increasing $\mathrm{N}$, increase with increasing $r_{d}$ for a given $\mathrm{N}$, and tend towards 1 at very high values of $\mathrm{N}$, in good agreement with the result obtained in an effective electron gas [66].

Then, in particular, in the As-Si system at $\mathrm{T}=10 \mathrm{~K}$ and for $\mathrm{N}=2.7 \times 10^{19} \mathrm{~cm}^{-3}$, the numerical results of Hall coefficient, $\left|\mathrm{R}_{\mathrm{H}}\left(\mathrm{N}^{*}\right)\right|$, where $\mathrm{N}^{*} \equiv \mathrm{N}-\mathrm{N}_{\mathrm{c}(\mathrm{As})}, \mathrm{N}_{\mathrm{c}(\text { As })}=$ $8.58 \times 10^{18} \mathrm{~cm}^{-3}$, and Hall mobility, $\mu_{\mathrm{H}}\left(\mathrm{N}^{*}\right)$, obtained using Eqs. $(64,66)$ for the PVCMM, and Eqs. $(69,71)$ for the $\mathrm{PM}$, and their absolute relative errors, |REs|, calculated using the corresponding data obtained by Morin and Maita [50], are tabulated in Table 8 .

Table 8. In the As-Si system at $T=10 \mathrm{~K}$ and for $N=2.7 \times 10^{19} \mathrm{~cm}^{-3}$, the numerical results of Hall mobility $\mu_{H}\left(N^{*}\right)$ and Hall coefficient $\left|R_{H}\left(N^{*}\right)\right|$, obtained in the PM and PVCMM, and their absolute relative errors, $|R E S|$, calculated using the corresponding data obtained by Morin and Maita [50], $\mu_{H(\text { data })}=155\left(\frac{\mathrm{cm}^{2}}{V \times s e c}\right)$ and $\left|R_{H(\text { data })}\right|=0.33\left(\mathrm{~cm}^{3} / C\right)$, are calculated and tabulated.

\begin{tabular}{llllll}
\hline $\mathbf{P M}$ & $\boldsymbol{\mu}_{\mathbf{H}}[|\mathbf{R E}|]$ & $\left|\mathbf{R}_{\mathbf{H}}\right|[|\mathbf{R E}|]$ & $\mathbf{P V C M M}$ & $\boldsymbol{\mu}_{\mathbf{H}}[|\mathbf{R E}|]$ & $\left|\mathbf{R}_{\mathbf{H}}\right|[|\mathbf{R E}|]$ \\
\hline 129.2 & 0.340 & 156.5 & 0.340 \\
& $0.17]$ & {$[0.03]$} & {$[0.01]$} & {$[0.03]$} \\
\hline
\end{tabular}

Table 8 indicates $|\mathrm{REs}|$ of $\mu_{\mathrm{H}}\left(\mathrm{N}^{*}\right)$ and $\left|\mathrm{R}_{\mathrm{H}}\left(\mathrm{N}^{*}\right)\right|$ are equal to $17 \%$ and $3 \%$ obtained for the PM, and $0.6 \%$ and $3 \%$ for PVCMM, respectively, confirming thus the use of $\mathrm{N}^{*}$ for the effective density of free electrons given in the conduction band when $\mathrm{N}>\mathrm{N}_{\mathrm{c}(\mathrm{d})}$, given in Eq. (43). 
In the $\mathrm{P}(\mathrm{As})-\mathrm{Si}$ systems at $\mathrm{T}=4.2 \mathrm{~K}, \mathrm{~N}_{\mathrm{c}(\mathrm{P})}=3.52 \times$ $10^{18} \mathrm{~cm}^{-3}$ and $\mathrm{N}_{\mathrm{c}(\mathrm{As})}=8.58 \times 10^{18} \mathrm{~cm}^{-3}$, as given in Table 1, the numerical results of resistivity $\rho\left(\mathrm{N}^{*}\right)=1$ / $\sigma\left(\mathrm{N}^{*}\right), \sigma\left(\mathrm{N}^{*}\right)$ being determined in Eq. (63) for the PVCMM and in Eq. (68) for the PM, are tabulated in Table 9, in which their absolute relative errors $\mid$ REs $\mid$, calculated using the data obtained by Chapman et al. [54], are also included, suggesting that the maximal $|\mathrm{REs}|$ of $\rho\left(\mathrm{N}^{*}\right)$ are equal to $10 \%$ (11\%), obtained respectively for the PM (PVCMM).

Table 9. In the $P(A s)-S i$ systems at $T=4.2 \mathrm{~K}$, the numerical results of resistivity $\rho\left(N^{*}\right)$, obtained for the PM and $P V C M M$ and expressed in $\left[10^{-4}\right.$ ohm $\times$ cm], are tabulated in this Table $I X$, in which their absolute relative errors $|R E s|$, calculated using the data obtained by Chapman et al. [54], are also included, suggesting that the maximal $|R E s|$ of $\rho\left(N^{*}\right)$ are equal to $10 \%(11 \%)$, obtained respectively for the PM (PVCMM).

\begin{tabular}{|c|c|c|c|c|c|c|c|}
\hline $\mathrm{N}\left(10^{19} \mathrm{~cm}^{-3}\right)$ & 1.1 & 1.6 & 2.7 & 3.9 & 5 & 7 & 13 \\
\hline$\rho_{\text {Exp. }}($ donor $)$ & $33(\mathrm{P})$ & $23(\mathbf{P})$ & $13(\mathbf{P})$ & $9.4(\mathrm{P})$ & 13 (As) & $6(\mathbf{P})$ & $3.8(\mathrm{P})$ \\
\hline \multicolumn{8}{|c|}{ In the PM, the results of $\rho$ are accompanied by their AREs as: } \\
\hline$\rho\left(\mathrm{N}^{*}\right)(|\mathrm{RE}|)$ & $35.8(0.08)$ & $23.9(0.04)$ & $14.5(0.10)$ & $10.4(0.10)$ & $13.9(0.07)$ & $6.2(0.03)$ & $3.6(0.05)$ \\
\hline \multicolumn{8}{|c|}{ In the PVCMM, the results of $\rho$ are accompanied by their AREs as: } \\
\hline$\rho\left(N^{*}\right)(|R E|)$ & $29.5(0.10)$ & $20.5(0.11)$ & $13.2(0.01)$ & $9.9(0.05)$ & $12.3(0.06)$ & $6.5(0.08)$ & $4.2(0.11)$ \\
\hline
\end{tabular}

The underlined $|R E|$-value is the maximal one.

In the P-Si system at $\mathrm{T}=77 \mathrm{~K}$ and for $\mathrm{N}_{\mathrm{c}(\mathrm{P})}=3.52 \times$ $10^{18} \mathrm{~cm}^{-3}$, the numerical results of conductivity $\sigma\left(\mathrm{N}^{*}\right)$, obtained respectively from Eqs. $(63,68)$ for the PVCMM and PM, are tabulated in this Table 10, in which their absolute relative errors $|\mathrm{REs}|$, calculated using the $\sigma$-data obtained by Finetti and Mazzone [60], are also included. This indicates that the maximal $|\mathrm{RE}|$ of $\sigma\left(\mathrm{N}^{*}\right)$ are equal to $12 \%$ and $14 \%$ for PM and PVCMM, respectively.

Table 10. In the P-Si system at $T=77 \mathrm{~K}$, the numerical results of conductivity $\sigma\left(N^{*}\right)$, obtained respectively for the PVCMM and PM, are tabulated in this Table $X$, in which their absolute relative errors $|R E s|$, calculated using the $\sigma$-data obtained by Finetti and Mazzone [60], are also included, indicating that its maximal $|R E s|$ are equal to $12 \%$ and $14 \%$ for PM and PVCMM, respectively.

\begin{tabular}{llll}
\hline $\mathbf{N}\left(10^{19} \mathrm{~cm}^{-3}\right)$ & 1.85 & 5.55 & $\mathbf{8 . 6 5}$ \\
\hline$\sigma_{\text {data }}\left(\mathrm{ohm}^{-1} \times \mathbf{c m}^{-1}\right)$ & 559 & 1500 & $\mathbf{2 0 0 0}$ \\
\hline In the PM, the results of $\sigma$ are accompanied by their $\mid$ REs $\mid$ as: \\
\hline
\end{tabular}

\begin{tabular}{llll}
\hline $\mathbf{N}\left(\mathbf{1 0}^{\mathbf{1 9}} \mathbf{~ c m}^{-\mathbf{3}}\right)$ & $\mathbf{1 . 8 5}$ & $\mathbf{5 . 5 5}$ & $\mathbf{8 . 6 5}$ \\
\hline $\boldsymbol{\sigma}_{\text {data }}\left(\mathbf{o h m ^ { - 1 }} \times \mathbf{c m}^{\mathbf{- 1}}\right)$ & $\mathbf{5 5 9}$ & $\mathbf{1 5 0 0}$ & $\mathbf{2 0 0 0}$ \\
\hline$\sigma\left(\mathrm{N}^{*}\right)(|\mathrm{RE}|)$ & $520(0.07)$ & $1339(0.12)$ & $1962(0.02)$ \\
In the PVCMM, the results of $\sigma$ are accompanied by their $|\mathrm{REs}|$ as: \\
$\sigma\left(\mathrm{N}^{*}\right)(|\mathrm{RE}|)$ & $575(0.03)$ & $1318(0.14)$ & $1799(0.11)$ \\
\hline
\end{tabular}

The underlined $|R E|$-value is the maximal one.

As noted above, in the following, we will only present the numerical results of various electrical and thermoelectric functions obtained in the PM, since those obtained in the PVCMM can also be investigated by a same treatment.

In the degenerate $\mathrm{d}-\mathrm{Si}$ systems at $77 \mathrm{~K}$, the numerical results of resistivity $\rho\left(\mathrm{N}^{*}, \mathrm{~T}, \mathrm{r}_{\mathrm{d}}\right)=1 / \sigma\left(\mathrm{N}^{*}, \mathrm{~T}, \mathrm{r}_{\mathrm{d}}\right)$, $\sigma\left(N^{*}, T, r_{d}\right)$ being calculated from Eq. (68), and those of mobility $\mu\left(\mathrm{N}^{*}, \mathrm{~T}, \mathrm{r}_{\mathrm{d}}\right)$ and Hall mobility $\mu_{\mathrm{H}}\left(\mathrm{N}^{*}, \mathrm{~T}, \mathrm{r}_{\mathrm{d}}\right)$ obtained respectively from Eqs. $(67,71)$, are tabulated in Tables 11 and 12.

Table 11. In the degenerate $d$-Si systems at $77 \mathrm{~K}$, the numerical results of resistivity $\rho\left(N^{*}, T, r_{d}\right)$ are expressed in $10^{-4}$ ohm $\times \mathrm{cm}$.

\begin{tabular}{|c|c|c|c|c|c|c|c|c|}
\hline Donor & $\mathbf{S b}$ & $\mathbf{P}$ & As & Bi & $\mathbf{T i}$ & Te & Se & $\mathbf{S}$ \\
\hline$N\left(10^{19} \mathrm{~cm}^{-3}\right)$ & $\rho$ & $\rho$ & $\rho$ & $\rho$ & $\rho$ & $\rho$ & $\rho$ & $\rho$ \\
\hline 3 & 11.58 & 12.68 & 22.37 & 25.92 & & & & \\
\hline 6 & 6.40 & 6.98 & 11.56 & 12.97 & & & & \\
\hline 10 & 4.12 & 4.49 & 7.32 & 8.14 & & & & \\
\hline 40 & 1.22 & 1.33 & 2.18 & 2.41 & 5.75 & 12.41 & 24.69 & 27.23 \\
\hline 70 & 0.74 & 0.81 & 1.33 & 1.48 & 3.48 & 6.70 & 10.22 & 10.70 \\
\hline 100 & 0.53 & 0.58 & 0.97 & 1.08 & 2.54 & 4.74 & 6.81 & 7.06 \\
\hline
\end{tabular}

Table 12. In the degenerate $d$-Si systems at $77 \mathrm{~K}$, the numerical results of mobility $\mu\left(N^{*}, T, r_{d}\right)$ and Hall mobility $\mu_{H}\left(N^{*}, T, r_{d}\right)$, both expressed in $\left(\frac{\text { cm }{ }^{2}}{V \text {.sec }}\right)$ and obtained respectively from Eqs. $(67,71)$, are tabulated here. This indicates that $\mu_{H}=\mu$ at $N=10^{21} \mathrm{~cm}^{-3}$.

\begin{tabular}{|c|c|c|c|c|c|c|c|c|}
\hline Donor & Sb & $\mathbf{P}$ & As & $\mathbf{B i}$ & $\mathbf{T i}$ & $\mathrm{Te}$ & $\mathrm{Se}$ & $\mathbf{S}$ \\
\hline $\mathrm{N}\left(10^{19} \mathrm{~cm}^{-3}\right)$ & $\boldsymbol{\mu}\left(\boldsymbol{\mu}_{\mathrm{H}}\right)$ & $\boldsymbol{\mu}\left(\boldsymbol{\mu}_{\mathrm{H}}\right)$ & $\boldsymbol{\mu}\left(\boldsymbol{\mu}_{\mathrm{H}}\right)$ & $\boldsymbol{\mu}\left(\boldsymbol{\mu}_{\mathrm{H}}\right)$ & $\boldsymbol{\mu}\left(\boldsymbol{\mu}_{\mathrm{H}}\right)$ & $\boldsymbol{\mu}\left(\boldsymbol{\mu}_{\mathrm{H}}\right)$ & $\boldsymbol{\mu}\left(\boldsymbol{\mu}_{\mathrm{H}}\right)$ & $\boldsymbol{\mu}\left(\boldsymbol{\mu}_{\mathrm{H}}\right)$ \\
\hline 3 & $200(228)$ & $186(213)$ & $130(155)$ & $123(148)$ & & & & \\
\hline 6 & $171(180)$ & $158(167)$ & $105(111)$ & $97(103)$ & & & & \\
\hline 10 & $156(160)$ & 144 (148) & $93(96)$ & $85(88)$ & & & & \\
\hline 40 & 129 (129) & 118 (119) & $73(74)$ & $66(67)$ & $31(31)$ & $20(20)$ & $18(18)$ & $18(18)$ \\
\hline 70 & $121(122)$ & $111(111)$ & $68(68)$ & $61(61)$ & $28(28)$ & $17(17)$ & $14(14)$ & $14(14)$ \\
\hline 100 & $117(117)$ & 107 (107) & $65(65)$ & $59(59)$ & $26(26)$ & $15(15)$ & $12(12)$ & $12(12)$ \\
\hline
\end{tabular}

Table 11 indicates that (i) at a given $r_{\mathrm{d}}$, the resistivity decreases with increasing $\mathrm{N}$, and (ii) at a given $\mathrm{N}$, it increases with increasing $r_{\mathrm{d}}$. That means: $\rho\left(\mathrm{r}_{\mathrm{Sb}}\right)<\rho\left(\mathrm{r}_{\mathrm{P}}\right)<\rho\left(\mathrm{r}_{\mathrm{As}}\right)<$ $\cdots<\rho\left(\mathrm{r}_{\mathrm{Se}}\right)<\rho\left(\mathrm{r}_{\mathrm{S}}\right)$, in good agreement with the observations by Logan et al. [53].
Table 12 suggests that (i) for a given $r_{d}$, the mobility and the Hall mobility decrease with increasing $\mathrm{N}$, (ii) for given $\mathrm{N}$, they decrease with increasing $r_{\mathrm{d}}$, since $\mu$ (or $\mu_{\mathrm{H}}$ ) is proportional to $\sigma \equiv 1 / \rho$, where $\rho$ increases with increasing $r_{d}$, as observed in above Table XI, (iii) for given $N$ and $r_{d}$, 
$\mu_{\mathrm{H}}>\mu$, and finally $\mu_{\mathrm{H}}=\mu$ for $\mathrm{N}=10^{21} \mathrm{~cm}^{-3}$, since the Hall factor $r_{H}$ is equal to 1 , as that given in the effective electron gas [66].

Now, in degenerate (d)-Si systems at $77 \mathrm{~K}$, from the generalized Einstein relation [62-67], it is interesting to present in following Table 13 our numerical results of diffusion coefficients: $D\left(N^{*}, T, r_{d}\right), D_{o}\left(N^{*}, T, r_{d}\right)$, and $\mathrm{D}_{1}\left(\mathrm{~N}^{*}, \mathrm{~T}, \mathrm{r}_{\mathrm{d}}\right)$, determined respectively in Eqs. (A15, A16, A17) of the Appendix $C$, being related to the mobility $\mu\left(N^{*}, T, r_{d}\right)$ given in Eq. (67).

Table 13. In degenerate (d)-Si systems at $77 \mathrm{~K}$, our numerical results of diffusion coefficients $\left(\frac{\mathrm{cm}^{2}}{\mathrm{sec}}\right)$ : $D, D_{o}$, and $D_{1}$ determined respectively in Eqs. (A15, A16, A17) of the Appendix $C$, being related to the mobility $\mu$ determined in Eq. (67), are tabulated here.

\begin{tabular}{|c|c|c|c|c|c|c|c|c|}
\hline Donor & $\mathbf{S b}$ & $\mathbf{P}$ & As & $\mathbf{B i}$ & $\mathbf{T i}$ & Te & Se & $\mathbf{S}$ \\
\hline $\mathbf{N}$ & D $\left(D_{1}\right)$ & $\mathrm{D}\left(\mathrm{D}_{1}\right)$ & $\mathrm{D}\left(\mathrm{D}_{1}\right)$ & D $\left(D_{1}\right)$ & D $\left(D_{1}\right)$ & $\mathrm{D}\left(\mathrm{D}_{1}\right)$ & $\mathrm{D}\left(\mathrm{D}_{1}\right)$ & D $\left(D_{1}\right)$ \\
\hline 3 & 5.795 & $(5.793)$ & 5.290 & $(5.288)$ & 3.074 & (3.069) & 2.701 & $(2.695)$ \\
\hline 6 & 8.264 & $(8.266)$ & 7.559 & $(7.560)$ & 4.539 & (4.539) & 4.049 & $(4.049)$ \\
\hline 10 & 10.873 & $(10.876)$ & 9.947 & $(9.949)$ & 6.036 & $(6.037)$ & 5.415 & $(5.416)$ \\
\hline 40 & $23.587(23.593)$ & $21.523(21.528)$ & $13.004(13.007)$ & 11.697 (11.699) & 4.808 (4.809) & $2.295(2.296)$ & $1.282(1.282)$ & 1.187 (1.187) \\
\hline 70 & $32.576(32.583)$ & $29.684(29.691)$ & $17.809(17.813)$ & $16.000(16.004)$ & $6.629(6.630)$ & $3.433(3.434)$ & $2.310(2.310)$ & $2.216(2.217)$ \\
\hline 100 & $40.129(40.138)$ & $36.535(36.544)$ & $21.814(21.819)$ & $19.579(19.584)$ & 8.097 (8.099) & $4.293(4.294)$ & $3.014(3.015)$ & $2.911(2.912)$ \\
\hline 100 & 40.127 & 36.534 & 21.812 & 19.578 & 8.096 & 4.292 & 3.013 & 2.910 \\
\hline
\end{tabular}

Table 13 indicates that: (i) for a given $r_{d}, D$ and $D_{1}$ increase with increasing $N$, (ii) for a given $N$, since $D, D_{1}$ and $\mu$, being expressed in terms of $\sigma \equiv 1 / \rho$, where $\rho$ increases with increasing $r_{d}$, as observed in above Table 11, our results of D and $D_{1}$ thus decrease with increasing $r_{d}$, due to the donor-size effect, and finally (iii) for $N=10^{21} \mathrm{~cm}^{-3}$, all the results of $D_{1}, D_{1}$ and $\mathrm{D}_{\mathrm{o}}$ are found to be almost the same, suggesting that the asymptotic behaviors of $\mathrm{D}$ and $\mathrm{D}_{1}$ are correct.

\subsection{Behaviors of Electrical Functions Obtained for $\mathbb{E} \leq 0$}

First of all, it should be noted from Eqs. $(26,68)$ that for any $\mathbb{E}$ the conductivity can be rewritten in a general form as

$$
\sigma_{\mathrm{PM}}\left(\mathbb{E}, r_{\mathrm{d}}\right) \equiv \sigma\left(\mathbb{E}, r_{\mathrm{d}}\right) \simeq \sigma_{\mathrm{o}}\left(\mathbb{E}_{\mathrm{Fno}}\right) \times\left\{\frac{\left\langle\mathrm{E}_{\mathrm{k}}^{2}\right\rangle_{\mathrm{KIM}}}{\mathbb{E}_{\mathrm{Fno}}^{2}}+\Delta_{\mathrm{PM}} \times \frac{\left\langle\mathrm{E}_{\mathrm{k}}^{3 / 2}\right\rangle_{\mathrm{KIM}}}{\mathbb{E}_{\mathrm{Fno}}^{3 / 2}}\right\}
$$

where $\sigma_{\mathrm{o}}\left(\mathbb{E}_{\mathrm{Fno}}\right)=\frac{(0.85)^{2}}{\pi} \times \frac{\mathrm{q}^{2} \times \mathrm{k}_{\mathrm{Fn}}}{\hbar} \times \frac{\mathrm{a}_{\mathrm{B}}}{\mathrm{k}_{\mathrm{Fn}}^{-1}} \times \frac{\mathrm{k}_{\mathrm{Sn}}^{-1}}{\mathrm{k}_{\mathrm{Fn}}^{-1}} \times \sqrt{\frac{\mathbb{E}_{\mathrm{Fno}}}{\eta_{\mathrm{n}}}}$ is proportional to $\mathbb{E}_{\mathrm{Fno}}^{2}$, and $\left\langle\mathrm{E}_{\mathrm{k}}^{\mathrm{a}-\frac{1}{2}}\right\rangle_{\mathrm{KIM}}$ is determined in Eq. (26) for a $=$ $5 / 2$ and $\mathrm{a}=2$, respectively.

Here, as $\mathbb{E} \leq 0$, using the functions: $\mathrm{H}_{\mathrm{n}}, \mathrm{K}_{\mathrm{n}}$ and $\mathrm{F}_{\mathrm{n}}$, given respectively in Eqs. (26-28) for a=5/2 and 2, the conductivity, given in Eq. (72), is now rewritten by

$$
\sigma\left(v_{\mathrm{n}}, \mathrm{r}_{\mathrm{d}}\right) \simeq \frac{\sigma_{\mathrm{o}}\left(\mathbb{E}_{\mathrm{Fno}}\right)}{\sqrt{2 \pi}} \times\left\{\frac{\Gamma(3) \times \beta\left(\frac{5}{2}\right)}{\mathrm{A}_{\mathrm{n}}^{2}} \times \mathrm{F}_{\mathrm{n}}(\mathrm{a}=5 / 2)+\Delta_{\mathrm{PM}} \times \frac{\Gamma(5 / 2) \times \beta(2)}{\mathrm{A}_{\mathrm{n}}^{3 / 2}} \times \mathrm{F}_{\mathrm{n}}(\mathrm{a}=2)\right\}, \mathrm{A}_{\mathrm{n}} \equiv \frac{\mathbb{E}_{\mathrm{Fno}}}{\eta_{\mathrm{n}}} .
$$

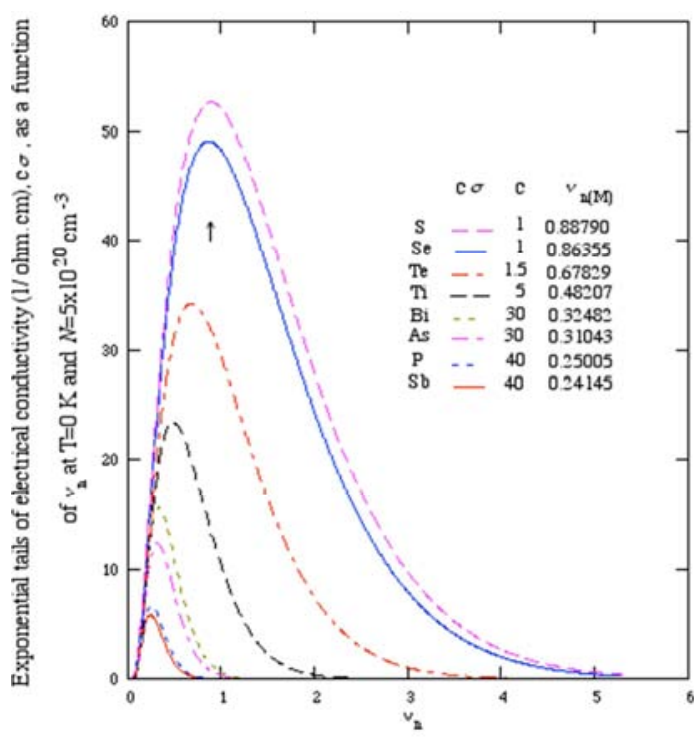

Figure 7. Our results of electrical conductivity $\sigma\left(v_{n}, r_{d}\right)$ increase with increasing $r_{d}$ for a given $v_{n}$, due to the donor-size effect, and present the maxima at $v_{n}=v_{n(M)}$ and go to zero as $v_{n} \rightarrow 0$ and $\infty$.
So, our numerical results of exponential tails of the electrical conductivity $\sigma\left(v_{\mathrm{n}}, \mathrm{r}_{\mathrm{d}}\right)$ at $0 \mathrm{~K}$ and for $\mathrm{N}=5 \times$ $10^{20} \mathrm{~cm}^{-3}$, calculated using Eq. (73), are plotted in Figure 7, as functions of $v_{\mathrm{n}}$.

Figure 7 shows that:

(i) our results of $\sigma\left(v_{n}, r_{d}\right)$ increase with increasing $r_{d}$ for a given $v_{\mathrm{n}}$, due to the donor-size effect, and

(ii) present the maxima at $v_{\mathrm{n}}=v_{\mathrm{n}(\mathrm{M})}$ and go to zero as $v_{\mathrm{n}} \rightarrow 0$ and $\infty$, being found to be in good agreement with theoretical results obtained by Lifshitz [18], Friedberg and Luttinger [20], our results given in Eq. (A.3) of the Appendix $\mathrm{A}$, and in particular with an asymptotic form for exponential conduction-band tail, obtained for $0 \lesssim v_{\mathrm{n}} \lesssim \infty$, by Halperin and Lax [19], using the minimum counting methods.

Further, our numerical results of the function $\ln \left[\sigma\left(v_{n}, r_{d}\right)\right]<0$, which can take its approximate form as: $\ln \left[\sigma\left(v_{\mathrm{n}}, \mathrm{r}_{\mathrm{d}}\right)\right] \simeq \mathrm{AF}\left(v_{\mathrm{n}}, \mathrm{r}_{\mathrm{d}}, v_{1}, v_{2}, \mathrm{z}, \mathrm{f}\right)=\mathrm{e}\left(\mathrm{r}_{\mathrm{d}}, v_{1}, v_{2}, \mathrm{z}\right) \times$ $v_{\mathrm{n}}^{\mathrm{z}}+\mathrm{f}<0$, are evaluated in small $v_{\mathrm{n}}$-intervals: $v_{1} \leq v_{\mathrm{n}} \leq v_{2}$, using Eq. (29) and Eq. (30), being now defined as: $\mathrm{e}\left(\mathrm{r}_{\mathrm{d}}, v_{1}, v_{2}, \mathrm{z}\right) \equiv \frac{\ln \left[\sigma\left(v_{2}, \mathrm{r}_{\mathrm{d}}\right)\right]-\ln \left[\sigma\left(v_{1}, \mathrm{r}_{\mathrm{d}}\right)\right]}{v_{2}^{z}-v_{1}^{z}}$, are tabulated in Table 14. 
Table 14. In the $d$-Si systems at $T=0 \mathrm{~K}$ and for $N=5 \times 10^{20} \mathrm{~cm}^{-3}$, using the expression for electrical conductivity determined in Eq. (73), $\sigma\left(v_{n}, r_{d}\right)$, the numerical results of $\ln \left[\sigma\left(v_{n}, r_{d}\right)\right]$ and its approximate form: $A F\left(v_{n}, r_{d}, v_{1}, v_{2}, z, f\right)=e\left(r_{d}, v_{1}, v_{2}, z\right) \times v_{n}^{z}+f$, determined in Eq. (29) for small $v_{n}$-intervals: $v_{1} \leq v_{n} \leq v_{2}$, and those of absolute relative errors: $|R E| \equiv 1-\frac{A F\left(v_{n}, r_{d}, v_{1}, v_{2}, z_{f}\right)}{\ln \left[\sigma\left(v_{n}, r_{d}\right)\right]}$, are evaluated and tabulated below.

\begin{tabular}{|c|c|c|c|c|c|c|c|c|}
\hline Donor & Sb & $\mathbf{P}$ & As & $\mathbf{B i}$ & $\mathbf{T i}$ & Te & Se & $\mathbf{S}$ \\
\hline$v_{n(M)}$ & 0.24145 & 0.25005 & 0.31043 & 0.32482 & 0.48207 & 0.67829 & 0.86355 & 0.88790 \\
\hline \multicolumn{9}{|c|}{ For $1.37 \leq v_{\mathrm{n}} \leq 1.42, \mathrm{AF}=\left(\mathrm{e} \times v_{\mathrm{n}}+\mathrm{f}\right)$ is accurate to within $1.9 \times 10^{-3}$, where } \\
\hline$-\mathrm{e}$ & 17.734 & 16.287 & 9.955 & 8.926 & 3.291 & 1.330 & 0.655 & 0.597 \\
\hline$f$ & 9.234 & 8.507 & 5.708 & 5.338 & 4.140 & 4.385 & 4.602 & 4.618 \\
\hline |RE| & $1.2 \times 10^{-4}$ & $1.2 \times 10^{-4}$ & $1.0 \times 10^{-4}$ & $1.2 \times 10^{-4}$ & $1.9 \times 10^{-3}$ & $2.4 \times 10^{-4}$ & $1.2 \times 10^{-4}$ & $1.2 \times 10^{-4}$ \\
\hline \multicolumn{9}{|c|}{ For $1.28 \leq v_{\mathrm{n}} \leq 1.30, \mathrm{AF}=\left(\mathrm{e} \times v_{\mathrm{n}}{ }^{1 / 2}+\mathrm{f}\right)$ is accurate to within $1.5 \times 10^{-3}$, where } \\
\hline$-\mathrm{e}$ & 38.134 & 35.052 & 21.508 & 19.293 & 7.088 & 2.792 & 1.300 & 1.173 \\
\hline$f$ & 29.621 & 27.264 & 17.269 & 15.714 & 7.937 & 5.835 & 5.229 & 5.177 \\
\hline |RE & $4.7 \times 10-5$ & $4.8 \times 10^{-5}$ & $1.2 \times 10^{-4}$ & $4.7 \times 10^{-5}$ & $1.5 \times 10^{-3}$ & $6.2 \times 10^{-5}$ & $3.1 \times 10^{-5}$ & $1.3 \times 10^{-4}$ \\
\hline \multicolumn{9}{|c|}{ For $1.180 \leq v_{\mathrm{n}} \leq 1.185, \mathrm{AF}=\left(\mathrm{e} \times v_{\mathrm{n}}{ }^{1 / 3}+\mathrm{f}\right)$ is accurate to within $9.4 \times 10^{-4}$, where } \\
\hline$-\mathrm{e}$ & 53.080 & 48.832 & 30.060 & 26.972 & 9.829 & 3.722 & 1.582 & 1.400 \\
\hline$f$ & 44.192 & 40.703 & 25.620 & 23.212 & 10.606 & 6.726 & 5.482 & 5.375 \\
\hline |RE & $3.2 \times 10^{-5}$ & $2.7 \times 10^{-5}$ & $7.1 \times 10^{-5}$ & $9.0 \times 10^{-5}$ & $9.4 \times 10^{-4}$ & $1.5 \times 10^{-4}$ & $5.5 \times 10^{-5}$ & $1.7 \times 10^{-5}$ \\
\hline \multicolumn{9}{|c|}{ For $v_{\mathrm{n}(\mathrm{M})}<1.155 \leq v_{\mathrm{n}} \leq 1.165, \mathrm{AF}=\left(\mathrm{e} \times v_{\mathrm{n}}^{1 / 4}+\mathrm{f}\right)$ is accurate to within $1.4 \times 10^{-3}$, where } \\
\hline$-\mathrm{e}$ & 69.838 & 64.260 & 39.580 & 35.514 & 12.909 & 4.837 & 2.003 & 1.761 \\
\hline$f$ & 60.894 & 56.079 & 35.109 & 31.727 & 13.674 & 7.834 & 5.898 & 5.731 \\
\hline |RE| & $4.1 \times 10^{-5}$ & $1.8 \times 10^{-5}$ & $6.9 \times 10^{-5}$ & $6.7 \times 10^{-5}$ & $1.4 \times 10^{-3}$ & $6.8 \times 10^{-5}$ & $1.8 \times 10^{-5}$ & $7.9 \times 10^{-5}$ \\
\hline \multicolumn{9}{|c|}{ For $0.110 \leq v_{\mathrm{n}} \leq 0.115<v_{\mathrm{n}(\mathrm{M})}, \mathrm{AF}=\left(\mathrm{e} \times v_{\mathrm{n}}^{1 / 4}+\mathrm{f}\right)$ is accurate to within $2.1 \times 10^{-3}$, where } \\
\hline e & 26.262 & 27.342 & 31.423 & 31.800 & 28.839 & 23.832 & 21.614 & 21.434 \\
\hline$f$ & -18.507 & -19.124 & -21.180 & -21.273 & -17.859 & -13.499 & -11.563 & -11.406 \\
\hline |RE| & $2.8 \times 10^{-4}$ & $1.5 \times 10^{-4}$ & $5.3 \times 10^{-4}$ & $4.9 \times 10^{-4}$ & $8.2 \times 10^{-4}$ & $2.1 \times 10^{-3}$ & $8.3 \times 10^{-4}$ & $4.3 \times 10^{-4}$ \\
\hline \multicolumn{9}{|c|}{ For $0.088 \leq v_{\mathrm{n}} \leq 0.090, \mathrm{AF}=\left(\mathrm{e} \times v_{\mathrm{n}}{ }^{1 / 3}+\mathrm{f}\right)$ is accurate to within $4.3 \times 10^{-3}$, where } \\
\hline e & 37.452 & 38.777 & 43.541 & 43.855 & 37.449 & 29.015 & 25.442 & 25.153 \\
\hline$f$ & -21.105 & -21.729 & -23.698 & -23.724 & -19.008 & -13.555 & -11.210 & -11.021 \\
\hline |RE $\mid$ & $9.5 \times 10^{-5}$ & $1.4 \times 10^{-4}$ & $9.7 \times 10^{-5}$ & $1.6 \times 10^{-4}$ & $3.0 \times 10^{-4}$ & $4.1 \times 10^{-4}$ & $4.3 \times 10^{-3}$ & $9.5 \times 10^{-4}$ \\
\hline \multicolumn{9}{|c|}{ For $0.070 \leq v_{\mathrm{n}} \leq 0.073, \mathrm{AF}=\left(\mathrm{e} \times v_{\mathrm{n}}^{1 / 2}+\mathrm{f}\right)$ is accurate to within $1.6 \times 10^{-3}$, where } \\
\hline e & 59.884 & 62.021 & 69.660 & 70.074 & 57.026 & 41.116 & 34.641 & 34.124 \\
\hline$f$ & -21.865 & -22.520 & -24.590 & -24.595 & -18.965 & -12.661 & -10.030 & -9.820 \\
\hline$|\mathrm{RE}|$ & $3.6 \times 10^{-4}$ & $3.9 \times 10^{-4}$ & $4.5 \times 10^{-4}$ & $7.5 \times 10^{-4}$ & $8.9 \times 10^{-4}$ & $6.1 \times 10^{-4}$ & $1.6 \times 10^{-3}$ & $9.2 \times 10^{-4}$ \\
\hline \multicolumn{9}{|c|}{ For $0.061 \leq v_{\mathrm{n}} \leq 0.064, \mathrm{AF}=\left(\mathrm{e} \times v_{\mathrm{n}}+\mathrm{f}\right)$ is accurate to within $1.5 \times 10^{-3}$, where } \\
\hline e & 162.658 & 168.842 & 191.433 & 192.696 & 152.729 & 104.514 & 85.401 & 83.890 \\
\hline f & -17.234 & -17.750 & -19.349 & -19.334 & -14.409 & -9.005 & -6.774 & -6.597 \\
\hline$|\mathrm{RE}|$ & $5.9 \times 10^{-4}$ & $6.7 \times 10^{-4}$ & $7.3 \times 10^{-4}$ & $6.9 \times 10^{-4}$ & $8.3 \times 10^{-4}$ & $9.3 \times 10^{-4}$ & $1.1 \times 10^{-3}$ & $1.5 \times 10^{-3}$ \\
\hline \multicolumn{9}{|c|}{ For $0.054 \leq v_{\mathrm{n}} \leq 0.056, \mathrm{AF}=\left(\mathrm{e} \times v_{\mathrm{n}}^{2}+\mathrm{f}\right)$ is accurate to within $9.9 \times 10^{-4}$, where } \\
\hline e & 2147.35 & 2236.99 & 2576.10 & 2597.50 & 2013.29 & 1302.33 & 1027.98 & 1006.55 \\
\hline$f$ & -15.033 & -15.491 & -16.923 & -16.906 & -12.330 & -7.329 & -5.282 & -5.120 \\
\hline |RE & $5.4 \times 10^{-4}$ & $5.2 \times 10^{-4}$ & $6.5 \times 10^{-4}$ & $6.2 \times 10^{-4}$ & $6.6 \times 10^{-4}$ & $8.6 \times 10^{-4}$ & $8.8 \times 10^{-4}$ & $9.9 \times 10^{-4}$ \\
\hline
\end{tabular}

The underlined $|R E|$-value is the maximal one for each donor-Si system.

Table 14 suggests that: (i) our results of $\operatorname{AF}\left(v_{n}, r_{d}, v_{1}, v_{2}, z, f\right)$ given for $(\mathrm{z}=1)$-exponent agree with the Urbach law obtained from linear exponential conductionband tail-behaviors by some workers [21, 29, 30, 37], (ii) ours for $(\mathrm{z}=1 / 2)$-exponent and $v_{\mathrm{n}}>v_{\mathrm{n}(\mathrm{M})}$ agree with other theoretical results $[19,37]$, and finally (iii) ours for $(z=1 / 3$, 1/4)-exponents when $v_{\mathrm{n}}>v_{\mathrm{n}(\mathrm{M})}$, and for $(\mathrm{z}=1 / 4,1 / 3,1 / 2,1$, 2)-exponents when $v_{\mathrm{n}}<v_{\mathrm{n}(\mathrm{M})}$ may thus be new.

Finally, our numerical results of energy parameter, $\mathbb{E}_{\text {no }}\left(\mathrm{N} ; \mathrm{r}_{\mathrm{d}}\right)$, obtained in the small interval: $1.37 \leq v_{\mathrm{n}} \leq 1.42$, using Eq. (31), are plotted as functions of $\mathrm{N}$ in Figures 8a and $8 \mathrm{~b}$, indicating that, for a given $\mathrm{N}, \mathbb{E}_{\mathrm{no}}$ increases with 
increasing $r_{d}$-values, due to the donor-size effect.

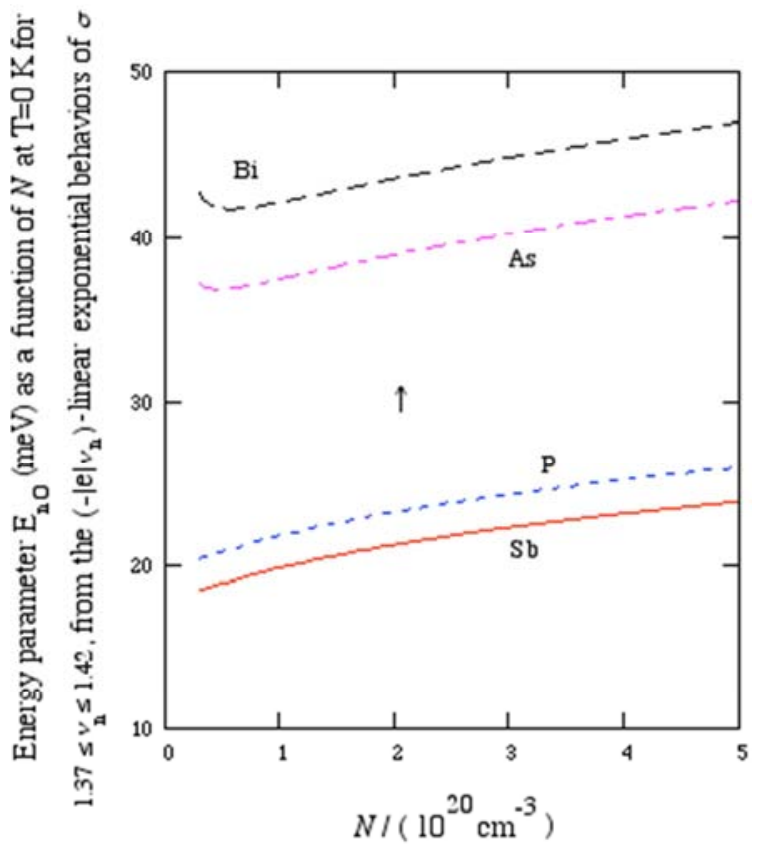

FIG. 8a

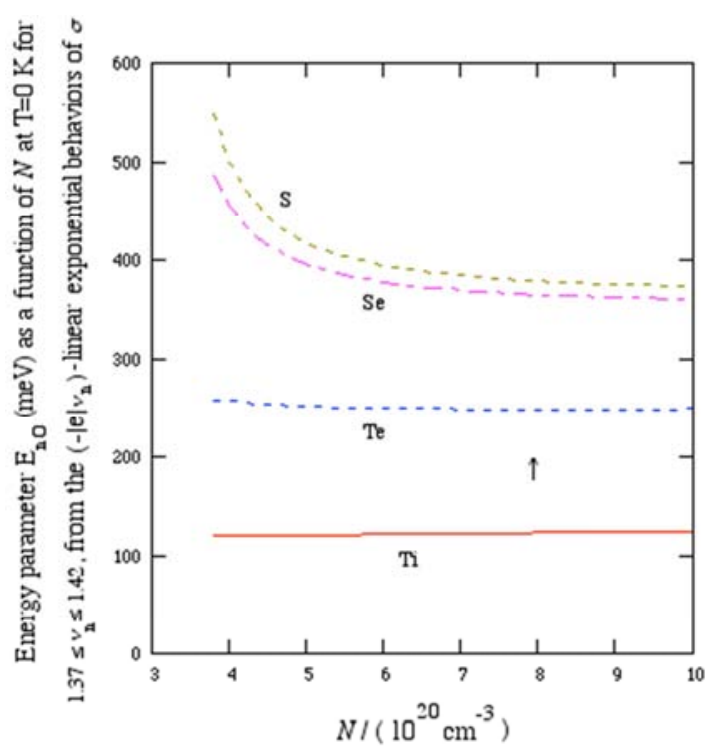

FIG. 8b

Figures 8. Our results of energy parameter, $\mathbb{E}_{n o}\left(N ; r_{d}\right)$, are plotted as functions of $N$, indicating that, for a given $N, \mathbb{E}_{n o}$ increases with increasing $r_{d}$-values, due to the donor-size effect.

\section{Thermoelectric Properties}

When the electron-electron and electron-phonon interactions are neglected, the Kubo formulae for the thermal transport coefficients [51], derived by very general arguments of Luttinger [55], are found to be reduced to the Greenwood ones [52]. Then, the phenomenological equations are written as [58]

$$
\vec{J}(\vec{r})=L^{(1)} \times \vec{\varepsilon}+L^{(2)} \times T \times \vec{\nabla}\left(\mathrm{T}^{-1}\right),
$$

$$
\overrightarrow{\mathrm{J}}(\overrightarrow{\mathrm{r}})=\mathrm{L}^{(3)} \times \vec{\varepsilon}+\mathrm{L}^{(4)} \times \mathrm{T} \times \vec{\nabla}\left(\mathrm{T}^{-1}\right),
$$

where $\vec{J}$ is the electric current density, $\overrightarrow{J^{\mathbb{E}}}$ is the energy current, $\vec{\varepsilon}$ is the electric field, and $\mathrm{L}^{(\mathrm{i})}$ is the transport coefficient determined in an isotropic system. Now, using the average of $\left\langle\mathbb{E}^{\mathrm{p}}\right\rangle_{\mathrm{FDDF}} \equiv \mathrm{G}_{\mathrm{p}}(\mathrm{y}) \times \mathbb{E}_{\mathrm{Fno}}^{\mathrm{p}}$, where the expressions for $\mathrm{G}_{\mathrm{p}}(\mathrm{y}), \mathrm{y}=\frac{\pi \mathrm{k}_{\mathrm{B}} \mathrm{T}}{\mathbb{F}_{\mathrm{Fn}}} \simeq \frac{\pi \mathrm{k}_{\mathrm{B}} \mathrm{T}}{\mathbb{E}_{\mathrm{Fno}}}$, are determined in Eq. (34) and given in Table III, calculated using the Fermi-Dirac distribution function (FDDF), and using also the expression for electrical conductivity as a function of $\mathbb{E}$, derived from Eq. (72) for $\mathbb{E} \geq 0$, as

$$
\sigma\left(\mathbb{E}, r_{\mathrm{d}}\right) \simeq \sigma_{\mathrm{o}}\left(\mathbb{E}_{\mathrm{Fno}}\right)\left\{\frac{\mathbb{E}^{2}}{\mathbb{E}_{\mathrm{Fno}}^{2}}+\Delta_{\mathrm{PM}} \times \frac{\mathbb{E}^{3 / 2}}{\mathbb{E}_{\text {Fno }}^{3 / 2}}\right\},
$$

the Onsager relations are found to be given as follows.

First, one has $[58,61]$

$$
\begin{gathered}
\mathrm{L}^{(1)} \equiv\left\langle\sigma\left(\mathbb{E}, r_{\mathrm{d}}\right)\right\rangle_{\mathrm{FDDF}}=\sigma_{\mathrm{o}}\left(\mathbb{E}_{\mathrm{Fno}}\right)\left\{\frac{\left\langle\mathbb{E}^{2}\right\rangle_{\mathrm{FDDF}}}{\mathbb{E}_{\mathrm{Fno}}^{2}}+\Delta_{\mathrm{PM}} \times \frac{\left\langle\mathbb{E}^{3 / 2}\right\rangle_{\mathrm{FDDF}}}{\mathbb{E}_{\mathrm{Fno}}^{3 / 2}}\right\}, \\
=\sigma_{\mathrm{o}}\left(\mathbb{E}_{\mathrm{Fno}}\right)\left\{\mathrm{G}_{2}(\mathrm{y})+\Delta_{\mathrm{PM}} \times \mathrm{G}_{\frac{3}{2}}(\mathrm{y})\right\},
\end{gathered}
$$

which is just the result obtained in Eq. (68).

Then, one gets [58]

$$
\begin{aligned}
\mathrm{L}^{(2)}=\mathrm{L}^{(3)}=- & \frac{1}{\mathrm{q}} \times\left\langle\mathbb{E} \times \sigma\left(\mathbb{E}, r_{\mathrm{d}}\right)\right\rangle_{\mathrm{FDDF}}=-\frac{\sigma_{\mathrm{o}}\left(\mathbb{E}_{\mathrm{Fno}}\right)}{\mathrm{q}} \times \\
& \left\{\mathrm{G}_{3}(\mathrm{y})+\Delta_{\mathrm{PM}} \times \mathrm{G}_{\frac{5}{2}}(\mathrm{y})\right\} .
\end{aligned}
$$

Finally, one obtains [58]

$$
\begin{gathered}
\mathrm{L}^{(4)}=\frac{1}{\mathrm{q}^{2}} \times\left\langle\mathbb{E}^{2} \times \sigma\left(\mathbb{E}, r_{\mathrm{d}}\right)\right\rangle_{\mathrm{FDDF}}=\frac{\sigma_{\mathrm{o}}\left(\mathbb{E}_{\mathrm{Fno}}\right)}{\mathrm{q}^{2}} \times\left\{\mathrm{G}_{4}(\mathrm{y})+\right. \\
\left.(\Delta \sigma)_{\mathrm{PM}} \times \mathrm{G}_{\frac{7}{2}}(\mathrm{y})\right\} .
\end{gathered}
$$

Now, from Eqs. (77-79), one can define the thermal conductivity by $[58,61]$

$$
\mathrm{K}_{\mathrm{T}}\left(\mathrm{N}^{*}, \mathrm{~T}, \mathrm{r}_{\mathrm{d}}\right) \equiv \frac{1}{\mathrm{~T}} \times\left\{\mathrm{L}^{(4)}-\frac{\left[\mathrm{L}^{(2)}\right]^{2}}{\mathrm{~L}^{(1)}}\right\} .
$$

Some remarks obtained from Eq. (80) are given as follows.

(i) First, our numerical calculation indicates that, in the degenerate (P)-Si system, for $\mathrm{N}=10^{21} \mathrm{~cm}^{-3}$ and at $\mathrm{T}=3 \mathrm{~K}$ and $300 \mathrm{~K}$, noting that at $300 \mathrm{~K}$ the degenerate temperature $\mathrm{T}_{\mathrm{D}}$ is equal to $7895 \mathrm{~K} \gg 300 \mathrm{~K}$, our results of $\mathrm{K}_{\mathrm{T}}$ are equal to $8 \times 10^{-4}$ and $0.125 \mathrm{~W} /(\mathrm{cm} . \mathrm{K})$, in good agreement with the experimental results obtained by Slack [68]: $5 \times 10^{-4}$ and between 0.1 and $0.2 \mathrm{~W} /(\mathrm{cm} . \mathrm{K})$, respectively.

(ii) Second, at $\mathrm{N}=10^{21} \mathrm{~cm}^{-3}$ and $\mathrm{T}=3 \mathrm{~K}$, the values of relative deviations between our results of $\mathrm{K}_{\mathrm{T}}\left(\mathrm{N}^{*}, \mathrm{~T}, \mathrm{r}_{\mathrm{d}}\right) /[\mathrm{T} \times$ $\left.\sigma\left(\mathrm{N}^{*}, \mathrm{~T}, \mathrm{r}_{\mathrm{d}}\right)\right]$, calculated using Eqs. (68) and (80), and the constant: $\quad \frac{\pi^{2}}{3}\left(\frac{\mathrm{k}_{\mathrm{B}}}{\mathrm{q}}\right)^{2}=2.443 \times 10^{-8}$ W. $\Omega . \mathrm{K}^{-2} \quad, \quad$ being obtained from the Wiedemann-Frank law for metals [58, 61], are tabulated in Table 15, indicating that our result (80) well verifies this law, with a precision of the order of $6.52 \times$ $10^{-7}$. 
Table 15. For $N=10^{21} \mathrm{~cm}^{-3}$ and $T=3 \mathrm{~K}$, the values of the relative deviations (RD) between our results of $\frac{K_{T}}{T \times \sigma}$ obtained in various degenerate donor-Si systems, and the constant: $\frac{\pi^{2}}{3}\left(\frac{k_{B}}{q}\right)^{2}=2.443 \times 10^{-8}$ W. $\Omega . K^{-2}$, obtained from the Wiedemann-Frank law for metals, indicating a perfect agreement between those results.

\begin{tabular}{|c|c|c|c|c|c|c|c|c|}
\hline Donor & Sb & $\mathbf{P}$ & As & $\mathbf{B i}$ & $\mathbf{T i}$ & Te & Se & $\mathbf{S}$ \\
\hline $\mathrm{RE}$ & $4.72 \times 10^{-7}$ & $-9.40 \times 10^{-8}$ & $-3.51 \times 10^{-8}$ & $3.79 \times 10^{-7}$ & $1.67 \times 10^{-7}$ & $-6.52 \times 10^{-7}$ & $-1.53 \times 10^{-7}$ & $-5.95 \times 10^{-8}$ \\
\hline
\end{tabular}

The underlined $|R E|$-value is the maximal one for each donor-Si system.

(iii) Finally, our numerical calculation shows that, in degenerate (d)-Si systems, for $\mathrm{N}=10^{21} \mathrm{~cm}^{-3}$ and in the temperature range from $\mathrm{T}=3$ to $300 \mathrm{~K}$, the maximal value of absolute deviations between $\mathrm{K}_{\mathrm{T}}\left(\mathrm{N}^{*}, \mathrm{~T}, \mathrm{r}_{\mathrm{d}}\right)$ given in Eq. (80) and its approximate form $\mathrm{K}_{\mathrm{T}}\left(\mathrm{N}^{*}, \mathrm{~T}, \mathrm{r}_{\mathrm{d}}\right) \simeq \mathrm{C}_{\mathrm{K}_{\mathrm{T}}} \times \mathrm{T}$ is found to be equal to $9.9 \times 10^{-4}$, in good agreement with our previous result $[58,61]$. Then, those are plotted in Figure 9a as functions of $\mathrm{T}$, suggesting that at a given $\mathrm{T}$ the thermal conductivity $K_{T}$ decreases with increasing $r_{d}$, due to the donor-size effect.

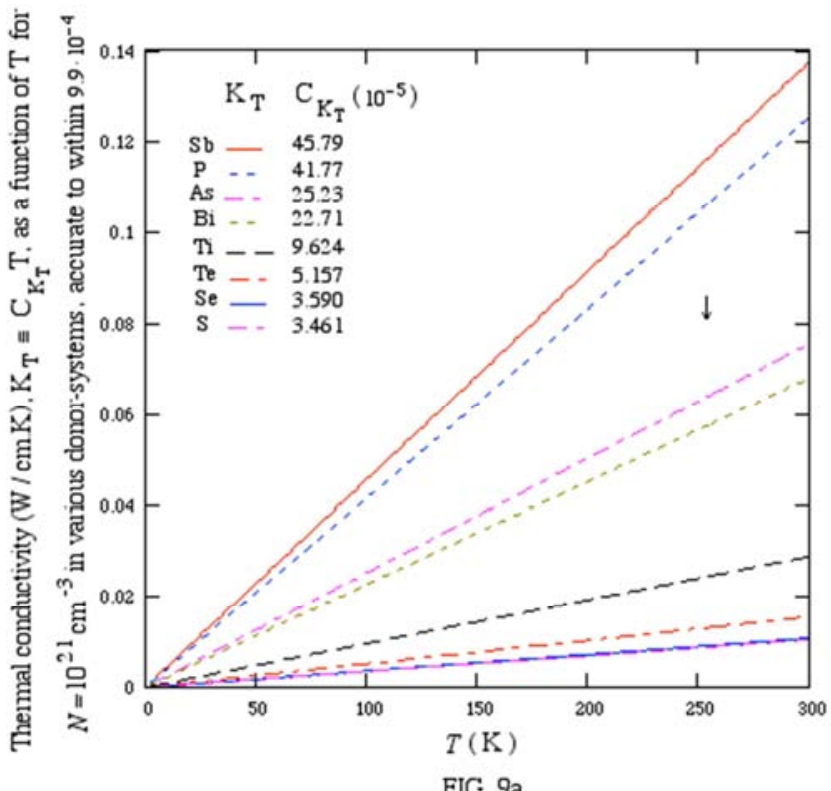

Figure 9a. Our results of $K_{T}\left(N^{*}, T, r_{d}\right) \simeq C_{K_{T}} \times T$ are plotted as functions of $T$, suggesting that at a given $T$ the thermal conductivity $K_{T}$ decreases with increasing $r_{d}$, due to the donor-size effect.

Then, from Eqs. $(77,78)$ for $\mathrm{L}^{(1)}$ and $\mathrm{L}^{(2)}$, and Eq. (D1) of the Appendix D for $\mathbb{E}_{\mathrm{Fn}}$, the absolute thermoelectric power $\mathrm{Q}$ can be defined by $[58,61]$

$$
\mathrm{Q}\left(\mathrm{N}^{*}, \mathrm{~T}, \mathrm{r}_{\mathrm{d}}\right) \equiv \frac{1}{\mathrm{~T}} \times\left\{\frac{\mathrm{L}^{(2)}}{\mathrm{L}^{(1)}}+\frac{\mathbb{E}_{\mathrm{Fn}}}{\mathrm{q}}\right\}
$$

This result (81) is a function commonly used to describe the following thermoelectric coefficients [58, 61], such as: the Thomson coefficient,

$$
\mathrm{T}_{\mathrm{S}}\left(\mathrm{N}^{*}, \mathrm{~T}, \mathrm{r}_{\mathrm{d}}\right) \equiv \mathrm{T} \times \frac{\mathrm{dQ}\left(\mathrm{N}^{*}, \mathrm{~T}, \mathrm{r}_{\mathrm{d}}\right)}{\mathrm{dT}}
$$

the Peltier coefficient,

$$
\mathrm{P}_{\mathrm{T}}\left(\mathrm{N}^{*}, \mathrm{~T}, \mathrm{r}_{\mathrm{d}}\right) \equiv-\mathrm{T} \times \mathrm{Q}\left(\mathrm{N}^{*}, \mathrm{~T}, \mathrm{r}_{\mathrm{d}}\right),
$$

the Seebeck thermoelectric potential,

$$
\mathrm{S}_{\mathrm{P}}\left(\mathrm{N}^{*}, \mathrm{~T}, \mathrm{r}_{\mathrm{d}}\right) \equiv \int_{0}^{\mathrm{T}} \mathrm{Q}\left(\mathrm{N}^{*}, \mathrm{~T}, \mathrm{r}_{\mathrm{d}}\right) \mathrm{dT},
$$

and finally the dimensionless figure of merit,

$$
\mathrm{ZT}\left(\mathrm{N}^{*}, \mathrm{~T}, \mathrm{r}_{\mathrm{d}}\right) \equiv \frac{\mathrm{T} \times \mathrm{S}_{\mathrm{P}}^{2}\left(\mathrm{~N}^{*}, \mathrm{~T}, \mathrm{r}_{\mathrm{d}}\right) \times \sigma\left(\mathrm{N}^{*}, \mathrm{~T}, \mathrm{r}_{\mathrm{d}}\right)}{\mathrm{K}_{\mathrm{T}}\left(\mathrm{N}^{*}, \mathrm{~T}, \mathrm{r}_{\mathrm{d}}\right)} .
$$

We now evaluate the above results (81-85) in the following.

In degenerate (d)-Si systems, for $\mathrm{N}=10^{21} \mathrm{~cm}^{-3}$ and in the temperature range from $\mathrm{T}=3$ to $300 \mathrm{~K}$, our numerical calculation indicates that: (i) the maximal value of absolute relative deviations between $\mathrm{Q}$ determined in Eq. (81) and its approximate form: $-\mathrm{C}_{\mathrm{Q}} \times \mathrm{T}$ is found to be equal to $6.16 \times$ $10^{-3}$, and (ii) the maximal value of absolute relative deviations between $T_{S}$ determined in Eq. (82) and its approximate form: $-\mathrm{C}_{\mathrm{S}} \times \mathrm{T}$ is equal to 0.019 . So, our numerical results of $\mathrm{Q} \simeq-\mathrm{C}_{\mathrm{Q}} \times \mathrm{T}$ and $\mathrm{T}_{\mathrm{S}} \simeq-\mathrm{C}_{\mathrm{S}} \times \mathrm{T}$ are plotted in Figures $9 \mathrm{~b}$ and $9 \mathrm{c}$, as functions of $\mathrm{T}$, respectively, suggesting that at a given $\mathrm{T}, \mathrm{Q}$ and $\mathrm{T}_{\mathrm{S}}$ both decrease with increasing $r_{d}$, due to the donor-size effect.

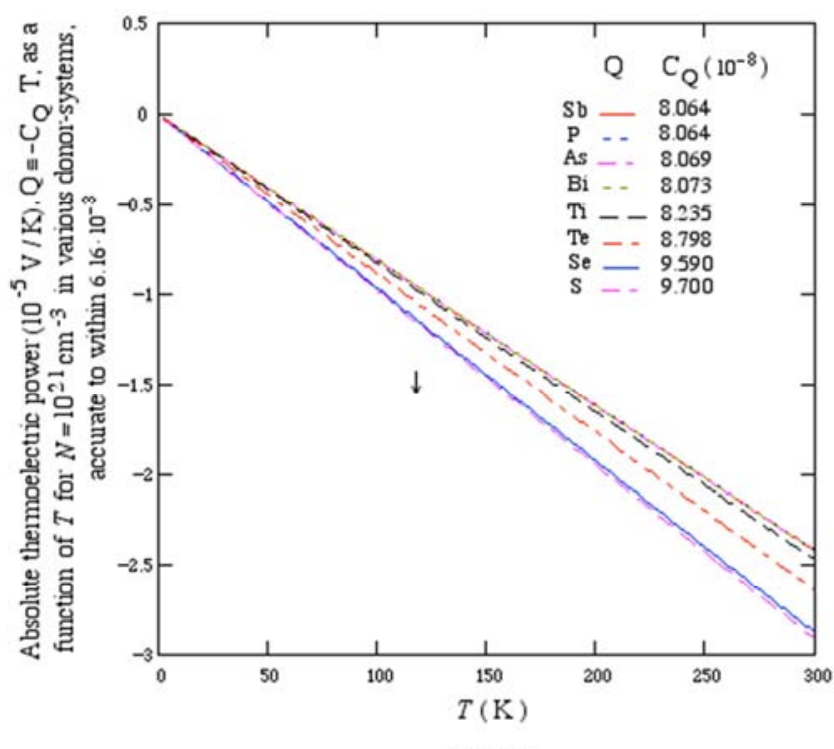

FIG. $9 \mathrm{~b}$

Figure 9b. Our results of $Q \simeq-C_{Q} \times T$ are plotted as functions of $T$, suggesting that, at a given T, $Q$ decreases with increasing $r_{d}$, due to the donor-size effect. 


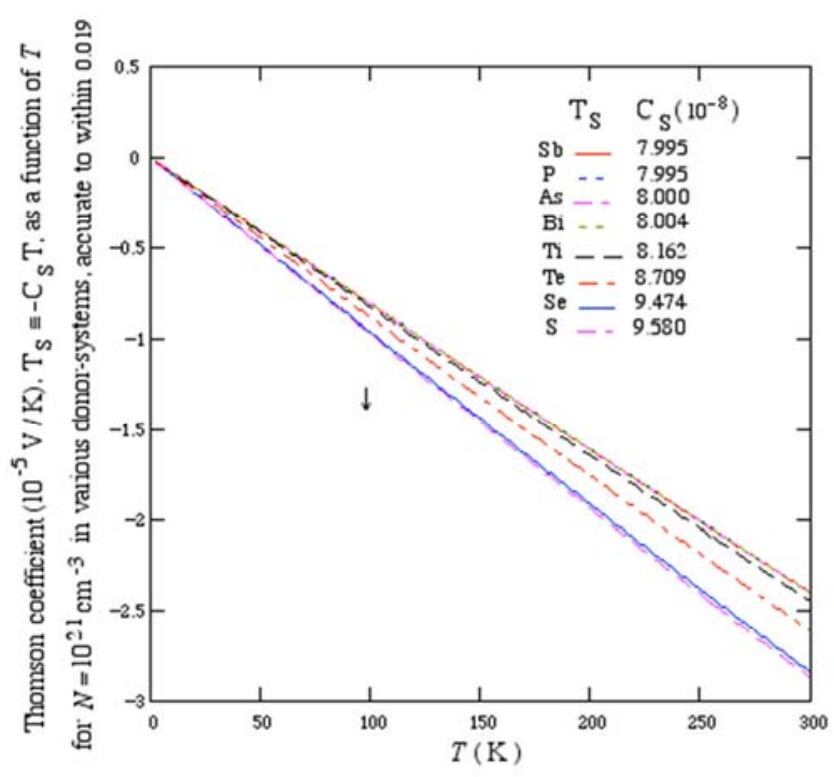

FIG. 9c

Figure 9c. Our results of $T_{S} \simeq-C_{S} \times T$ are plotted as functions of $T$, suggesting that at a given $T, T_{S}$ decreases with increasing $r_{d}$, due to the donor-size effect.

Finally, in the following Figures $9 \mathrm{~d}, 9 \mathrm{e}$ and $9 \mathrm{f}$, our numerical results of Peltier coefficient $\mathrm{P}_{\mathrm{T}}$, Seebeck thermoelectric potential $S_{B}$, and dimensionless figure of merit ZT, calculated using Eqs. (83-85), are plotted as functions of $\mathrm{T}$, respectively.

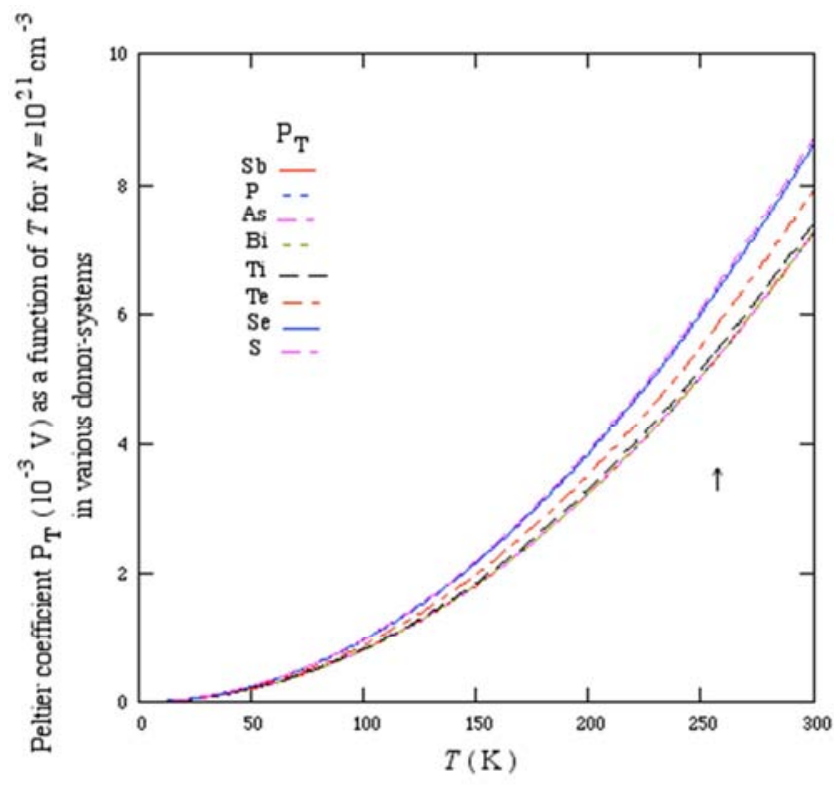

FIG. 9d

Figure 9d. Our results of Peltier coefficient $P_{T}$ are plotted as functions of $T$, suggesting that at a given $T, P_{T}$ increases with increasing $r_{d}$, due to the donor-size effect.

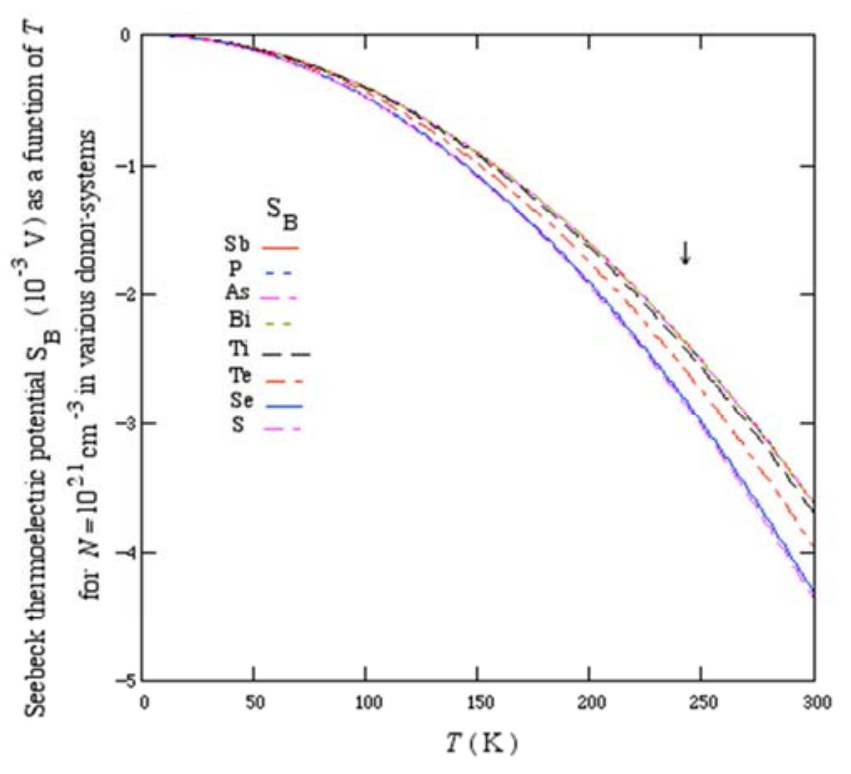

FIG. 9e

Figure 9e. Our results of Seebeck thermoelectric potential $S_{B}$ are plotted as functions of $T$, suggesting that at a given $T, S_{B}$ decreases with increasing $r_{d}$, due to the donor-size effect.

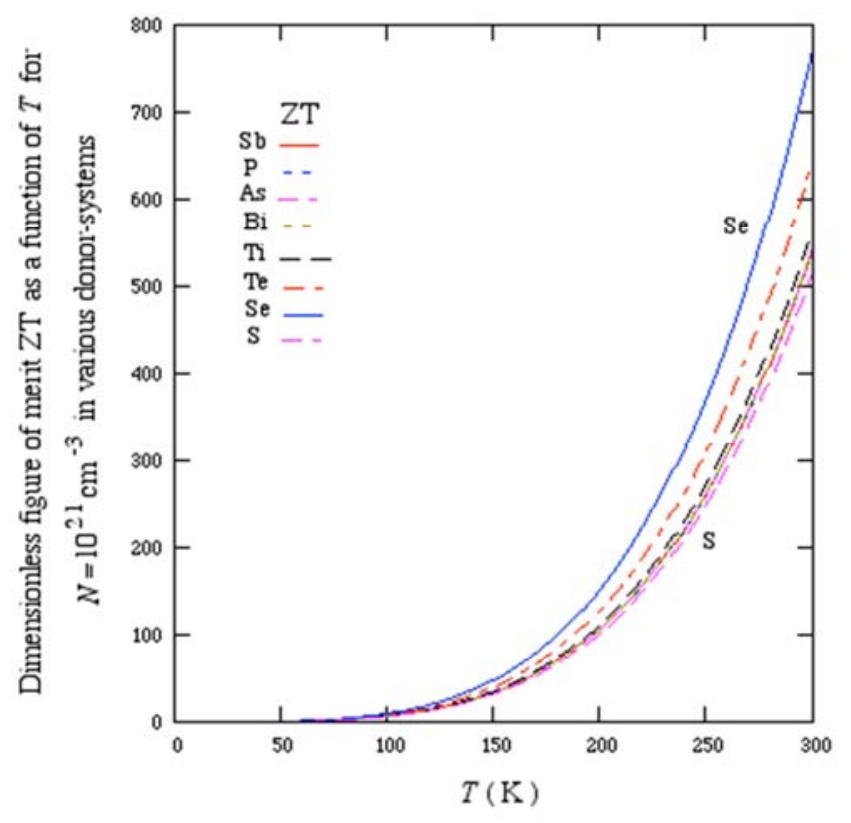

FIG. 9f

Figure 9f. Our results of dimensionless figure of merit ZT are plotted as functions of $T$.

\section{Concluding Remarks}

Using the effective autocorrelation function for potential fluctuations $\mathrm{W}_{\mathrm{n}}$, developed in Eq. (B.6) of the Appendix B, expressed in terms of the Heisenberg uncertainty relation given in Eq. (B.5), and an expression for the Gaussian average of $\mathbb{E}_{\mathrm{k}}^{\mathrm{a}-\overline{2}},\left\langle\mathbb{E}_{\mathrm{k}}^{\mathrm{a}} \overline{\bar{T}}_{\mathrm{KIM}}\right.$, obtained in Eq. (20) by the Kane integration method (KIM), we developed the expressions for density of states, optical absorption coefficient, and electrical conductivity, obtained in various degenerate d-Si systems, 
being due to the effects of donor-size and heavy doping, as given respectively in Eqs. $(36,49,72)$. It should be noted that this average expression was found to be equivalent to that obtained by the Feynman path-integral method. Then, those above results were expressed in terms of $\mathbb{E}^{\mathrm{a}-(1 / 2)}$, as given in Eq. (24) for $\mathbb{E} \geq 0$ and $\mathrm{a} \geq 1$, vanished at the band edge: $\mathbb{E}=0$, and exhibited their exponential tail behaviors for $\mathbb{E} \leq 0$, as obtained in Eqs. (28-31), in Tables 4, 7, 14, and in Figures 1, 2a (b), 3a (b, c), 4, 5a (b), 7 and $8 \mathrm{a}$ (b). Furthermore, in Figures 1, 4, and 7, some important conclusions were obtained as follows.

(i) First, for a given value of $-\mathbb{E}$, those exponential tails increased with increasing $r_{d}$, being due to the donor-size effect.

(ii) Secondly, they vanished at the conduction-band edge $\mathbb{E}=-0$, as given in Eq. (26), in good accordance with our other results obtained in Eq. (A3) of the Appendix A. Furthermore, those exponential tail-results were also compared with other theoretical ones, being found to be constant, at $\mathbb{E}=-0$, obtained in the small time approximation $[21,29,30]$ and in the full ground-state case and deep-tail approximation [21]. Thus, their results should be not correct, as discussed in Eq. (26).

(iii) Finally, for $\mathbb{E} \leq 0$, they went to zero as $\mathbb{E} \rightarrow$ -0 and $-\infty$ and presented the maxima, being found to be in good accordance with an asymptotic form for the exponential conduction-band tail, obtained by Halperin and Lax [19], using the minimum counting methods. Hence, the problem posed in the past for those exponential tails $[14,17,19,21$, 23, 25, 29, 30, 37] should now be solved.

Then, an expression for the average of $\mathbb{E}^{\mathrm{p}}$, at low temperatures and for $p \geq 3 / 2$, calculated by the Fermi-Dirac distribution function, was determined in Eq. (34), being used to evaluate, in degenerate $\mathrm{d}-\mathrm{Si}$ systems, the mobility, conductivity, resistivity, Hall coefficient, Hall factor, Hall mobility, thermal conductivity, diffusion coefficient, absolute thermoelectric power, Thomson coefficient, Peltier coefficient, Seebeck thermoelectric potential, and finally dimensionless figure of merit, as those given in Tables 5, 6, 8-13 and 15, and in Figures 6a (b) and 9a (b, c, d, e, f), suggesting a satisfactory description for our obtained results.

In summary, the central results of the present paper were found to be:

(i) the effective autocorrelation function for potential fluctuations $W_{n}$, determined in Eq. (A9) and expressed in terms of the Heisenberg uncertainty relation given in Eq. (B.5), being also equivalent to that given in Eq. (A1) of the

Appendix A,

(ii) an expression for the Gaussian average of $\mathbb{E}_{\mathrm{k}}^{\mathrm{a}-\frac{1}{2}}$ for $a \geq 1$, obtained in Eq. (20), being strongly affected by $W_{n}$, and

(iii) an expression for the average of $\mathbb{E}^{\mathrm{p}}$, at low temperatures and for $p \geq 3 / 2$, determined in Eq. (34).

Finally, we hope that our present results could be verified by future experiments, and those given in degenerate acceptor-Si systems at low temperatures would also be investigated by a similar treatment.

\section{Acknowledgements}

The author thanks Dr. Nghi Q. Lam, Former Editor-inChief of Applied Physics Letters, for his helpful suggestions which have greatly improved the presentation of this paper, and also Professors: P. Aigrain, M. Balkanski, J. L. Birman, D. E. Cox, P. G. De Gennes, G. J. Dienes, J. Friedel, L. Néel, and A. Salam for their encouragements when he arrived in Paris (Orsay University) in 1979.

\section{Appendices}

\section{Appendix A: Joint Density of States at $0 \mathrm{~K}$}

Friedberg and Luttinger (FL) [20] studied the behavior of the density of states (DOS) $)_{\mathrm{n}}$ or the joint DOS (JDOS) $)_{\mathrm{n}} \equiv$ $\mathrm{J}_{\mathrm{n}}(\mathbb{E})$ for a simple method used for the n-type crystal in the limit of very low positive energies $\left(\mathbb{E} \rightarrow 0_{+}\right)$by reformulating the problem conjectured by Lifshitz (L) [18] as that given in the Brownian motion. Here, they showed that $\mathrm{J}_{\mathrm{n}}\left(\mathbb{E} \rightarrow 0_{+}\right) \rightarrow 0$, and $\mathrm{J}_{\mathrm{n}}(\mathbb{E})$ vanishes for $\mathbb{E} \leq 0$, neglecting the exponential conduction-band tail, due to the heavy doping effect, $\mathbb{E}$ being the total electron energy. Then, these LFL results were reviewed by Mieghem [24]. In Sections III$\mathrm{VI}$, since $(\mathrm{DOS})_{\mathrm{n}}$ given in Eq. (36) for $\mathrm{a}=1$, is proportional to $\left\langle\mathbb{E}_{\mathrm{k}}^{\frac{1}{2}}\right\rangle_{\mathrm{KIM}}$, being defined in Eq. (20), we obtained: (DOS) $)_{\mathrm{n}} \rightarrow 0$ when $\mathbb{E} \rightarrow+0$ and -0 , as discussed in Eqs. (23, 26), respectively. In other words, (DOS $)_{\mathrm{n}} \rightarrow 0$, when $|\mathbb{E}| \rightarrow 0$ or $(\mathrm{DOS})_{\mathrm{n}}$ vanishes at the conduction-band edge $(\mathbb{E}=0)$, suggesting thus a generalized (LFL)-method (GLFLM) to be study as follows.

In the very large volume $\mathbb{V}_{\mathrm{o}} \equiv\left(\frac{4 \pi}{3}\right) \mathbb{R}_{\mathrm{o}}^{3}$ of radius $\mathbb{R}_{o}$, being empty of donors, and for lowest $|\mathbb{E}| \equiv \frac{\hbar^{2} \pi^{2}}{2 \mathrm{~m}_{\mathrm{n}}^{\mathrm{HDE}} \times \mathrm{R}_{\mathrm{O}}^{2}} \equiv \frac{\hbar^{2} \times \mathrm{k}^{2}}{2 \mathrm{~m}_{\mathrm{n}}^{\mathrm{HDE}}}, \mathbb{R}_{O}$ is thus defined by $[18,20]$

$$
\mathbb{R}_{\mathrm{o}}\left(\left|v_{\mathrm{n}}\right| ; \mathrm{B}\right) \equiv \sqrt{\mathrm{B}^{2} \hbar^{2} /\left(2 \mathrm{~m}_{\mathrm{n}}^{\mathrm{HDE}} \times|\mathbb{E}|\right)}=\frac{\mathrm{B}}{\mathrm{k}}=\frac{\mathrm{B}}{\mathrm{k}_{\mathrm{Fn}} \times \sqrt{\left|v_{\mathrm{n}}\right|}},
$$

where from the LFL-method $[18,20]: \mathrm{B}=\mathrm{B}_{\mathrm{LFL}}=\pi$ and $\mathbb{R}_{\mathrm{o}}=\mathbb{R}_{\mathrm{o}(\mathrm{LFL})}=\frac{\mathrm{B}_{\mathrm{LFL}}}{\mathrm{k}}, \mathrm{k}$ being the wave number. Here, $\mathrm{m}_{\mathrm{n}}^{\mathrm{HDE}}\left(\mathrm{N}, \mathrm{r}_{\mathrm{d}}\right)$ is determined in Eq. (8), and $\left|v_{\mathrm{n}}\right| \equiv \frac{|\mathbb{E}|}{\mathbb{E}_{\mathrm{Fno}}}$ is determined in Eq. (21). In fact, Eq. (A1) is thus the Heisenberg uncertainty relation, which can be compared with that given in next Eq. (A8) of the Appendix B, as: $\Delta \mathrm{r} \equiv$
$\left|\vec{r}-\overrightarrow{r^{\prime}}\right|=\frac{B_{n}}{k}=\frac{B_{n}}{k_{F n} \times \sqrt{\left|v_{n}\right|}}, B_{n}=2.7185$. Here, $\vec{r}$ and $\overrightarrow{r^{\prime}}$ are the electron positions, according to the first-and-second scatterings at the times $\mathrm{t}$ and $\mathrm{t}^{\prime}$.

Then, using a transformation given in Eq. (48), as a $\geq 1$, Eq. (A1) thus becomes 


$$
\mathbb{R}_{\mathrm{o}}^{\mathrm{GLFLM}}\left(\left|v_{\mathrm{n}}\right| ; \mathrm{B}\right) \equiv \mathbb{R}_{\mathrm{o}}\left(\left|v_{\mathrm{n}}\right| ; \mathrm{B}\right) \times\left(\frac{1}{\left|v_{\mathrm{n}}\right|}\right)^{\mathrm{a}-1}
$$

Now, in our GLFLM, in which the very large volume is $\mathbb{V} \equiv \frac{4 \pi}{3} \times \mathbb{R}^{3}, \mathbb{R} \equiv\left(\mathbb{R}_{\mathrm{o}}^{\mathrm{GLFLM}}-\mathrm{d} \mathbb{R}\right)$ being its radius, where $\mathrm{d} \mathbb{R} \ll \mathbb{R}$, the low-lying levels for states localized in it will be insensitive to the exact conditions on the boundary $d \mathbb{V}$ of $\mathbb{V}$, and we may take the wave function to be zero on $d \mathbb{V}$. Here, one has

$$
\mathbb{V} \equiv \frac{4 \pi}{3} \times \mathbb{R}^{3}=\frac{4 \pi}{3} \times\left[\left(\mathbb{R}_{\mathrm{o}}^{\mathrm{GLFLM}}\right)^{3}-3\left(\mathbb{R}_{\mathrm{o}}^{\mathrm{GLFL}}\right)^{2} \times \mathrm{d} \mathbb{R}+3 \mathbb{R}_{\mathrm{o}}^{\mathrm{GLFLM}} \times(\mathrm{d} \mathbb{R})^{2}-(\mathrm{d} \mathbb{R})^{3}\right]
$$

The probability of such a large region is proportional to: $\exp \left(-\frac{\mathrm{N}}{\mathrm{g}_{\mathrm{c}}} \times \mathbb{V}\right)$, where $\frac{\mathrm{N}}{\mathrm{g}_{\mathrm{c}}}=\frac{\mathrm{k}_{\mathrm{Fn}}^{3}}{3 \pi^{2}}$, such that the reduced $\mathrm{J}_{\mathrm{n}}$ can be defined by: $\mathbb{h}_{\mathrm{n}}^{\mathrm{GLFLM}}\left(\left|v_{\mathrm{n}(\mathrm{p})}\right| ; \mathrm{B}\right) \equiv \exp \left(-\frac{\mathrm{N}}{\mathrm{g}_{\mathrm{c}}} \times \mathbb{V}\right)$ [20]. Here, $d \mathbb{R}(\ll \mathbb{R})$ is determined from the FL-results as [20]: $\mathrm{d} \mathbb{R} \equiv 2 \mathrm{c} \lambda_{\mathrm{o}} \simeq \lambda_{\mathrm{o}}$, since $\mathrm{c}=0.628$ and $\lambda_{\mathrm{o}} \equiv$ $1 / \sqrt{4 \pi \mathrm{L} \times\left(\frac{\mathrm{N}}{\mathrm{g}_{\mathrm{c}}}\right)}$ is the skin depth, L being the scattering

$$
\begin{aligned}
\ln \mathbb{h}_{\mathrm{n}}^{\mathrm{GLFLM}}\left(\left|v_{\mathrm{n}}\right| \rightarrow 0 ; \mathrm{B}\right)=-\frac{\mathrm{k}_{\mathrm{Fn}}^{3}}{3 \pi^{2}} \times \mathbb{V}= & -\frac{4 \mathrm{~B}^{3}}{9 \pi} \times\left|v_{\mathrm{n}}\right|^{-3\left(\mathrm{a}-\frac{1}{2}\right)}+4 \mathrm{c} \times \mathrm{B}^{2} \times \sqrt{\frac{\mathrm{R}_{\mathrm{sn}}}{3 \pi} \times\left|v_{\mathrm{n}}\right|^{-2\left(\mathrm{a}-\frac{1}{2}\right)}-4 \mathrm{~B} c^{2} \times \mathrm{R}_{\mathrm{sn}} \times\left|v_{\mathrm{n}}\right|^{-\left(\mathrm{a}-\frac{1}{2}\right)}+} \\
& 4 \mathrm{c}^{3} \times \sqrt{\frac{\pi \times \mathrm{R}_{\mathrm{sn}}^{3}}{3}} \rightarrow-\infty, \mathbb{h}_{\mathrm{n}}^{\mathrm{GLFLM}}\left(\left|v_{\mathrm{n}}\right| \rightarrow 0 ; \mathrm{B}\right) \rightarrow 0,
\end{aligned}
$$

where $\mathrm{R}_{\mathrm{sn}} \equiv \frac{\mathrm{k}_{\mathrm{sn}}}{\mathrm{k}_{\mathrm{Fn}}}$ is determined in Eq. (4), being in good accordance with our results $(23$, 26). Furthermore, for a=1 and $\mathrm{B}=\mathrm{B}_{\mathrm{LFL}}=\pi$, the first-and-second terms of the last member of Eq. (A3) are found to be identical to the L-and-FL results, respectively.

\section{Appendix B: Effective Autocorrelation Function}

In degenerate d-Si systems, if denoting the electron positions and the corresponding wave vectors, according to the first-andsecond scatterings at the times $\mathrm{t}$ and $\mathrm{t}^{\prime}$ by $(\overrightarrow{\mathrm{r}}, \overrightarrow{\mathrm{k}})$ and $\left(\overrightarrow{\mathrm{r}^{\prime}}, \overrightarrow{\mathrm{k}^{\prime}}\right)$, and working with the Fourier transform given in Eq. (18), the effective autocorrelation function for potential fluctuations is then defined by [25]

$$
\mathrm{W}_{\mathrm{n}} \equiv\left\langle\mathrm{V}(\mathrm{r}) \mathrm{V}\left(\mathrm{r}^{\prime}\right)\right\rangle=\sum_{\left(\overrightarrow{\mathrm{k}}, \overrightarrow{\mathrm{k}^{\prime}}\right)} \mathrm{v}_{\mathrm{j}}(\overrightarrow{\mathrm{k}}) \mathrm{v}_{\mathrm{j}}\left(\overrightarrow{\mathrm{k}^{\prime}}\right) \times \mathrm{e}^{\mathrm{i}\left(\overrightarrow{\mathrm{k}} \cdot \overrightarrow{\mathrm{r}}+\overrightarrow{\mathrm{k}^{\prime}} \cdot \overrightarrow{\mathrm{r}^{\prime}}\right)} \times \sum_{\left(\mathrm{j}, \mathrm{j}^{\prime}\right)}\left\langle\mathrm{e}^{-\mathrm{i}\left(\overrightarrow{\mathrm{k}} \cdot \overrightarrow{\mathrm{R}_{\mathrm{j}}}+\overrightarrow{\mathrm{k}^{\prime}} \cdot \overrightarrow{\mathrm{R}^{\prime}}\right)}\right\rangle
$$

where the total potential energy $V(r)$ is defined in Eq. (16), and $\mathrm{i}^{2}=-1$. Then, since $\langle\mathrm{V}(\mathrm{r})\rangle=\left\langle\mathrm{V}\left(\mathrm{r}^{\prime}\right)\right\rangle=0$ as remarked in Eqs. $(16,17), W_{n}$ is non-zero only when $\overrightarrow{\mathrm{R}_{\mathrm{J}}}=\overrightarrow{\mathrm{R}_{\mathrm{J}^{\prime}}}$ and $\overrightarrow{\mathrm{k}}=-\overrightarrow{\mathrm{k}^{\prime}}$, meaning that the electron scattered on each donor twice, and giving:

$$
\Delta \mathrm{k}=\left|\overrightarrow{\mathrm{k}^{\prime}}-\overrightarrow{\mathrm{k}}\right|=2 \mathrm{k}
$$

Hence, for $W_{n}\left(\left|\vec{r}-\overrightarrow{r^{\prime}}\right|\right) \neq 0$, Eq. (A4) thus becomes

$$
\mathrm{W}_{\mathrm{n}}\left(\left|\overrightarrow{\mathrm{r}}-\overrightarrow{\mathrm{r}^{\prime}}\right|\right)=\mathcal{N} \sum_{\overrightarrow{\mathrm{k}}}\left|\mathrm{v}_{\mathrm{j}}(\overrightarrow{\mathrm{k}})\right|^{2} \exp \left[\mathrm{i} \overrightarrow{\mathrm{k}} \cdot\left(\overrightarrow{\mathrm{r}}-\overrightarrow{\mathrm{r}^{\prime}}\right)\right]
$$

noting that $\mathrm{v}_{\mathrm{j}}(\overrightarrow{\mathrm{k}}) \mathrm{v}_{\mathrm{j}}\left(\overrightarrow{\mathrm{k}^{\prime}}\right)=\mathrm{v}_{\mathrm{j}}(\overrightarrow{\mathrm{k}}) \mathrm{v}_{\mathrm{j}}^{*}(\overrightarrow{\mathrm{k}})=\left|\mathrm{v}_{\mathrm{j}}(\overrightarrow{\mathrm{k}})\right|^{2}$ for real potential energies. Here, $v_{j}(\vec{k})$ is determined in Eq. (18) and $\mathcal{N}$ is the total number of donors. Further, from the Fourier transform [25], one has

$$
\frac{\exp \left(-\mathrm{k}_{\mathrm{sn}} \times\left|\overrightarrow{\mathrm{r}}-\overrightarrow{\mathrm{r}^{\prime}}\right|\right)}{\left|\overrightarrow{\mathrm{r}}-\overrightarrow{\mathrm{r}^{\prime}}\right|} \equiv \sum_{\overrightarrow{\mathrm{k}}} \frac{4 \pi}{\Omega} \times \frac{1}{\mathrm{k}^{2}+\mathrm{k}_{\mathrm{sn}}^{2}} \times \exp \left[\mathrm{i} \overrightarrow{\mathrm{k}} \cdot\left(\overrightarrow{\mathrm{r}}-\overrightarrow{\mathrm{r}^{\prime}}\right)\right]
$$

where $\Omega$ is the total crystal volume, and taking its partial derivative (i.e., $\partial / \partial \mathrm{k}_{\mathrm{sn}}$ ), one finally finds

$$
\mathrm{W}_{\mathrm{n}}\left(\left|\overrightarrow{\mathrm{r}}-\overrightarrow{\mathrm{r}^{\prime}}\right|\right) \equiv \eta_{\mathrm{n}}^{2} \exp \left(-\mathrm{k}_{\mathrm{sn}} \times\left|\overrightarrow{\mathrm{r}}-\overrightarrow{\mathrm{r}^{\prime}}\right|\right) \text {. }
$$

Here, $\eta_{\mathrm{n}}^{2} \equiv \mathrm{N} \int_{0}^{\infty} \mathrm{v}_{\mathrm{j}}(\mathrm{r})^{2} \times 4 \pi \mathrm{r}^{2} \mathrm{dr}=2 \pi \mathrm{Nq}^{4} \mathrm{k}_{\mathrm{sn}}^{-1} \varepsilon_{\mathrm{n}}^{-2}$, where -q is the electron charge, $v_{j}(r)$ is determined in Eq. (17) and the accurate screening length $\mathrm{k}_{\mathrm{sn}}^{-1}$ is determined in Eq. (4). Then, some concluding remarks can be obtained below.

(i) In the small time approximation, $\left|\vec{r}-\overrightarrow{r^{\prime}}\right| \simeq 0$, Eq. (A7) is thus reduced to $\eta_{\mathrm{n}}^{2}[17,21,22,29,30]$.

(ii) Using Eq. (A5), the Heisenberg uncertainty relation between $\Delta \mathrm{r} \equiv\left|\overrightarrow{\mathrm{r}}-\overrightarrow{\mathrm{r}^{\prime}}\right|$ and $\Delta \mathrm{k}=2 \mathrm{k}$ is given by

$$
\Delta \mathrm{r} \times \Delta \mathrm{k}=\mathcal{H}_{\mathrm{n}} \geq 1 / 2 \Rightarrow \Delta \mathrm{r}=\mathrm{B}_{\mathrm{n}} / \mathrm{k}, \mathrm{B}_{\mathrm{n}}=\mathcal{H}_{\mathrm{n}} / 2
$$

which can be compared with that given in Eq. (A1), as discussed above. Here, the values of empirical Heisenberg parameter $\mathcal{H}_{\mathrm{n}}$ was proposed in Section $\mathrm{V}$ as: $\mathcal{H}_{\mathrm{n}}=5.4370$. Futher, if replacing the constant $\mathrm{B}$ given in above Eqs. (A1A3) by $\mathrm{B}=\mathrm{B}_{\mathrm{n}}=\mathcal{H}_{\mathrm{n}} / 2=2.7185$, which gives: $\mathrm{B}_{\mathrm{LFL}}=\pi=$ $3.1416>B_{n}$, then, from Eq. (A3), we also obtain: $\ln \mathbb{h}_{n}^{\mathrm{GLFLM}}\left(\left|v_{\mathrm{n}}\right| \rightarrow 0 ; \mathrm{B}_{\mathrm{n}}\right) \rightarrow-\infty$ or $\mathbb{h}_{\mathrm{n}}^{\mathrm{GLFLM}}\left(\left|v_{\mathrm{n}}\right| \rightarrow 0 ; \mathrm{B}\right) \rightarrow$ 
0 , in good accordance with our results $(23,26)$.

(iii) Finally, using Eq. (A8) and defining the kinetic energy of localization by: $\quad \mathbb{E}_{\mathrm{k}_{\mathrm{sn}}} \equiv \frac{\hbar^{2} \mathrm{k}_{\mathrm{sn}}^{2}}{2 m_{\mathrm{n}}^{\mathrm{HDE}}\left(\mathrm{N}, \mathrm{r}_{\mathrm{d}}\right)}$, the effective autocorrelation function for potential fluctuations (A7) can be rewritten as

$$
\mathrm{W}_{\mathrm{n}}\left(v_{\mathrm{n}}, \mathrm{N}, \mathrm{r}_{\mathrm{d}}\right)=\eta_{\mathrm{n}}^{2} \times \exp \left(\frac{-\mathcal{H}_{\mathrm{n}} \mathrm{R}_{\mathrm{sn}}}{2 \times \sqrt{\left|v_{\mathrm{n}}\right|}}\right)
$$

where the ratio $\mathrm{R}_{\mathrm{sn}} \equiv \frac{\mathrm{k}_{\mathrm{sn}}}{\mathrm{k}_{\mathrm{Fn}}}$ is determined in Eq. (4). Here, one remarks that $W_{n}\left(v_{n}, N, r_{d}\right) \rightarrow 0$ and $\eta_{n}^{2}$, as $v_{n} \rightarrow 0$ and $\infty$, respectively, while in many other works for any $v_{\mathrm{n}}$-values, $\mathrm{W}_{\mathrm{n}}\left(v_{\mathrm{n}}, \mathrm{N}\right) \simeq \eta_{\mathrm{n}}^{2}$, obtained in the small time approximation $[17,21,22,29,30]: \Delta \mathrm{r} \simeq 0$, being only valid as $v_{\mathrm{n}} \rightarrow \infty$, but is not correct as $v_{\mathrm{n}} \rightarrow 0$, since from Eq. (A8), $\Delta \mathrm{r} \gg 0$. Therefore, Eq. (A9) is an important result of the present paper.

\section{Appendix C: Fermi Energy and Generalized Einstein Relation}

The Fermi energy $\mathbb{E}_{\mathrm{Fn}}$ and the generalized Einstein relation $\frac{\mathrm{D}}{\mu} \equiv \frac{\mathrm{N}}{\mathrm{q}} \times \frac{\mathrm{dE}_{\mathrm{Fn}}}{\mathrm{dN}}$, which relates the diffusion coefficient D with the mobility $\mu$,obtained for any $\mathrm{T}$ and $\mathrm{N}$, being investigated in our previous papers, with precisions of the order of: $2.11 \times 10^{-4}$ and $10^{-3}$, respectively, [27, 63] are now summarized in the following.

Fermi Energy, $\mathbb{E}_{\mathrm{Fn}}$

We first define the reduced impurity density as: $\mathrm{u} \equiv \frac{\mathrm{N}}{\mathrm{N}_{\mathrm{CB}}}$, $\mathrm{N}_{\mathrm{CB}}$ being the effective density of conduction-band (CB)states defined by: $\mathrm{N}_{\mathrm{CB}}=2 \mathrm{~g}_{\mathrm{c}}\left(\frac{\mathrm{m}_{\mathrm{n}}^{\mathrm{HDE}}\left(\mathrm{N}, \mathrm{r}_{\mathrm{d}}\right) \times \mathrm{k}_{\mathrm{B}} \mathrm{T}}{2 \pi \hbar^{2}}\right)^{\frac{3}{2}}\left(\mathrm{~cm}^{-3}\right)$, where $m_{n}^{H D E}\left(N, r_{d}\right)$ is determined in Eq. (8). Then, for any $T$ and $\mathrm{N}$, our expression for reduced Fermi energy, $\theta_{\mathrm{n}}$, determined in our previous paper [27], is given by

$$
\theta_{\mathrm{n}}(\mathrm{u}) \equiv \frac{\mathbb{E}_{\mathrm{Fn}}(\mathrm{u})}{\mathrm{k}_{\mathrm{B}} \mathrm{T}}=\frac{\mathrm{G}(\mathrm{u})+\mathrm{Au}^{\mathrm{B}} \mathrm{F}(\mathrm{u})}{1+A u^{\mathrm{B}}}, \mathrm{A}=0.0005372, \mathrm{~B}=4.82842262,
$$

where, in the degenerate case or as $\theta_{n}(u \gg 1) \rightarrow \infty$, Eq. (A10) is reduced to

$$
\mathrm{F}(\mathrm{u})=\mathrm{au}^{2 / 3}\left(1+\mathrm{bu}^{-4 / 3}+\mathrm{cu}^{-8 / 3}\right)^{-2 / 3}, \mathrm{a}=[3 \sqrt{\pi} / 4]^{2 / 3}, \mathrm{~b}=\frac{1}{8}\left(\frac{\pi}{\mathrm{a}}\right)^{2}, \mathrm{c}=\frac{62.3739855}{1920}\left(\frac{\pi}{\mathrm{a}}\right)^{4},
$$

and in the non-degenerate case or for $\theta_{\mathrm{n}}\left(u_{\mathrm{n}} \ll 1\right) \ll 0$, to

$$
\mathrm{G}(\mathrm{u}) \simeq \operatorname{Ln}(\mathrm{u})+2^{-\frac{3}{2}} \times \mathrm{u} \times \mathrm{e}^{-\mathrm{du}}, \mathrm{d}=2^{3 / 2}\left[\frac{1}{\sqrt{27}}-\frac{3}{16}\right]>0 .
$$

Further, one notes that Eq. (A11) can thus be rewritten as

$$
\mathbb{E}_{\mathrm{Fn} 1}(\mathrm{u})=\mathbb{E}_{\mathrm{Fno}} \times\left(1+\mathrm{bu}^{-4 / 3}+\mathrm{cu}^{-8 / 3}\right)^{-2 / 3},
$$

being the Fermi energy given in the degenerate d-Si systems.

For example, in the degenerate $\mathrm{P}-\mathrm{Si}$ system at $\mathrm{T}=77 \mathrm{~K}$ and $\mathrm{N}\left(10^{19} \mathrm{~cm}^{-3}\right)=3$ and 100 , the relative deviations between $\mathbb{E}_{\mathrm{Fn} 1}\left(\mathrm{~N}^{*}, \mathrm{~T}, \mathrm{r}_{\mathrm{d}}\right)$ determined in Eq. (A13) and $\mathbb{E}_{\mathrm{Fn}}\left(\mathrm{N}^{*}, \mathrm{~T}, \mathrm{r}_{\mathrm{d}}\right)=\theta_{\mathrm{n}} \times \mathrm{k}_{\mathrm{B}} \mathrm{T}$ in Eq. (A10), defined by: $1-$ $\frac{\mathbb{E}_{\mathrm{Fn} 1}}{\mathbb{E}_{\mathrm{Fn}}}$, are equal to 0.052 and $4.6 \times 10^{-4}$, respectively.

Generalized Einstein Relation

The generalized Einstein relation is defined by [51, 62-67]

$$
\frac{\mathrm{D}(\mathrm{u})}{\mu} \equiv \frac{\mathrm{N}}{\mathrm{q}} \times \frac{\mathrm{dE_{Fn }}}{\mathrm{dN}} \equiv \frac{\mathrm{k}_{\mathrm{B}} \times \mathrm{T}}{\mathrm{q}} \times\left(\mathrm{u} \frac{\mathrm{d} \theta_{\mathrm{n}}}{\mathrm{du}}\right),
$$

where $\mu$ is the mobility and in particular in the degenerate case it is determined in Eq. (67), $\theta_{\mathrm{n}}(\mathrm{u}) \equiv \frac{\mathrm{V}(\mathrm{u})}{\mathrm{W}(\mathrm{u})}, \mathrm{V}(\mathrm{u})=$ $\mathrm{G}(\mathrm{u})+\mathrm{Au}^{\mathrm{B}} \mathrm{F}(\mathrm{u})$, and $\mathrm{W}(\mathrm{u})=1+\mathrm{Au}^{\mathrm{B}}[27,63]$ as those given in Eqs. (A10, A11, A12). Then, differentiating this function $\theta_{\mathrm{n}}(\mathrm{u})$ with respect to $u$, one thus obtains $\frac{\mathrm{d} \theta_{\mathrm{n}}}{\mathrm{du}}$. Therefore, Eq. (A14) becomes [63]

$$
\frac{\mathrm{D}(\mathrm{u})}{\mu}=\frac{\mathrm{k}_{\mathrm{B}} \times \mathrm{T}}{\mathrm{q}} \times \mathrm{u} \frac{\mathrm{V}^{\prime}(\mathrm{u}) \times \mathrm{W}(\mathrm{u})-\mathrm{V}(\mathrm{u}) \times \mathrm{W}^{\prime}(\mathrm{u})}{\mathrm{W}^{2}(\mathrm{u})},
$$

where $\mathrm{W}^{\prime}(\mathrm{u})=\mathrm{ABu}^{\mathrm{B}-1}$ and $\mathrm{V}^{\prime}(\mathrm{u})=\mathrm{u}^{-1}+2^{-\frac{3}{2}} \mathrm{e}^{-\mathrm{du}}(1-$ $\mathrm{du})+\frac{2}{3} A u^{B-1} \mathrm{~F}(\mathrm{u})\left[\left(1+\frac{3 \mathrm{~B}}{2}\right)+\frac{4}{3} \times \frac{\mathrm{bu}^{-\frac{4}{3}}+2 c \mathrm{u}^{-\frac{8}{3}}}{1+\mathrm{bu}^{-\frac{4}{3}}+c u^{-\frac{8}{3}}}\right]$. One remarks that: (i) as $\mathrm{u} \rightarrow 0$, one has: $\mathrm{W}^{2} \simeq 1$ and $\mathrm{u}\left[\mathrm{V}^{\prime} \times \mathrm{W}-\mathrm{V} \times\right.$ $\left.\mathrm{W}^{\prime}\right] \simeq 1$, and therefore: $\frac{\mathrm{D}}{\mu}=\frac{\mathrm{k}_{\mathrm{B}} \times \mathrm{T}}{\mathrm{q}}$, and (ii) as $\mathrm{u} \rightarrow \infty$, one has: $\mathrm{W}^{2} \approx \mathrm{A}^{2} \mathrm{u}^{2 \mathrm{~B}}$ and $\mathrm{u}\left[\mathrm{V}^{\prime} \times \mathrm{W}-\mathrm{V} \times \mathrm{W}^{\prime}\right] \approx \frac{2}{3} \mathrm{au}^{2 / 3} \mathrm{~A}^{2} \mathrm{u}^{2 \mathrm{~B}}$, and therefore:

$$
\frac{\mathrm{D}(\mathrm{u})}{\mu} \simeq \frac{\mathrm{D}_{\mathrm{o}}(\mathrm{u})}{\mu}=\frac{2}{3}\left(\mathbb{E}_{\mathrm{Fn} 1} / \mathrm{q}\right)
$$

where $\mathbb{E}_{\mathrm{Fn} 1}$ is determined in Eq. (A13).

Now, in the degenerate case, replacing $\mathbb{E}_{\mathrm{Fn}}$ given in Eq. (A14) by $\mathbb{E}_{\mathrm{Fn} 1}$ determined in Eq. (A13), Eq. (A14) thus becomes

$$
\frac{\mathrm{D}_{1}(\mathrm{u})}{\mu} \approx \frac{2}{3}\left(\mathbb{E}_{\mathrm{Fn} 1} / \mathrm{q}\right) \times\left\{1+\frac{4}{3} \times \frac{\left(\mathrm{bu}^{-4 / 3}+2 \mathrm{cu}^{-8 / 3}\right)}{\left(1+\mathrm{bu}^{-4 / 3}+\mathrm{cu}^{-8 / 3}\right)}\right\},
$$

where $\mu$ is determined in Eq. (67).

For example, in the degenerate $\mathrm{P}-\mathrm{Si}$ system at $\mathrm{T}=77 \mathrm{~K}$ and for $\mathrm{N}\left(10^{19} \mathrm{~cm}^{-3}\right)=3$ and 100 , the relative deviations between $\mathrm{D}_{1}\left(\mathrm{~N}^{*}, \mathrm{~T}, \mathrm{r}_{\mathrm{d}}\right)$ given in Eq. (A17) and $\mathrm{D}\left(\mathrm{N}^{*}, \mathrm{~T}, \mathrm{r}_{\mathrm{d}}\right)$ in Eq. (A15), defined by: $1-\frac{\mathrm{D}_{1}}{\mathrm{D}}$, are equal to: $5 \times 10^{-4}$ and $-2 \times 10^{-4}$, respectively. 


\section{References}

[1] R. J. Van Overstraeten, IEEE Trans. Electron Dev., vol. ED20, pp. 290-298, 1973.

[2] R. K. Jain, Physica Status Solidi (a), vol. 42, 221-226, 1977.

[3] H. Van Cong and S. Brunet, Solar Cells, vol. 5, pp. 355-365, 1982.

[4] H. Van Cong, Physica Status Solidi (a), vol. 149, pp. 619-628, 1995.

[5] H. Van Cong and G. Debiais, Solar Energy Materials and Solar Cells, vol. 45, pp. 385-399, 1997; H. Van Cong, Physica Status Solidi (a), vol. 171, pp. 631-645, 1999.

[6] D. M. Riffe, J. Opt. Soc. Am. B, vol. 19, pp. 1092-1100, 2002.

[7] J. Wagner and J. A. del Alamo, J. Appl. Phys., vol. 63, pp. 425-429, 1988.

[8] R. Pässler, Phys. Rev. B, vol. 66, p. 085201, 2002.

[9] R. Pässler, Phys. Status Solidi B, vol. 236, pp. 710-728, 2003.

[10] D. Yan and A. Cuevas, J. Appl. Phys., vol. 114, p. 044508, 2013.

[11] H. Van Cong, S. Abide, B. Zeghmati and X. Chesneau, Physica B, vol. 436, pp. 130-139, 2014.

[12] H. Van Cong, Physica B, vol. 487, pp. 90-101, 2016.

[13] J. Binbin and S. Chihtang, J. Semicond., vol. 32, p. 121002, 2011.

[14] E. O. Kane, Phys. Rev., vol. 131, pp. 79-88, 1963.

[15] M. Abramowitz and I. A. Stegum, Handbook of Mathematical Functions, Dover Publications, Inc., New York, 1972; I. S. Gradshteyn and I. M. Ryzhik, Table of Integrals, Series, and Products, Academic Press, Inc., New York, 1980.

[16] R. B. Feynman and A. R. Hibbs, Quantum Mechanics and Path Integral, McGraw-Hill, New York, 1965.

[17] S. F. Edwards, Proc. Phys. Soc., vol. 85, pp. 1-25, 1965.

[18] I. M. Lifshitz, Sov. Phys. -USp., vol. 7, pp. 549-573, 1965 [Russian original: Usp. Fiz. Nauk, vol. 83, pp. 617-663, 1964].

[19] I. Halperin and M. Lax, Phys. Rev., vol. 148, pp. 722-740, 1966.

[20] R. Friedberg and J. M. Luttinger, Phys. Rev. B, vol. 12, pp. 4460-4474, 1975.

[21] H. Van Cong, J. Phys. Chem. Solids, vol. 36, pp. 1237-1240, 1975.

[22] H. Van Cong, S. Charar, S. Brunet, M. Averous and J. L. Birman, Physica Status Solidi (b), vol. 118, pp. 757-777, 1982; H. Van Cong, S. Brunet, S. Charar, J. L. Birman and M. Averous, Solid State Commun., vol. 45, pp. 611-614, 1983.

[23] V. Sa-yakanit, W. Sritrakool, and H. R. Glyde, Phys. Rev. B, vol. 25, pp. 2776-2780, 1982.

[24] P. V. Mieghem, Rev. Mod. Phys., vol. 64, pp. 755-793, 1982.
[25] H. Van Cong, Il Nuovo Cimento D, vol. 6, pp. 513-520, 1985.

[26] X. Chang and A. Izabelle, J. Appl. Phys., vol. 65, pp. 2162 2164,1989

[27] H. Van Cong and G. Debiais, J. Appl. Phys., vol. 73, pp. 1545$15463,1993$.

[28] T. H. Nguyen and S. K. O’Leary, J. Appl. Phys., vol. 88, pp. $3479-3483,2000$

[29] T. Lukes and K. T. S. Somaratna, J. Phys. C: Solid St. Phys., vol. 3, pp. 2044-2056, 1970.

[30] H. Van Cong, Phil. Mag., vol. 28, pp. 983-991, 1973.

[31] J. I. Pankove, Optical Process in Semiconductors, Dover Publications, Inc., New York, 1975.

[32] H. A. Weakliem and D. Redfield, J. Appl. Phys., vol. 50, pp. $1491-1493,1979$

[33] D. E. Aspnes and A. A. Studna, Phys. Rev. B, vol. 27, pp. 985$1009,1983$.

[34] D. E. Aspnes, A. A. Studna, and E. Kinsbron, Phys. Rev. B, vol. 29, pp. 768-779, 1984.

[35] L. Vina and M. Cardona, Phys. Rev. B, vol. 29, pp. 6739-6751, 1984.

[36] E. D. Palik, Handbook of Optical Constants of Solids I and II, Academic Press, Inc., New York, 1985 and 1991, respectively.

[37] S. John, C. Soukoulis, M. H. Cohen, and E. N. Economou, Phys. Rev. Lett., vol. 57, pp. 1777-1780, 1986.

[38] P. Lautenschlager, M. Garriga, L. Vina, and M. Cardona, Phys. Rev. $B$, vol. 36, pp. 4821-4830, 1987.

[39] F. Orapunt and S. K. O'Leary, Solid State Commun., vol. 151, 411-414, 2011

[40] A. R. Forouhi and I. Bloomer, Phys. Rev. B, vol. 38, pp. 18651874, 1988.

[41] G. E. Jr. Jellison and F. A. Modine, Appl. Phys. Lett., vol. 69 , pp. 371-373, 1996.

[42] L. Ding, T. P. Chen, Y. Liu, C. Y. Ng, and S. Fung, Phys. Rev. $B$, vol. 72, p. 125419, 2005.

[43] H. Van Cong and S. Brunet, Solid State Commun., vol. 58, pp. $551-554,1986$

[44] N. K. Hon, R. Soref, and B. Jalali, J. Appl. Phys., vol. 110, pp. 011301, 2011.

[45] T. Wang, N. Venkatram, J. Gosciniak, Y. Cui, G. Qian, W. Ji, and D. T. H. Tan, Optics express, vol. 21, 32192, 2013.

[46] L. Vivien and L. Pavesi, Handbook of Silicon Photonics, Taylor and Francis Group, LLC, New York, 2013.

[47] A. Malasi, H. Taz, M. Ehrsam, J. Goodwin, H. Garcia, and R. Kalyanaraman, APL Photonics, vol. 1, p. 076101, 2016.

[48] H. T. Nguyen, F. E. Rougieux, B. Mitchell, and D. Macdonald, J. Appl. Phys., vol. 115, p. 043710, 2014.

[49] R. J. Jaffe, Degenerate Fermion systems, MIT 8.322 Lecture Notes: Quantum Theory II-2006, 1996. 
[50] F. J. Morin and J. P. Maita, Phys. Rev., vol. 96, pp. 28-35, 1954.

[51] R. Kubo, J. Phys. Soc. Japan, vol. 12, pp. 570-586, 1957.

[52] D. A. Greenwood, Proc. Phys. Soc., vol. 71, pp. 585-596, 1958.

[53] R. A. Logan, J. F. Gilbert, and F. A. Trumbore, J. Appl. Phys., vol. 32, pp. 131-132, 1961; F. Mousty, P. Ostoja, and L. Passari, J. Appl. Phys., vol. 45, pp. 4576-4580, 1974.

[54] P. W. Chapman, O. N. Tufte, J. D. Zook, and D. Long, Phys. Rev., vol. 34, pp. 3291-3295, 1963.

[55] J. M. Luttinger, Phys. Rev., vol. 135, pp. A1505-A1514, 1964.

[56] J. Zittartz and J. S. Langer, Phys. Rev., vol. 148, pp. 741-747, 1966.

[57] R. Jones, J. Phys. C (Solid State Phys.), vol. 8, pp. 190-201, 1970.

[58] H. Van Cong and G. Mesnard, Physica Status Solidi (b), vol. 48, pp. 293-310, 1971; vol. 49, pp. 179-189, 1972; vol. 50, pp. 53-58, 1972.

[59] M. Yussouff and J. Zittartz, Solid State Commun., vol. 12, pp. 959-962, 1973.

[60] M. Finetti and A. M. Mazzone, J. Appl. Phys., vol. 48, pp. 4597-4600, 1977.
[61] H. Van Cong, Physica Status Solidi (b), vol. 90, pp. 401-407, 1978.

[62] P. T. Landsberg, Handbook on Semiconductors, Volume 1, Basic Properties of Semiconductors, Elsevier Science Publishers B. V., Amsterdam, 1992; Eur. J. Phys., vol. 2, pp. 213-219, 1981.

[63] H. Van Cong and Debiais, Solid-St. Electron., vol. 38, pp. 8387, 1995.

[64] T. H. Nguyen and S. K. O'Leary, Appl. Phys. Lett., vol. 83, 1998-2000, 2003; J. Appl. Phys., vol. 98, p. 076102, 2005.

[65] A. Khan and A. Das, Z. Naturforsch., vol. 65a, pp. 882-886, 2010; Physica B, vol. 405, pp. 817-821, 2010.

[66] V. Palenskis, World J. Condens. Matt. Phys., vol. 4, pp. $123-$ 133, 2014; AIP Advances, vol. 4, p. 047119, 2014.

[67] K. P. Ghatak, S. Bhattacharya, and D. De, Einstein Relation in Compound Semiconductors and Their Nanostructures, Springer-Verlag, Berlin, Heidelberg, 2009; K. P. Ghatak, S. Bhattacharya, S. Bhowmik, R. Benedictus, and S. Choudhury, J. Appl. Phys., vol. 103, p. 094314, 2008; K. P. Ghatak and B. Mitra, Physica Scripta., vol. 42, pp. 103-108, 1990.

[68] G. A. Slack, J. Appl. Phys., vol. 35, pp. 3460-3466, 1964.

[69] G. D. Mahan, J. Appl. Phys., vol. 66, pp. 1578-1583, 1989. 